\title{
Human thermoregulation : individual differences in cold induced thermogenesis
}

Citation for published version (APA):

van Ooijen, A. M. J. (2008). Human thermoregulation : individual differences in cold induced thermogenesis. [Doctoral Thesis, Maastricht University]. Universitaire Pers Maastricht. https://doi.org/10.26481/dis.20080910ao

Document status and date:

Published: 01/01/2008

DOI:

10.26481/dis.20080910ao

Document Version:

Publisher's PDF, also known as Version of record

\section{Please check the document version of this publication:}

- A submitted manuscript is the version of the article upon submission and before peer-review. There can be important differences between the submitted version and the official published version of record.

People interested in the research are advised to contact the author for the final version of the publication, or visit the DOI to the publisher's website.

- The final author version and the galley proof are versions of the publication after peer review.

- The final published version features the final layout of the paper including the volume, issue and page numbers.

Link to publication

\footnotetext{
General rights rights.

- You may freely distribute the URL identifying the publication in the public portal. please follow below link for the End User Agreement:

www.umlib.nl/taverne-license

Take down policy

If you believe that this document breaches copyright please contact us at:

repository@maastrichtuniversity.nl

providing details and we will investigate your claim.
}

Copyright and moral rights for the publications made accessible in the public portal are retained by the authors and/or other copyright owners and it is a condition of accessing publications that users recognise and abide by the legal requirements associated with these

- Users may download and print one copy of any publication from the public portal for the purpose of private study or research.

- You may not further distribute the material or use it for any profit-making activity or commercial gain

If the publication is distributed under the terms of Article $25 \mathrm{fa}$ of the Dutch Copyright Act, indicated by the "Taverne" license above, 


\section{Human Thermoregulation}

Individual differences in cold induced thermogenesis 
(C) Anne Marie Japke Claessens - van Ooijen Cover Design by Marieke Claessens and Datawyse Printed by Datawyse, Universitaire Pers Maastricht

ISBN 978-90-5278-743-5 


\section{Human Thermoregulation}

Individual differences in cold induced thermogenesis

\section{PROEFSCHRIFT}

ter verkrijging van de graad van doctor aan de Universiteit Maastricht op gezag van de Rector Magnificus, Prof. mr. G.P.M.F.Mols, volgens het besluit van het College van Decanen, in het openbaar te verdedigen op woensdag 10 September 2008 om 14.00 uur

door

Anne Marie Japke Claessens - van Ooijen geboren te Breda op 8 Januari 1976

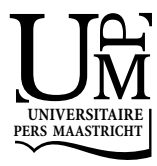




\section{Promotores}

Prof. dr. K.R. Westerterp

Prof. dr. Ir. A.A. van Steenhoven, TU/e

\section{Copromotor}

Dr. W.D. van Marken Lichtenbelt

\section{Beoordelingscommissie}

Prof. dr. H. Kingma (voorzitter)

Prof. dr. H.A.M. Daanen, TNO Soesterberg

Dr. E.J.W. van Someren, KNAW

Prof. dr. G.J.J. Teule

Prof. dr. G. van der Vusse

The studies presented in this thesis were made possible and fully funded by the Departement of Biomedical Engineering of the University of Technology, Eindhoven, The Netherlands.

The studies presented in this thesis were performed at the Nutrition and Toxicology research Institute Maastricht (NUTRIM), which participates in the Graduate School VLAG (Food Technology, Agrobiotechnology, Nutrition and Health Sciences), accredited by the Royal Netherlands Academy of Art and Sciences. 

Table of contents 


\section{Table of contents}

\section{Chapter 1}

General Introduction

\section{Chapter 2}

Individual differences in body temperature and the relation to energy expenditure:

The influence of mild cold.

\section{Chapter 3}

Seasonal changes in metabolic and temperature responses to cold air in humans

\section{Chapter 4}

Cold induced heat production preceding shivering

\section{Chapter 5}

Heat production and body temperature during cooling and rewarming in over-

weight and lean men

\section{Chapter 6}

Adaptive thermogenesis, skin blood flow and sympathetic activity in lean and overweight men: Effects of cold exposure

\section{Chapter 7}

Validation of an individualized model of human thermoregulation for predicting responses to cold air

\section{Chapter 8}

General Discussion

Summary

Samenvatting

Dankwoord

Curriculum Vitae

Publications 


\section{Chapter 1}

General Introduction 


\section{Thermoregulation}

The earliest civilizations on earth were located in areas where the environmental temperature approximately corresponded to human thermal neutrality ${ }^{(5)}$. Exposure to temperatures above or below the thermoneutral zone increases energy expenditure. Humans are homeotherms and need a relatively constant deep body temperature to survive $^{(32)}$. Humans are also endotherms, coming from the Greek words, endos and therme, inside and heat respectively. This means that humans rely on internal heat production to regulate body temperature. The ability to physiologically regulate body temperature may have made it possible to move to relatively cold and warm parts of the world. In hot or cold regions, thermoregulation is evident in the form of sweating and shivering. These are effective ways to either lose or gain heat, phenomena necessary for survival. However, cold or hot conditions are not comfortable and are therefore usually avoided, by means of behavioral thermoregulation. In fact the most powerful form of thermoregulation is behavioral: change clothing, change posture, or change location ${ }^{(36)}$. In western societies, people seek thermoneutrality indoors by using air-conditioning and wear clothes to maintain body temperature.

Despite the behavioral temperature regulation described above, humans are exposed to changing environmental conditions without even noticing. When getting up out of a chair, walking into another room, corridor, kitchen or when going outside, air moves and temperature and humidity fluctuate. All these situations and the transitions expose humans to changes in the environmental conditions that influence heat loss and are picked up by the thermoregulatory system. Even within the range of thermoneutrality, thermoregulation takes place. In this range the actions of thermoregulation include vasoconstriction and dilation of blood vessels in the skin in order to change heat loss without resulting in changes in heat production.

Body temperature is kept constant if heat gain equals heat loss ${ }^{(2,22,37)}$. If heat gain does not equal heat loss, the extra heat is stored, or lost from the body ${ }^{(2,37)}$, which affects the temperature distribution in the body. The core temperature in humans is kept relatively constant in an environment with temperatures ranging from values below the lower critical temperature and above the upper critical temperature. This implies that despite large variations in ambient temperature, heat production balances heat loss, resulting in a stable core temperature ${ }^{(5)}$.

\section{Heat balance and energy balance}

Energy enters the body as food and leaves as heat or external work. Thus, heat balance is linked to energy balance. When energy intake exceeds energy expenditure, the body is in a positive energy balance resulting in weight gain and if this state remains, overweight will be the result ${ }^{(34,42)}$. The regulation of energy balance and the differences between individuals in the regulation play a role in the development of overweight. The study of inter-individual differences in heat balance can therefore provide additional information about the development of under- or overweight. 


\section{Components of energy expenditure}

Several approaches exist in dividing total energy expenditure in components. Energy expenditure can be divided in obligatory and adaptive heat production, each consisting of subcomponents (Figure 1) and is subject to different influences and regulated by different mechanisms. These components are described in more detail in the next paragraph.

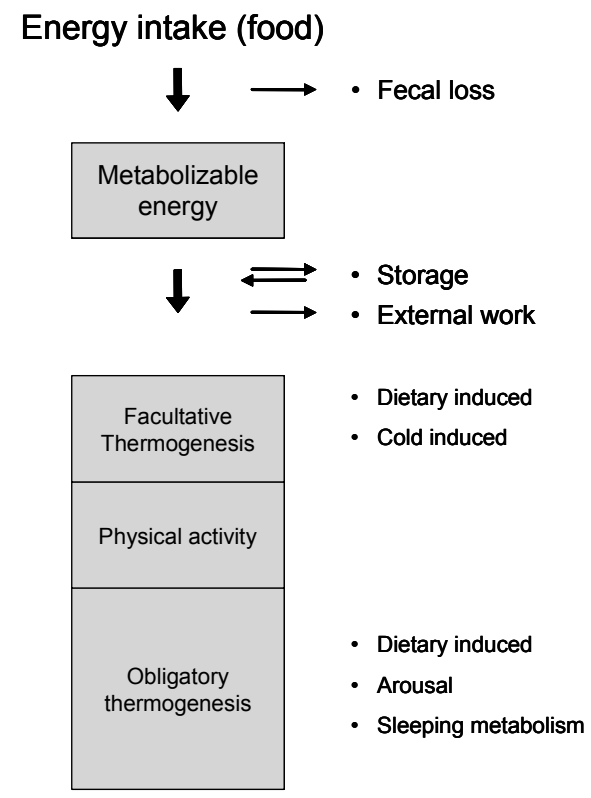

Figure 1. Components of energy balance.

Energy enters the body as food and is stored, transferred to external work and faeces or dissipated as heat. Energy can also be mobilized from energy stores in the body (mostly adipose tissue). Total energy expenditure can be subdivided in obligatory, activity induced and facultative thermogenesis. Both obligatory and facultative thermogenesis can be divided in smaller subcomponents. (Adapted from Dulloo 2004, Lowell $2000^{(13,34)}$.

\section{Heat production}

\section{Obligatory and facultative thermogenesis}

Obligatory thermogenesis refers to the heat produced as a product of food intake and other processes in cells and organs ${ }^{(43)}$. In addition, facultative thermogenesis, also referred to as adaptive thermogenesis, is defined as thermogenesis in response to environmental temperature or diet ${ }^{(5,43)}$ and serves the purpose of protecting the organism from cold exposure or regulating energy balance after changes in $\operatorname{diet}^{(34)}$.

Diet induced thermogenesis consists of an obligatory and facultative part. Cold exposure can result in an increase in thermogenesis or cold-induced non shivering thermogenesis (CIT). CIT can be defined and measured as the increase of thermogenesis during cold exposure compared to baseline thermogenesis when shivering is absent. When cooling continues, shivering further increases thermogenesis. Frequent cold exposure results in a shift from shivering thermogenesis to non-shivering thermogenesis. After a few days of cold exposure shivering disappears, while non shivering thermogenesis increases (Figure 2$)^{(12)}$. In rodents this can be attributed to brown adipose tissue ${ }^{(8)}$. In humans, lowering temperature from $28^{\circ} \mathrm{C}$ to $22^{\circ} \mathrm{C}$ has been reported to cause an average of $7 \%$ increase in thermogenesis in clothed humans without shivering ${ }^{(11)}$. 

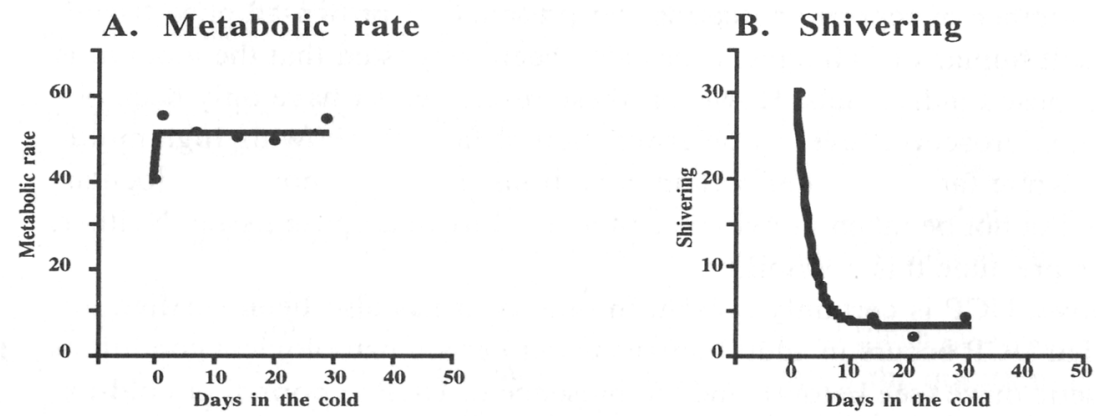

Figure 2. Shivering and metabolic rate in the cold. Adapted from Davies $1961^{(5,12)}$.

\section{Heat loss}

Heat can be exchanged between the skin and the environment by radiation, conduction, convection and evaporation. Radiative heat exchange from humans to the environment is established by mainly infrared heat rays in all directions. Conduction is the transfer of heat through a non-moving medium in direct contact with the skin. When heat is conducted to and carried away by a moving medium, it is called convection ${ }^{(5)}$.

Energy is needed for evaporation of fluids or in other words to transfer water from the liquid to the gaseous state. If this happens at the body surface, energy in the form of heat is lost ${ }^{(5)}$. Evaporation always takes place to some extent from skin and respiratory surfaces (insensible). Additionally sweating can occur (sudomotor response) ${ }^{(21)}$. Evaporation of sweat can be a major contribution to heat loss.

\section{Heat transfer from the core to the skin}

The body can be divided into two compartments: the thermal core and shell ${ }^{(4)}$. Most of the heat produced within the core is dissipated onto the environment via the body surface including the lungs.

The heat produced by metabolism must be transported from the core to the skin where it can be exchanged with the environment. Body temperature distribution thus strongly depends on convective heat transfer by the blood. Blood flow is driven by metabolic rate. Higher tissue temperature comprises an increase in metabolic rate, and consequently an increase in blood flow. By vasomotion the amount of blood flow is further regulated. Under thermoneutral conditions skin temperature is lower than the core and varies with ambient temperature ${ }^{(44)}$. During exercise and heat exposure, cutaneous vasodilation and sweating are triggered. On exposure to cold environments, skin blood flow decreases via cutaneous vasoconstriction ${ }^{(10)}$. This results in reduced heat transfer from the core to the skin, followed by decreased heat loss from the skin. 


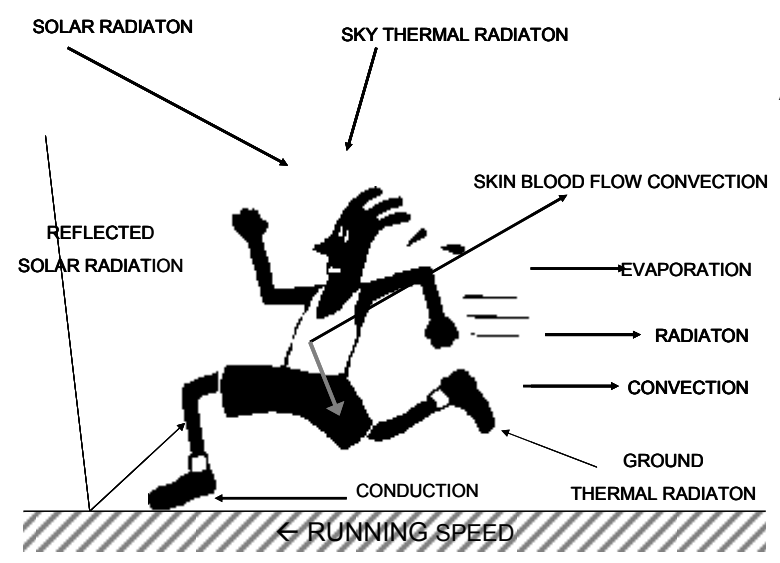

Figure 3

Heat exchange processes in man. Adapted from Blatteis $1998^{(5)}$

\section{Regulation of heat loss by changes in skin blood flow}

The subcutaneous adipose tissue layer works as an insulator in the cold. Skin blood flow, however, bypasses this layer and is the most influencing factor of skin temperature and therefore of heat loss. Skin blood flow is varied by the mechanisms of vasoconstriction and dilation. Vasoconstriction and dilation are both subject to sympathetic stimulation $^{(10)}$. Nonglabrous skin (glabrous skin is restricted to the lips, palms and soles) is innervated by both sympathetic adrenergic vasoconstrictor and sympathetic vasodilator nerves. Glabrous skin however, is innervated by sympathetic vasoconstrictor nerves only ${ }^{(5)}$. Substantial changes in bloodflow in glabrous skin can be caused by constriction and dilation of arteriovenous anastomoses (AVA's), these are thick-walled, lowresistance conduits that allow high flow rates directly form arterioles to venules ${ }^{(10)}$. Nonglabrous skin has only few AVA's if any ${ }^{(10)}$.

\section{a. Vasoconstriction}

Sympathetic vasoconstrictor nerves release norepinephrine, which interacts with postsynaptic $\alpha-1$ and $\alpha-2$ receptors on cutaneous arterioles and AVA's. In addition, noradrenergic vasoconstrictor nerves release one or more, not yet identified, co-transmitters that also cause vasoconstriction ${ }^{(39)}$. Kellogg et al. conclude that neuro-peptide Y (NPY) that was found to be a co-transmitter in animal models could also be one of the cotransmitters in humans ${ }^{(30)}$.

\section{b. Vasodilation}

Under normal circumstances decreasing and increasing sympathetic vasoconstrictor nerve activity is sufficient for thermoregulation ${ }^{(37)}$. During heat stress, tonic sympathetic vasoconstriction is released and in addition cutaneous active vasodilation is initiated. Although the mechanism of cutaneous active vasodilation is not entirely understood, there is evidence that it is affected by cholinergic nerves and that the substances causing vasodilation must include at least one neurotransmitter co-released with acetylcholine from cholinergic nerves ${ }^{(30)}$. Other investigators conclude that it is unlikely that acetylcholine is responsible, but they agree that co-transmitters are released to elicit a response $^{(10,37)}$. 
Sweating and active vasodilation begin at approximately the same time in resting heatstressed persons. Furthermore, persons with congenital absence of sweat glands, also lack a cutaneous active vasodilator response to heat stress ${ }^{(30)}$, indicating that they are related. The vasodilator substance and the relation between sudomotor and active vasodilator nerves are not yet known ${ }^{(10)}$.

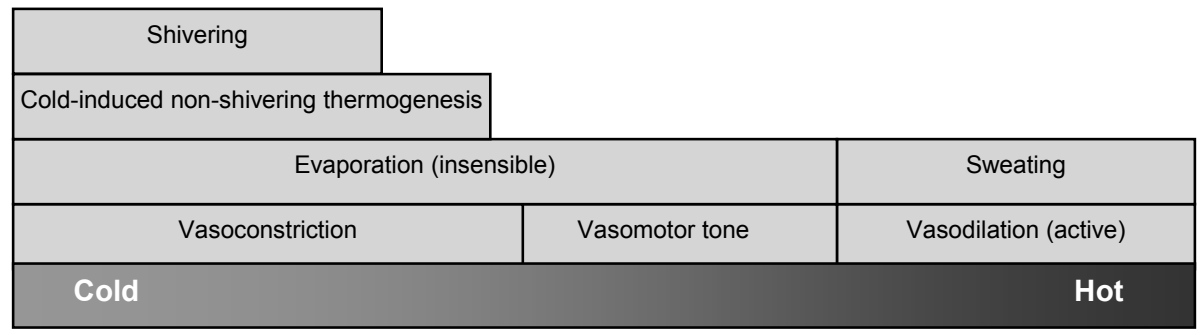

Figure 4. Human processes of heat loss and extra heat production over a range of environmental temperatures.

\section{Homeothermy}

Temperature regulation, set-point theory

Classically, heat regulation is considered as regulation of processes around a temperature set-point. This is based around the core-shell principle. The core is kept almost constant whereas peripheral temperature rises and falls with the environmental temperature enabling a certain amount of heat loss ${ }^{(21)}$. The preoptic / anterior hypothalamus $(\mathrm{PO} / \mathrm{AH})$ coordinates these processes. It is located in and near the rostral hypothalamus and contains neurons that are sensitive to subtle changes in hypothalamic or core temperature. Preoptic thermo-sensitive neurons also receive a somato-sensory input from skin and spinal thermoreceptors. In this way, preoptic neurons compare and integrate central and peripheral thermal information ${ }^{(6)}$, and coordinate the appropriate efferent response ${ }^{(6,10)}$. Input from more proximally located neurons (in the core) typically contributes more to autonomic and metabolic responses than input from the skin.

If exposed to a cold environment, heat balance is disturbed. The physiological response can be insulative, metabolic or a combination of these two in order to re-establish the balance. This has been investigated in humans but most widely in various animal species. From animal studies it is known that with regard to the metabolic response, it is preoptic cooling that results in an increase in metabolism by shivering ${ }^{(7,24,27)}$. Preoptic cooling can also elicit cold-induced thermogenesis by increased metabolic activity in brown adipose tissue ${ }^{(26)}$ and increased levels of plasma metabolic hormones, including thyroxine ${ }^{(3,14)}$, catecholamines, and glucocorticoids ${ }^{(17)}$. Human studies also show an increase in metabolic activity in response to cooling ${ }^{(11,46)}$. Regulation of cold-induced thermogenesis can follow two pathways, the sympathetic nervous system and the hypothalamic-pituitary-thyroid axis ${ }^{(34)}$. Possible mechanisms that have been suggested for cold-induced thermogenesis are mitochondrial uncoupling and futile- and calciumcycles. Several uncoupling proteins have been identified of which, at least in animals, UCP-1 is the key regulator ${ }^{(8,35)}$. Furthermore, mitochondrial ATP-synthase is a possible regulator of mitochondrial efficiency ${ }^{(34,43)}$. These possibilities will be addressed further in the discussion section of this thesis. 
In addition, from animal studies it is known that it is preoptic cooling that initiates heatretention responses, which include cutaneous vasoconstriction and a variety of behavioural responses that conserve body heat ${ }^{(1,16)}$. In comparison, it is preoptic warming that elicits cutaneous vasodilatation, sweating, panting, and various behavioural responses that enhance heat loss ${ }^{(16,18,28,29)}$

\section{Heat regulation versus temperature regulation}

Is it really temperature that is regulated? More and more evidence points in the direction of heat regulation or heat balance regulation. Although a core temperature of approximately $37^{\circ} \mathrm{C}$ is generally accepted as normal ${ }^{(37)}$, it is also well known that variation exists within and between individuals. Webb and colleagues state that body temperature is not constant but heat balance is kept at different levels of heat production and loss, throughout the day and during exercise ${ }^{(47-49)}$. There are more experiments that show that circadian variation in rectal temperature is a consequence of endogenous circadian rhythms in both heat production and heat loss even under unmasking conditions ${ }^{(31)}$. In these experiments, external stimuli (e.g. light and dark and knowledge of time) are taken away and the circadian variation still exists.

In line with this concept it was recently proposed to explain the regulation of body temperature by a balance of processes (both active and passive), as opposed to a set point or single control center ${ }^{(38)}$. Under circumstances like fever and exercise but also during activities of daily living, the "set-point" seems to shift and in that way adapt to another level. A description of processes would make fever a situation where body temperature balances above its normal value. Romanovsky et al. ${ }^{(38)}$ are in favor of using the term "balance-point" in stead of "set point". With this change in definition, the adjustable nature of the set point used by Caputa and co-workers ${ }^{(9)}$ is not needed and the balance point applies to all situations where set-point does not.

Tikuisis et al. showed that during cooling, shivering already reached a plateau while core temperature was still decreasing ${ }^{(41)}$. This again indicates that heat balance exists at different levels while body temperature changes. In favor of heat regulation, Tikuisis concludes that heat balance is attained while body temperatures are still stabilizing. The regulation of mean body temperature actually equals heat content regulation. The question remains what in addition to heat content is of influence since heat debt continued to increase in this study ${ }^{(41)}$.

\section{Individual differences}

Thermoregulation is influenced by behavioral, physiological and pathological factors and as such differences both within and between individuals exists. Age, gender, body composition, and acclimatization status are all subject characteristics that can influence body temperature and energy expenditure ${ }^{(45)}$. The influence of genetic composition is largely unknown ${ }^{(45)}$.

Most gender related differences may be caused by variation in body composition, anthropometry and hormones. However, significant variation remains to be explained. The increase in $24 \mathrm{~h}$ energy expenditure in response to mild cold was shown to have a range 
from 2 to $12 \%^{(11)}$. This means that the components of adaptive thermogenesis are subject to large variation between individuals. In this thesis, adaptive thermogenesis, at rest, in response to cold is studied.

\section{Modeling human thermoregulation}

Various detailed models of the human thermal system have been developed in the past three decades predicting human thermoregulatory responses to the environment, clothing and/or different levels of activity. Such models, also called rational models ${ }^{(36)}$, provide a mathematical description of human responses to thermal environments. Thermal models refer to a dynamic mathematical simulation of the human body and its response to thermal environments, involving both a passive and a controlling system for the body as well as mechanisms of heat exchange.

Most of the models available today are based on the work of Stolwijk who modeled the body as a composite of several cylinders representing the head, the corpus, and the upper and lower extremities ${ }^{(40)}$. Useful refinements of this model have been implemented, among others by Gordon, Lotens and Huizinga ${ }^{(20,25,33)}$, and also new thermoregulatory models have been developed e.g. by Wissler, Xu and Fiala ${ }^{(15,50)}$. Virtually all models are population based, i.e. they predict an average response of the population or use an average subject with standardized body characteristics.

Currently, there is growing interest in 'personalized' models capable of predicting the thermal behavior of individuals or specific groups of population. The fields of application for such models include e.g. indoor climate and thermal comfort research (e.g. air conditioning systems in buildings and cars), biometeorology and the textile and military research (e.g. to assess exposure limits and the performance of protective clothing systems), in health sciences (e.g. study of factors determining the metabolic efficiency), risks under stressful conditions (e.g. heat stress, cold stress, strenuous exercise), and in clinical environment (e.g. surgery, anaesthetics, recovery, accidental hypothermia).

Recently, some models have emerged which incorporate individual human characteristics $^{(19,23,51)}$, but although promising, the validation results are still limited. In this respect it is important that the development and validation of individualized models is based on actually measured subjective characteristics such as the body composition and metabolism.

\section{Objectives}

The general objective of the thesis was to study human thermoregulation in mild cold in order to gain insight in inter individual differences in adaptive thermogenesis as a result of mild cold.

\section{Research questions}

- What is the magnitude and individual variation of cold-induced thermogenesis?

- What is the influence of the seasons (acclimatization) on cold-induced thermogenesis? 
- What is the role of body composition and the difference between lean and overweight subjects for cold-induced thermogenesis?

- What is the role of the sympathetic nervous system on cold-induced thermogenesis?

- Can thermal models be improved for personalized predictions or to be applied in specific conditions?

\section{Outline of the thesis}

The existence of cold-induced non-shivering thermogenesis in humans is still under discussion. Further the magnitude of individual variation in heat production response to mild cold is important because it can have an influence on energy balance. In Chapter 2 the existence of cold-induced thermogenesis and the magnitude of inter-individual differences in resting metabolic rate and cold-induced thermogenesis were investigated. In Chapter 3 the previous experiment was repeated in winter to find out if this result was a subject specific characteristic. In Chapter 4 the individual variation in the time until shivering was studied and related to body temperature and body-composition. To further explore factors that are related to cold-induced thermogenesis, overweight and lean subjects were compared in Chapter 5 . Not only the period of exposure to cold was studied but also the rewarming period. The role of the SNS in cold-induced thermogenesis was studied in Chapter 6 by measurements of catecholamines and skin blood flow. Finally the data that was created in the previously mentioned experiments was used to extend the applicability of a mathematical model of human thermoregulation which is described in Chapter 7.

Chapter 8 discusses the results of the above mentioned experiments. 


\section{Literature}

1 Adair ER. Skin, preoptic, and core temperatures influence behavioral thermoregulation. J Appl Physiol 42: 559-564, 1977.

2 Adair ER and Black DR. Thermoregulatory responses to RF energy absorption. Bioelectromagnetics Suppl 6: S17-38, 2003.

3 Andersson B, Ekman L, Gale CC and Sundsten JW. Control of Thyrotrophic Hormone (Tsh) Secretion by the "Heat Loss Center". Acta Physiol Scand 59: 12-33, 1963.

4 Aschoff $\mathrm{J}$ and Wever R. Kern und Schale im Wärmehaushalt des Menschen. Naturwiss 45: 477-485, 1958.

5 Blatteis CM. Physiology and pathophysiology of temperature regulation. Singapore: World Scientific, 1998.

6 Boulant JA. Role of the preoptic-anterior hypothalamus in thermoregulation and fever. Clin Infect Dis 31 Suppl 5: S157-161, 2000.

7 Boulant JA and Gonzalez RR. The effect of skin temperature on the hypothalamic control of heat loss and heat production. Brain Res 120: 367-372, 1977.

8 Cannon B and Nedergaard J. Brown adipose tissue: function and physiological significance. Physiol Rev 84: 277-359, 2004.

9 Caputa M. Comments on "Do fever and anapyrexia exist? Analysis of set point-based definitions". Am J Physiol Regul Integr Comp Physiol 289: R281; author reply R281-282, 2005.

10 Charkoudian N. Skin blood flow in adult human thermoregulation: how it works, when it does not, and why. Mayo Clin Proc 78: 603-612, 2003.

11 Dauncey MJ. Influence of mild cold on $24 \mathrm{~h}$ energy expenditure, resting metabolism and diet-induced thermogenesis. Br J Nutr 45: 257-267, 1981.

12 Davies TRA. Chamber cold acclimatization in man. J Appl Physiol 16: 1011-1015, 1961.

13 Dulloo AG, Seydoux $\mathrm{J}$ and Jacquet J. Adaptive thermogenesis and uncoupling proteins: a reappraisal of their roles in fat metabolism and energy balance. Physiol Behav 83: 587-602, 2004.

14 Evans SE and Ingram DL. The significance of deep body temperature in regulating the concentration of thyroxine in the plasma of the pig. J Physiol 236: 159-170, 1974.

15 Fiala D, Lomas KJ and Stohrer M. A computer model of human thermoregulation for a wide range of environmental conditions: the passive system. J Appl Physiol 87: 1957-1972, 1999.

16 Freeman WJ and Davis DD. Effects on cats of conductive hypothalamic cooling. Am J Physiol 197: 145-148, 1959.

17 Gale CC, Jobin M, Proppe DW, Notter D and Fox H. Endocrine thermoregulatory responses to local hypothalamic cooling in unanesthetized baboons. Am J Physiol 219: 193-201, 1970.

18 Gisolfi CV, Owen MD, Wall PT and Kregel KC. Effects of changing hypothalamic temperature on eccrine sweating in the patas monkey. Brain Res Bull 20: 179-182, 1988.

19 Gonzalez RR. SCENARIO revisited: comparison of operational and rational models in predicting human responses to the environment. J Therm Biol 29: 515-527, 2004.

20 Gordon RG. The response of human thermoregulatory system in the cold (PhD Thesis in mechanical engineering). Santa Barbara: University of California, 1974.

21 Guyton AC and Hall JE. Textbook of medical physiology. Philadeplhia: Sounders, 2000.

22 Havenith G. Clothing and thermoregulation. Curr Probl Dermatol 31: 35-49, 2003.

23 Havenith G. Individualized model of human thermoregulation for the simulation of heat stress response. $J$ Appl Physiol 90: 1943-1954, 2001.

24 Hellstrom B and Hammel HT. Some characteristics of temperature regulation in the unanesthetized dog. Am J Physiol 213: 547-556, 1967.

25 Huizinga $\mathrm{C}$, Zang $\mathrm{H}$ and Arens $\mathrm{E}$. A model of human phsysiology and comfort for assessing complex thermal environments. Building and Environment 36: 691-699, 2001.

26 Imai-Matsumura $\mathrm{K}$ and Nakayama $\mathrm{T}$. The central efferent mechanism of brown adipose tissue thermogenesis induced by preoptic cooling. Can J Physiol Pharmacol 65: 1299-1303, 1987.

27 Jacobson $\mathrm{FH}$ and Squires RD. Thermoregulatory responses of the cat to preoptic and environmental temperatures. Am J Physiol 218: 1575-1582, 1970.

28 Kanosue K, Yanase-Fujiwara M and Hosono T. Hypothalamic network for thermoregulatory vasomotor control. Am J Physiol 267: R283-288, 1994.

29 Kanosue $\mathrm{K}$, Zhang $\mathrm{YH}$, Yanase-Fujiwara $\mathrm{M}$ and Hosono T. Hypothalamic network for thermoregulatory shivering. Am J Physiol 267: R275-282, 1994.

30 Kellogg DL, Jr. In vivo mechanisms of cutaneous vasodilation and vasoconstriction in humans during thermoregulatory challenges. J Appl Physiol 100: 1709-1718, 2006. 
31 Krauchi K and Wirz Justice A. Circadian rhythm of heat production, heart rate, and skin and core temperature under unmasking conditions in men. Am J Physiol 267: R819-829, 1994.

32 LeBlanc J. Man in the Cold. Springfield, Illinois: Charles C Thomas, 1975.

33 Lotens WA. Heat transfer from humans wearing clothing. Delft: Technical University Delft, 1993.

34 Lowell BB and Spiegelman BM. Towards a molecular understanding of adaptive thermogenesis. Nature 404: 652-660, 2000.

35 Nedergaard J, Matthias A, Golozoubova V, Jacobsson A and Cannon B. UCP1: the original uncoupling protein--and perhaps the only one? New perspectives on UCP1, UCP2, and UCP3 in the light of the bioenergetics of the UCP1-ablated mice. J Bioenerg Biomembr 31: 475-491, 1999.

36 Parsons K. Human Thermal Environments: The effects of moderate to cold environments on human health, comfort and performance. London: Taylor \& Francis, 2003.

37 Passlick-Deetjen $\mathrm{J}$ and Bednebender-Stoll E. Why thermosensing? A primer on thermoregulation. Nephrol Dial Transplant 30: 1784 - 1789, 2005.

38. Romanovsky AA. Do fever and anapyrexia exist? Analysis of set point-based definitions. Am J Physiol Regul Integr Comp Physiol 287: R992-995, 2004.

39 Stephens DP, Aoki K, Kosiba WA and Johnson JM. Nonnoradrenergic mechanism of reflex cutaneous vasoconstriction in men. Am J Physiol Heart Circ Physiol 280: H1496-1504, 2001.

40 Stolwijk JA and Wexler I. Peripheral nerve activity in response to heating the cat's skin. J Physiol 214: 377 392, 1971.

41 Tikuisis $\mathrm{P}$. Heat balance precedes stabilization of body temperatures during cold water immersion. $J$ Appl Physiol 95: 89-96, 2003.

42 Tremblay A, Perusse L and Bouchard C. Energy balance and body-weight stability: impact of geneenvironment interactions. Br J Nutr 92 Suppl 1: S63-66, 2004.

43 Van Marken Lichtenbelt WD and Daanen HA. Cold-induced metabolism. Curr Opin Clin Nutr Metab Care 6: 469-475, 2003.

44 van Marken Lichtenbelt WD, Schrauwen P, van De Kerckhove S and Westerterp-Plantenga MS. Individual variation in body temperature and energy expenditure in response to mild cold. Am J Physiol Endocrinol Metab 282: E1077-1083, 2002.

45 Van Someren EJ, Raymann RJ, Scherder EJ, Daanen HA and Swaab DF. Circadian and age-related modulation of thermoreception and temperature regulation: mechanisms and functional implications. Ageing Res Rev 1: 721-778, 2002.

46 Vybiral S, Lesna I, Jansky L and Zeman V. Thermoregulation in winter swimmers and physiological significance of human catecholamine thermogenesis. Exp Physiol 85: 321-326, 2000.

47 Webb P. Continuous measurement of heat loss and heat production and the hypothesis of heat regulation. Ann N Y Acad Sci 813: 12-20, 1997.

48 Webb P. Daily activity and body temperature. Eur J Appl Physiol Occup Physiol 66: 174-177, 1993.

49 Webb P. The physiology of heat regulation. Am J Physiol 268: R838-850, 1995.

50 Wissler $\mathrm{EH}$. Mathematical simulation of human thermal behavior using whole body models. In: Heat transfer in medicine and biology. Analysis and applications, edited by Eberhart RC. New York: Plenum Press, 1985, p. 325-373.

51 Zhang $\mathrm{H}$, Huizinga $\mathrm{C}$, Arens $\mathrm{E}$ and $\mathrm{Yu}$ T. Considering individual physiological differences in a human thermal model. J Therm Biol 26: 401-408, 2001. 


\section{Chapter 2}

\section{Individual differences in body temperature and the relation to energy expenditure: The influence of mild cold.}




\begin{abstract}
Inter-individual differences in body temperature and resting metabolic rate (RMR), during comfortable temperature and mild cold were studied. Sleeping metabolic rate was measured overnight at $22^{\circ} \mathrm{C}$ and RMR the following morning at $22^{\circ} \mathrm{C}$ and at $16^{\circ} \mathrm{C}$. Intestinal, rectal and skin temperatures were measured as well as electromyography (EMG). SMR and RMR corrected for body composition were significantly related $\left(p<0.001, r^{2}=0.57\right)$ meaning that individual levels of energy expenditure during the night remained during the day. At $16^{\circ} \mathrm{C}$, RMR was higher compared to $22^{\circ} \mathrm{C}$ without increase of EMG activity, indicating non-shivering thermogenesis. Gender differences exist for intestinal, rectal, pectoralis and hand temperature $(p<0.05)$.
\end{abstract}

\title{
Acknowledgements
}

We thank Anton van Steenhoven and Harry van Lenthe for constructive comments (University of Technology, Eindhoven, The Netherlands). Further we thank the department of Movement Sciences of Maastricht University for availability of EMG equipment and Loek Wouters and Paul Schoffelen for technical support. 


\section{Introduction}

Inter individual differences in resting metabolic (RMR) rate can, to a large extent be explained by body composition (fat free mass (FFM) and fat mass (FM)). However, RMR adjusted for these covariates is still subject to significant inter-individual variation ${ }^{(2,7)}$. These differences in metabolic rate may be genetically determined and can have important health implications. People with low metabolic rates have a higher risk of weight gain.

Studies in animals and humans have shown that the differences in metabolic rate are related to differences in body temperature. In a study on the relation between aerobic power and RMR in women, oral body temperature correlated with RMR $(\mathrm{kJ} \cdot \mathrm{kg}$ fat free mass $\left.^{-1} \cdot h^{-1}\right)^{(10)}$. Another study showed that in Pima Indians, metabolic rate adjusted for body composition was related to body temperature ${ }^{(8)}$.

24h Energy expenditure was found to be higher at mild cold compared to a comfortable environmental temperature. However there is a controversy in results on the separate components of $24 \mathrm{~h}$ energy expenditure (e.g. RMR, dietary induced thermogenesis, activity induced energy expenditure $)^{(3,12)}$. Additionally, we found that ADMR corrected for body composition, correlates with core temperature and that metabolic rate responds to changes in ambient temperature ${ }^{(13)}$. Moreover, experiments on short-term exposure to cold (i.e. several hours or less) describe an increase in energy expenditure. The discussion in this case is whether or not non-shivering thermogenesis contributes to the process $^{(4,6,14)}$.

The aim of this study was to determine the magnitude of inter-individual and gender differences in body temperature and RMR, during comfortable temperature and mild cold. The second goal was to study the relation between body temperature (BT) and RMR and the change of BT and RMR in response to a decrease in ambient temperature.

\section{Materials and Methods}

\section{Design}

Subjects visited the University building for an overnight stay and the following morning to conduct the experiment. Body composition was determined on a separate visit within one week of the experiment. During the overnight stay at $22^{\circ} \mathrm{C}$, sleeping metabolic rate (SMR) and intestinal temperature were measured. In the morning, RMR, intestinal, rectal and skin temperatures were measured for one hour at $22^{\circ} \mathrm{C}$ followed by three hours at $16^{\circ} \mathrm{C}$. Data was averaged over the second half hour at $22^{\circ} \mathrm{C}$ and over the second and the last half hour at $16^{\circ} \mathrm{C}$. Subjects were lying supine on a stretcher. Clothing was standardized and consisted of a jogging suit with long trousers and long sleeves. The face, hands and ankles were exposed directly to the mild cold.

\section{Subjects}

Subjects were 13 women and 12 men age 19 - 36 years, BMI 17 to $30 \mathrm{~kg} / \mathrm{m}^{2}$, nonsmoking and non-medicated (Table 1). 
Detailed information concerning purpose and methods used in the study was provided before written consent was obtained. The Ethics Committee of Maastricht University approved the study.

Table 1. Subject characteristics

\begin{tabular}{lccc}
\hline & Mean & Males & Females \\
& $\mathrm{n}=25$ & $\mathrm{n}=12$ & $\mathrm{n}=13$ \\
\hline Age $(\mathrm{y})$ & $26 \pm 5$ & $27 \pm 6$ & $25 \pm 3$ \\
Height $^{1}(\mathrm{~m})$ & $1.75 \pm 0.09$ & $1.83 \pm 0.04$ & $1.67 \pm 0.06$ \\
Weight $^{1}(\mathrm{~kg})$ & $70.4 \pm 14.4$ & $79.4 \pm 14.4$ & $62.2 \pm 8.4$ \\
$\mathrm{BMl}\left(\mathrm{kg} / \mathrm{m}^{2}\right)$ & $22.9 \pm 3.3$ & $23.8 \pm 3.9$ & $22.2 \pm 2.6$ \\
$\mathrm{FM}^{1}(\%)$ & $22 \pm 9$ & $16 \pm 8$ & $27 \pm 7$ \\
\hline
\end{tabular}

${ }^{1} \mathrm{p}<0.01$ between males and females

\section{Measurements}

Body composition was determined using underwaterweighing and calculated according to Siri (1956).

During the night $\mathrm{O}_{2}$ consumption and $\mathrm{CO}_{2}$ production were measured in a $14 \mathrm{~m}^{3}$ respiration chamber as previously described ${ }^{(9)}$. During the morning tests, $\mathrm{O}_{2}$ consumption and $\mathrm{CO}_{2}$ production were measured with an automated respiratory gas analyzer using a ventilated hood system (Omnical, Maastricht University, The Netherlands). Gas analyzers were calibrated previous to the experiments. Energy expenditure was calculated from these data according to Weir (1990).

SMR was defined as the average metabolic rate during at least three hours of sleep with the lowest activity according to radar. RMR was defined as the metabolic rate, lying still, awake.

Intestinal temperature was measured by an ingestible telemetry pill (CorTemp, Human Technologies, Inc., St Petersburg, FL) which was ingested before entering the respiration chamber ${ }^{(5)}$. Rectal temperature was measured by a thermistor-probe (YSI probes, series 402, Yellow Springs Instruments Co. Ltd., Ohio, U.S.A.) inserted $10 \mathrm{~cm}$. Skin temperatures were measured by surface-thermistors (YSI probes, series 409B, Yellow Springs Instruments Co. Ltd., Ohio, U.S.A.) placed at the back of the hand, upperarm, $\mathrm{m}$. pectoralis, abdomen located at the liver, at the back located at the liver, thigh, calf, foot and one sensor placed above the clothing located at the liver. Temperatures were measured at one-minute intervals. Skin temperature was calculated according to Ramanathan (1964). Proximal temperature was calculated, averaging temperatures measured at the upperarm, infraclavicular area, abdomen located at the liver, back located at the liver and thigh. Distal temperature was calculated, averaging temperatures measured at the hand and foot. Temperature gradients were calculated between core and skin, skin and ambient temperature and between proximal and distal skin temperature.

The possible onset of shivering was detected using electromyography (EMG) (K_lab, Amsterdam, The Netherlands) at the $\mathrm{m}$. pectoralis major ${ }^{(1,11)}$. 


\section{Analyses}

Data are reported as means \pm SD. For intra-individual differences in body temperatures between the two ambient temperatures and for inter-individual differences between genders, respectively paired and unpaired T-tests were used. Regression analysis was used to study the relation between energy expenditure and body temperature. Residuals of SMR and RMR were calculated as the difference between the measured and predicted values of energy expenditure. Calculation of predicted values of SMR and RMR was based on multiple regression analysis including FFM and FM. Analysis of covariance (ancova) was used to compare energy expenditure corrected for FFM. Level of significance was set at $\alpha=0.05$.

\section{Results}

\section{Energy expenditure}

Absolute values of both SMR and RMR could be explained by FFM for more than $85 \%$ (SMR $r^{2}=0.86$, RMR $r^{2}=0.85$ ). Including FM or gender did not result in a significant increase of explained variation; nevertheless, for comparability to other studies, FM was included in multiple linear regression analyses for calculations of residuals. Women had a lower SMR, RMR and FFM than men. After adjustment for body composition, no significant gender differences in SMR and RMR were found. Residuals of SMR were related to residuals in RMR ( $\left.p<0.001, r^{2}=0.57\right)$ (Figure 1). This means that individual levels of energy expenditure during the night remained during the day.

In the first hour at $16^{\circ} \mathrm{C}$, RMR increased on average by $5 \%$ compared to $22^{\circ} \mathrm{C}(\mathrm{p}<0.05)$ (Figure 2). Although the difference was smaller than during the first hour at $16^{\circ} \mathrm{C}$, during the last hour at $16^{\circ} \mathrm{C}$, RMR remained significantly elevated compared to $22^{\circ} \mathrm{C}$. During the $16^{\circ} \mathrm{C}$ test, no possible onset of shivering was registered by EMG and the subjects reported no sensation of shivering.

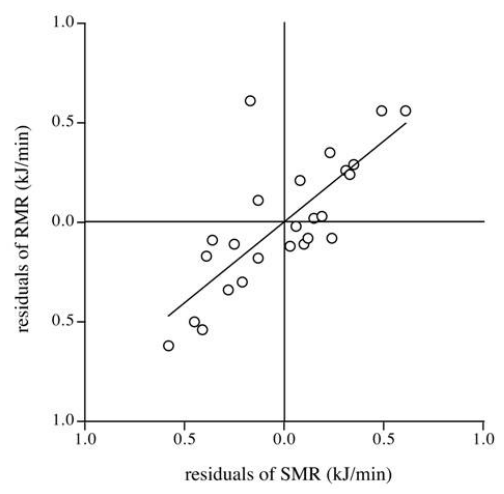

Figure 1. Residuals of resting metabolic rate and FFM and FM versus residuals of sleeping metabolic rate and FFM and FM $\left(r^{2}=0.59 ; p<0.001\right)$.

In the first hour at $16^{\circ} \mathrm{C}$, RMR increased on average by $5 \%$ compared to $22^{\circ} \mathrm{C}(\mathrm{p}<0.05)$ (Figure 2). Although the difference was smaller than during the first hour at $16^{\circ} \mathrm{C}$, during the last hour at $16^{\circ} \mathrm{C}, \mathrm{RMR}$ remained significantly elevated compared to $22^{\circ} \mathrm{C}$. During the 
$16^{\circ} \mathrm{C}$ test, no possible onset of shivering was registered by EMG and the subjects reported no sensation of shivering.

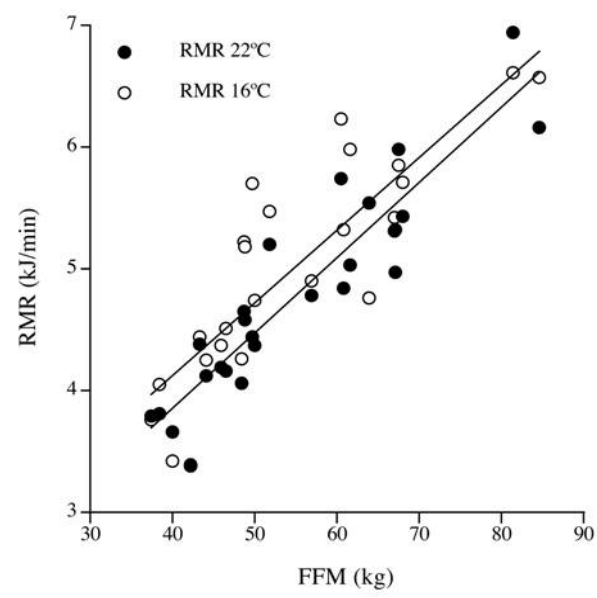

Figure. 2

Resting metabolic rate versus FFM at $22^{\circ} \mathrm{C}$ and $16{ }^{\circ} \mathrm{C}$

$\mathrm{RMR}$ at $22{ }^{\circ} \mathrm{C}(\mathrm{kJ} / \mathrm{min})=0.062 \mathrm{FFM}(\mathrm{kg})+1.353\left(\mathrm{r}^{2}=\right.$ $0.85 ; p<0.001)$.

$\mathrm{RMR}$ at $16{ }^{\circ} \mathrm{C}(\mathrm{kJ} / \mathrm{min})=0.060 \mathrm{FFM}(\mathrm{kg})+1.737\left(\mathrm{r}^{2}=\right.$ $0.71 ; p<0.001)$.

The RMR was significantly higher at an ambient temperature of $16{ }^{\circ} \mathrm{C}$ compared to $22^{\circ} \mathrm{C}(\Delta 5 \%, \mathrm{p}<0.05$; ANCOVA). The slopes of the lines are comparable $(p>0.75 ;$ ANCOVA).

\section{Temperature}

Intestinal temperature was not significantly different from rectal temperature in this study. Intestinal, rectal and $\mathrm{m}$. pectoralis temperatures were higher in women compared to men $(p<0.01, p<0.01, p<0.05$, respectively) (Table 2). Skin temperature measured at the back was slightly higher in women compared to men and hand temperature was slightly lower, but the difference was only significant during the last two hours at $16^{\circ} \mathrm{C}(p<0.05)$. No gender differences were found in the remaining skin temperatures (i.e. upperarm, liver, clothing, thigh, calf, foot). In spite of gender differences in skin temperature at specific sites, the average of proximal or distal skin temperatures was not significantly different and neither was average skin temperature.

No significant change of intestinal or rectal temperature was measured when ambient temperature decreased (Table 2). All skin temperatures decreased after the decrease in ambient temperature $(p<0.001$.) The temperature decrease was larger as the distance from the location to the core was larger. The increase in temperature gradient between intestinal and distal temperature was significantly larger than the increase in temperature gradient between intestinal and proximal temperature from $22^{\circ} \mathrm{C}$ to $16^{\circ} \mathrm{C}(p<0.001)$. Gradients between proximal and distal temperature were significantly higher in women compared to men during the last two hours at $16^{\circ} \mathrm{C}(p<0.05)$. Although temperature gradients between core and skin and between skin and environment were slightly larger in women, no significant gender differences were found (Table 2). All calculated gradients increased significantly after the decrease in ambient temperature $(p<0.001)$ for both women and men separately as for the complete group. The increase in temperature gradient between skin and environment was significantly smaller in women during the first hour at $16^{\circ} \mathrm{C}(p<0.05)$. 
Table 2. Skin, intestinal and rectal temperatures of men and women at $22^{\circ} \mathrm{C}$ and $16^{\circ} \mathrm{C}$

\begin{tabular}{|c|c|c|c|c|}
\hline & \multicolumn{2}{|c|}{$22^{\circ} \mathrm{C}$} & \multicolumn{2}{|c|}{$16^{\circ} \mathrm{C}$} \\
\hline & $M$ & $\mathrm{~F}$ & $\mathrm{M}$ & $\mathrm{F}$ \\
\hline Tintestine & $36.7 \pm 0.4$ & $37.3 \pm 0.6^{* *}$ & $36.7 \pm 0.5$ & $37.6 \pm 0.5^{\star \star}$ \\
\hline Trectum & $36.6 \pm 0.2$ & $37.0 \pm 0.3^{* *}$ & $36.6 \pm 0.3$ & $37.1 \pm 0.2^{* *}$ \\
\hline Tpectoralis $^{1}$ & $33.5 \pm 1.2$ & $34.3 \pm 0.5^{*}$ & $32.3 \pm 1.6$ & $33.4 \pm 0.8^{*}$ \\
\hline Tback $^{1}$ & $33.7 \pm 0.9$ & $34.2 \pm 0.7$ & $32.9 \pm 1.2$ & $33.7 \pm 0.8$ \\
\hline Thand $^{1}$ & $31.6 \pm 2.4$ & $30.3 \pm 2.4$ & $27.5 \pm 3.6$ & $25.0 \pm 2.8$ \\
\hline Tskin $_{\text {ave }}{ }^{1}$ & $32.3 \pm 0.8$ & $32.4 \pm 0.4$ & $30.5 \pm 1.0$ & $30.8 \pm 0.5$ \\
\hline Tproximal $^{1}$ & $32.7 \pm 0.7$ & $32.9 \pm 0.4$ & $31.2 \pm 0.8$ & $31.6 \pm 0.5$ \\
\hline Tdistal $^{1}$ & $30.5 \pm 1.8$ & $29.6 \pm 1.5$ & $26.1 \pm 2.8$ & $24.9 \pm 1.7$ \\
\hline Tskin-amb ${ }^{1}$ & $9.9 \pm 1.1$ & $9.8 \pm 0.7$ & $13.3 \pm 1.6$ & $12.3 \pm 0.8$ \\
\hline
\end{tabular}

\section{Relation of energy expenditure versus body temperature}

No relations were found between the calculated residuals of energy expenditure and body temperatures. A negative relation was found between absolute values of RMR and temperature gradients between core and skin $\left(r^{2}=0.37, p<0.001\right)$. In search for a relation between heat production and heat loss, RMR was compared with body surface area (BSA) and the gradient between skin and ambient temperature. Stepwise regression with RMR as dependent variable and as independent variables, BSA and the gradient between skin and ambient temperature, showed a significant contribution of the temperature gradient in addition to $\mathrm{BSA}$ at $22^{\circ} \mathrm{C}$ and the last hour at $16^{\circ} \mathrm{C}$ (respectively $r^{2}=0.84$, $\left.r^{2}=0.70, p<0.001\right)$. When ambient temperature decreased from $22^{\circ} \mathrm{C}$ to $16^{\circ} \mathrm{C}$, both the temperature gradient at the skin and RMR increased. However, these changes were not related.

\section{Discussion}

Energy expenditure being explained for $85 \%$ by FFM is in concordance with previous literature ${ }^{(2,7)}$. Earlier studies indicate individual RMR differences after correction for body composition $^{(7)}$. The relation between residuals of SMR and RMR shows that subjects with a relatively high energy expenditure during the night have a relatively high energy expenditure during the day which is an individual characteristic. As no sign of shivering was reported after the decrease in ambient temperature, the increase in RMR indicates the existence of non-shivering thermogenesis during short-term exposure to a mild cold environment $^{(14)}$.

Higher intestinal and rectal temperatures in women compared to men are in agreement with the findings of Kim et al. (1998). The slightly lower hand temperature at an ambient temperature of $22^{\circ} \mathrm{C}$ was not significant. This means that the results of Kim et al. (1998) who found a significantly lower hand temperature in women at room temperature were not reproduced in this study. The relative high skin temperatures measured at the back and $\mathrm{m}$. pectoralis site, in women compared to men could be caused by a relatively short distance to the core, however a similar difference was not found for skin temperature near the liver. 
Glickman-Weiss et al (1999) found in men with low and high FM no significant different rectal temperatures caused by a significantly greater aerobic metabolic rate in the low fat group. In women however, the high fat group maintained a higher rectal temperature than the low fat group that did not have an accompanying higher RMR. This suggests that women have a lower capacity to increase RMR. We found no significant gender difference in RMR increase. However, we did find a smaller increase in temperature gradient between skin and environment in women compared to men during the first hour at $16^{\circ} \mathrm{C}$. This indicates a gender difference in vasoconstriction response to a decrease in ambient temperature.

In summary, it appears that individual levels of energy expenditure during the night remained during the day. We found an increase in RMR without an increase in EMG activity in response to a decrease in ambient temperature, indicating non-shivering thermogenesis. Further we found gender differences in body temperature and in temperature distribution in reaction to a decrease in ambient temperature indicating a difference in thermoregulation between genders. 


\section{References}

1 Bell DG, Tikuisis $\mathrm{P}$ and Jacobs I. Relative intensity of muscular contraction during shivering. J Appl Physiol 72: 2336-2342, 1992.

2 Bogardus C, Lillioja S, Ravussin E, Abbott W, Zawadzki JK, Young A, Knowler WC, Jacobowitz R and Moll PP. Familial dependence of the resting metabolic rate. N Engl J Med 315: 96-100, 1986.

3 Dauncey MJ. Influence of mild cold on $24 \mathrm{~h}$ energy expenditure, resting metabolism and diet-induced thermogenesis. Br J Nutr 45: 257-267, 1981.

4 Huttunen P, Lando NG, Meshtsheryakov VA and Lyutov VA. Effects of long-distance swimming in cold water on temperature, blood pressure and stress hormones in winter swimmers. J Therm Biol 25: 171-174, 2000.

5 O'Brien C, Hoyt RW, Buller MJ, Castellani JW and Young AJ. Telemetry pill measurement of core temperature in humans during active heating and cooling. Med Sci Sports Exerc 30: 468-472, 1998.

6 Paolone VJ and Paolone AM. Thermogenesis during rest and exercise in cold air. Can J Physiol Pharmacol 73: 1149-1153, 1995.

7 Ravussin E and Bogardus C. Relationship of genetics, age, and physical fitness to daily energy expenditure and fuel utilization. Am J Clin Nutr 49: 968-975, 1989.

8 Rising R, Keys A, Ravussin E and Bogardus C. Concomitant interindividual variation in body temperature and metabolic rate. Am J Physiol 263: E730-734, 1992.

9 Schoffelen PF, Westerterp KR, Saris WH and Ten Hoor F. A dual-respiration chamber system with automated calibration. J Appl Physiol 83: 2064-2072, 1997.

10 Smith DA, Dollman J, Withers RT, Brinkman M, Keeves JP and Clark DG. Relationship between maximum aerobic power and resting metabolic rate in young adult women. J Appl Physiol 82: 156-163, 1997.

11 Tikuisis P, Bell DG and Jacobs I. Shivering onset, metabolic response, and convective heat transfer during cold air exposure. J Appl Physiol 70: 1996-2002, 1991

12 Valencia ME, McNeill G, Brockway JM and Smith JS. The effect of environmental temperature and humidity on $24 \mathrm{~h}$ energy expenditure in men. Br J Nutr 68: 319-327, 1992.

13 van Marken Lichtenbelt WD, Westerterp-Plantenga $M$ and van Hoydonck $P$. Individual variation in body temperature and energy expenditure in response to elevated ambient temperature. In: Environmental ergonomics IX, edited by Werner J and Hexamer M. Aachen: Shaker Verlag, 2000, p. 51-54.

14 Vybiral S, Lesna I, Jansky L and Zeman V. Thermoregulation in winter swimmers and physiological significance of human catecholamine thermogenesis. Exp Physiol 85: 321-326, 2000. 


\section{Chapter 3}

\section{Seasonal changes in metabolic and temperature responses to cold air in humans}

Published as: A.M.J. van Ooijen, W.D. van Marken Lichtenbelt, A.A. van Steenhoven, K.R. Westerterp.

Physiol behav (2004) 2-3, 545-553 


\begin{abstract}
The metabolic and temperature response to mild cold were investigated in summer and winter in a moderate oceanic climate.

Subjects were 10 women and 10 men, age $19-36$ y and BMI $17-32 \mathrm{~kg} / \mathrm{m}^{2}$. Metabolic rate and body temperatures were measured continuously in a climate chamber with an ambient temperature of $22^{\circ} \mathrm{C}$ for one hour and subsequently three hours of $15^{\circ} \mathrm{C}$.

The average metabolic response during cold exposure, measured as the increase in $\mathrm{kJ} / \mathrm{min}$ over time, was significantly higher in winter (11.5\%) compared to summer $(7.0 \%$, $p<0.05)$. The temperature response was comparable in both seasons. The metabolic response in winter was significantly related to the response in summer $\left(r^{2}=0.47, p<\right.$ $0.001)$. Total heat-production during cold exposure was inversely related to the temperature response in both seasons (summer, $r^{2}=0.39, p<0.01$; winter $r^{2}=0.32, p<0.05$ ). In conclusion, the observed higher metabolic response in winter compared to summer indicates cold adaptation. The magnitude of the cold response varies, but the relative contribution of metabolic and temperature response was subject specific and consistent throughout the seasons, which can have implications for energy balance and body composition.
\end{abstract}

\title{
Acknowledgements
}

We thank Martine Mol for data collection and enthusiastic support.

We thank Harry van Lenthe (University of Technology, Eindhoven, The Netherlands), for constructive comments. Further we thank the department of Movement Sciences of Maastricht University for availability of EMG equipment and Loek Wouters and Paul Schoffelen for technical support.

The experiments described in this paper comply with the current laws of The Netherlands. 


\section{Introduction}

In thermal physiology, there is a strong interest in human responses to extreme temperatures. Few studies are available about mild cold conditions and even less studies that focused on individual patterns of cold responses (Chapter 2$)^{(8,34,36)}$. With respect to mild cold exposure as met under daily living circumstances in many places on earth, metabolic and temperature effects cannot be deduced from the existing studies. Therefore, we studied physiological mild-cold responses in a modern society in a moderate oceanic climate.

Upon entering a cold environment, heat balance is disturbed, and consequently two main patterns of physiological adjustments may occur: insulative and metabolic, or a combination of these. The insulative adjustment in response to cold exposure is accomplished by peripheral vasoconstriction. This is called insulative vasomotor response. This restricts heat transfer from the internal organs to the skin, resulting in a decrease in skin temperature, which in turn results in a decrease in body heat loss ${ }^{(4)}$. The metabolic response results in an increase in metabolic rate (MR), thus increasing heat production ${ }^{(3,4)}$. Several components of energy expenditure may contribute to the process: shivering thermogenesis $(\mathrm{ST})^{(1,13)}$, non-shivering thermogenesis $(\mathrm{NST})^{(17,19,37)}$, non-exercise activity thermogenesis $(\mathrm{NEAT})^{(20)}$, and activity-induced thermogenesis (AT). Under resting conditions, only the components ST and NST and NEAT remain.It is well known that the magnitude of the cold response and to a lesser extent the relative contribution of the metabolic and insulative vasomotor response, depends on the duration and severity of the cold exposure, the medium, water or air, and acclimatization ${ }^{(5,28)}$.

With respect to cold exposure, most studies are conducted using severe cold stress, with maximal temperatures $20^{\circ} \mathrm{C}$ water or $5^{\circ} \mathrm{C}$ air ${ }^{(14,24,37,43)}$. Only a few studies are available using mild cold responses in air ${ }^{(6,9,21,38)}$. These studies, however, focus on energy metabolism, not on insulation. None of these studies are concerned with individual differences.

Physiological adjustments in response to chronic cold exposure are referred to as acclimatization, or acclimation under laboratory conditions. The acclimatization pattern appears to differ depending on the type of cold exposure, like the effect of the artic climate $^{(18)}$, sleeping nude in the col ${ }^{(31)}$, or regular cold water immersions ${ }^{(2)}$. We wondered if the relatively small differences in environmental temperature as encountered in modern society, with central heated houses and good clothing, in a moderate oceanic climate would affect the physiological cold response.

In an acclimation study, using water immersion as cold stimulus, Bittel ${ }^{(4)}$ showed interindividual differences in metabolic and insulative vasomotor response to extreme cold, and changes in response after acclimation. Recently, inter-individual variation in mild cold response was shown in subjects staying for 2 days in a respiration chamber at our laboratory ${ }^{(34)}$. Subjects that responded with increased metabolism in the cold, showed less insulative vasomotor response and vice versa. The average increase in energy metabolism amounted to $5 \%$ of $24 \mathrm{~h}$ energy expenditure. More interesting, the observed range in changes in metabolism compared to thermoneutral conditions was $0.15-1.45$ $\mathrm{MJ} / \mathrm{d}$, which can have significant metabolic consequences on the long term. A relatively large contribution of an insulative vasomotor response and failure of activation of thermogenesis is a risk for weight gain ${ }^{(27)}$. 
If seasonal changes in cold response exist, we wondered if the observed inter-individual variation will be maintained throughout the seasons as well. In other words, is the type of cold response an individual trait? For example, it is known that relative body temperature is subject specific as shown by Rising et al. (1992). They found a significant individual variation in fasting oral temperature and in spite of changes of the temperature, inter individual differences in body temperature were maintained throughout semi starvation and refeeding ${ }^{(29)}$.

This paper aims to investigate seasonal changes in response to mild cold. The study was conducted in a moderate oceanic climate with mild seasonal differences in environmental temperature and, in general, small differences between indoor and outdoor temperatures. In order to avoid the effect of activity and diet during cold exposure, resting conditions were studied.

It was hypothesized that individual differences in cold response exist ranging from a more insulative vasomotor response to a more metabolic response to cold, and that the metabolic response is inversely related to the insulative vasomotor response. Secondly, the individual pattern of cold response remains during acclimatization in winter compared to summer, while the magnitude of the response changes.

\section{Materials and Methods}

\section{Subjects}

10 women and 10 men age ranging from 19 to 36 years and BMI ranging from 17 to 32 $\mathrm{kg} / \mathrm{m}^{2}$ participated in the study (Table 1 ). Subjects were not using any medication and were non-smokers.

The volunteers were provided with detailed information concerning purpose and methods used in the study, before written consent was obtained. The Ethics Committee of Maastricht University approved the study. Most subjects were students spending average time on sports or daily living activities, none of them were extreme athletes or extremely active in outdoor activities. All but one of the women were either users of oral contraceptives or in pre-ovulatory phase at the measurement day.

\section{Design}

Experiments took place at the end of the summer, in August and September, and all measurements were repeated with the same subjects at the end of the winter, in February and March, just after the warmest and coldest months of the year (Figure 1). Subjects visited the laboratory for an overnight stay and the following morning to carry out the experiment. In order to avoid an effect of diet induced thermogenesis, subjects fasted starting $10 \mathrm{~h}$ prior to the cold test until the end of the test. From 22.00 PM till 8.00 AM the ambient temperature was $22^{\circ} \mathrm{C}$. Sleeping metabolic rate (SMR) and intestinal temperature were measured. Subjects were lying on a bed and covered with a duvet $\left(375 \mathrm{~g} / \mathrm{m}^{2}\right)$. In the morning, subjects moved to a stretcher where they were lying in semi-supine position. MR, intestinal, rectal and skin temperatures were measured for one hour at an 
ambient temperature of $22^{\circ} \mathrm{C}$ followed by three hours during which the subjects were exposed to the cold. The subjects stayed in de same room, which was cooled from $22^{\circ} \mathrm{C}$ to $15^{\circ} \mathrm{C}$ in 45 minutes. They were wearing standard clothing with an insulative value of $0.71 \mathrm{clo}\left(\mathrm{Icl}=0.109 \mathrm{~m}^{2} \cdot{ }^{\circ} \mathrm{C} / \mathrm{W}\right)$, consisting of sweatpants $(0.28 \mathrm{clo})$, a sweater $(0.37 \mathrm{clo})$, socks that cover only the feet $(0.02 \mathrm{clo})$ and panties and a bra for women and briefs for men (0.04 clo). The face, hands and ankles were exposed directly to the environment.

Data was averaged over the last 45 minutes of the hour at $22^{\circ} \mathrm{C}\left(\mathrm{t}_{0}\right)$ and over every hour at $15^{\circ} \mathrm{C}\left(\mathrm{t}_{1}, \mathrm{t}_{2}, \mathrm{t}_{3}\right)$.

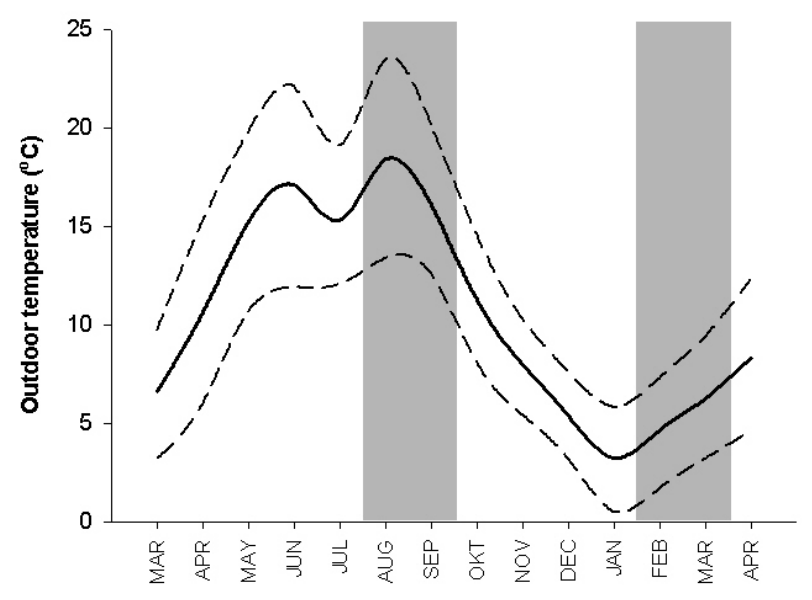

Figure 1.

Monthly mean of daily average temperatures from March 2000 until April 2001 with monthly mean values of daily maximum and minimum temperatures $\left({ }^{\circ} \mathrm{C}\right)$ at station Maastricht, The Netherlands. Measured by the Royal Dutch Meteorological Institute.

Legend

- Monthly mean of daily average temperatures

- - Monthly mean of daily maximum temperatures

- - Monthly mean of daily minimum temperatures

Test period

Subjects were not allowed to exercise the day before the measurement and were fasting from the moment they entered the chamber until the experiment was finished.

Body composition and maximal oxygen uptake $\left(\mathrm{VO}_{2 \max }\right)$ were determined on a separate visit within one week of the experiment.

\section{Measurements}

Body composition was calculated using the three-compartment model according to Siri (1961) with the following equation ${ }^{(32)}$.

$$
F M(\%)=\left(\frac{2.118}{D b(\mathrm{~kg} / \mathrm{l})}-0.78 \times \frac{T B W(\mathrm{l})}{B M(\mathrm{~kg})}-1.354\right) \times 100
$$

Where $\mathrm{Db}$ is the density of the body, TBW the total amount of body water and BM is body mass.

For this calculation, body density and total body water were determined using underwater weighing and deuterium dilution, respectively ${ }^{(12)}$. The latter was determined according to the Maastricht protocol ${ }^{(41)}$. In the evening after collecting a baseline urine sample, a single dose of deuterium dilution was ingested. Deuterium enrichment was measured in urine from the second voiding of the following morning.

During the night, $\mathrm{O}_{2}$ consumption and $\mathrm{CO}_{2}$ production were measured in a $14 \mathrm{~m}^{3}$ respiration chamber as previously described ${ }^{(30)}$. Sleeping metabolic rate (SMR) was defined as 
the average metabolic rate during at least three hours of sleep with the lowest activity as registered by radar. In most cases, this was between 3 and 6 AM. During the morning tests, $\mathrm{O}_{2}$ consumption and $\mathrm{CO}_{2}$ production were measured with an automated respiratory gas analyser using a ventilated hood system (Omnical, IDEE, Maastricht, The Netherlands) using the same methods of analysis as the respiration chamber. Gas analyses were performed by dual paramagnetic $\mathrm{O}_{2}$ analysers and dual infrared $\mathrm{CO}_{2}$ analysers (type 1156, 1507, 1520; Servomex, Crowborough, Sussex, UK), similar to the analysis system described by Schoffelen et al $(1997)^{(30)}$. Metabolic rate was calculated from these data according to Weir (1949) republished as classical article (1990) using the following equation ${ }^{(40)}$.

$M R(\mathrm{~kJ} / \mathrm{min})=16.3 \times$ oxygen.consumed $(l / \mathrm{min})+4.6 \times$ carbon.dioxide. produced $(l / \mathrm{min})(2)$

Resting metabolic rate (RMR) was defined as the metabolic rate $(\mathrm{kJ} / \mathrm{min})$ in a thermo neutral environment, lying still and awake in a post-absorptive state.

$\mathrm{VO}_{2 \max }$ was determined during an incremental exercise test, performed on a cycle ergometer (Lode, Excalibur, Groningen, The Netherlands). Men and women started to cycle at 100 and 75 Watts, respectively. This workload was used as a warming up period for 5 minutes, followed by a workload increase of 50 Watts every 2.5 minutes until heart rate reached $160 \mathrm{bpm}$, then the workload was increased 25 Watts every 2.5 minutes until exhaustion. The highest oxygen uptake averaged over 30 seconds was used as $\mathrm{VO}_{2 \text { max. }}$ Criteria for maximal performance were a forced ventilation, a levelling off of oxygen uptake or a respiratory quotient above 1.1.

Core temperature was measured by two means, rectally and in the intestine. The variation in intestinal temperature can be quite large. The disadvantage of rectal temperature however, is that it can be delayed compared to core temperature especially during cold exposure tests, and when core compartment size is reduced, rectal temperature can deviate from the core ${ }^{(39)}$. Therefore, we measured intestinal temperature as well.

Rectal temperature was measured continuously by a thermistor-probe (YSI probes, series 402, Yellow Springs Instruments Co. Ltd., Ohio, U.S.A.) inserted for $10 \mathrm{~cm}$. Intestinal temperature was measured by an ingestible telemetry pill (CorTemp, Human Technologies Inc., St Petersburg, FL, U.S.A.), which was ingested before entering the respiration chamber ${ }^{(23)}$, which was the evening before the measurements in the morning. Skin temperatures were measured by surface thermistors (YSI probes, series 409B, Yellow Springs Instruments Co. Ltd., Ohio, U.S.A.) placed on the back of the hand, upper arm, chest located at the m. pectoralis, abdomen located just below the right ribs, on the back located just below the right ribs, thigh, calf, foot. Temperatures were measured continuously for 50 seconds out of every minute and saved every minute.

Shivering was detected using electromyography (EMG) (Tiretherm, IDEE, Maastricht, The Netherlands). EMG signals were amplified $x$ 100. These signals were filtered between 33 and $160 \mathrm{~Hz}$ and at the same time amplified for the second time between 2 and $11 \times$ (adjustable). The signal proceeded through a signal comparator at a fixed reference level ( 1 Volt). The signal output then consisted of high frequency pulses, which were counted and recorded for 50 out of every 60 seconds. The second amplification factor was adjustable by the experimenter and was set before the start of the experiment, when the subject was already in the experimental set up. The factor was chosen between 2 and $11 \mathrm{x}$, as sensitive as possible just above noise level. EMG electrodes were placed 
$3 \mathrm{~cm}$ apart on the skin at the $\mathrm{m}$. pectoralis major ${ }^{(1,33)}$. This site was chosen because in people having a normal amount of fat, shivering starts in the upper trunk region, and propagates towards the extremities ${ }^{(33)}$. In addition, every 15 minutes, subjects were asked if they felt if they were shivering and the observer checked the subjects to see if they were shivering. Examples of EMG measurements with and without shivering are presented in Figure 2.
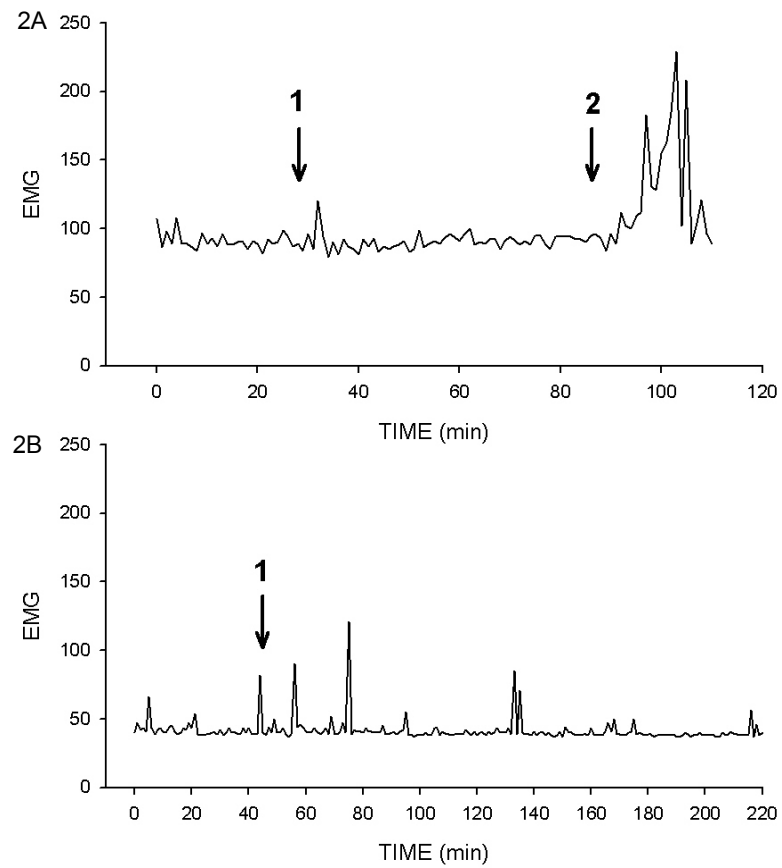

Figure 2. Example of EMG measurement.

Figure $2 \mathrm{~A}$ is an EMG measurement of a test where shivering was induced.
Figure $2 \mathrm{~B}$ is a typical example of an EMG measurement of the present study. No shivering was induced

$1=$ Start of cooling

$2=$ Onset of shivering.

\section{Calculations}

Mean skin temperature was calculated according to Ramanathan (1964), using the following equation ${ }^{(26)}$.

Mean.skin.temperature $\left({ }^{\circ} \mathrm{C}\right)=0.3 \times\left(\operatorname{Tchest}\left({ }^{\circ} \mathrm{C}\right)+\operatorname{Tarm}\left({ }^{\circ} \mathrm{C}\right)\right)+0.2\left(\operatorname{Tthigh}\left({ }^{\circ} \mathrm{C}\right)+\operatorname{Tleg}\left({ }^{\circ} \mathrm{C}\right)\right)(3)$

The distal temperature, calculated averaging hand and foot temperatures, represents the skin most distant from the core and is expected to show the strongest insulative vasomotor response. Temperature gradients, as a measure of insulation, were calculated between intestine and mean skin temperature (Tintestine-skin), intestine and distal skin temperature (Tintest-dist), rectal and mean skin (Trectal-skin) and between rectal and distal skin temperature (Trect-dist) ${ }^{(2)}$.

The incremental area under the curve (AUCinc) was calculated by subtracting RMR (MR at $22^{\circ} \mathrm{C}$ ) from the total area under the curve, and represents the total cold induced thermogenesis. The area under the curve was calculated using data over one minute intervals. The change in MR during cold exposure (during $t_{0}-t_{3}$ ) was calculated as well $(\mathrm{kJ} / \mathrm{min})$ as a measure of cold induced thermogenesis. 


\section{Statistical analyses}

Data are reported as means \pm SD. For statistical analyses, all data was averaged over the last 45 minutes of the hour at $22^{\circ} \mathrm{C}$ ambient temperature $\left(t_{0}\right)$ and over every subsequent hour at $15^{\circ} \mathrm{C}\left(t_{1}, t_{2}, t_{3}\right)$. For intra-individual differences (i.e. between the two ambient temperatures) in metabolic rate and body temperatures and for inter-individual differences, paired and unpaired T-tests were used respectively. ANOVA for repeated measurements was used to test the metabolic response to mild cold. For metabolic rate calculation, the incremental and total areas under the curve (AUCinc and AUCtot) were calculated over $t_{0}-t_{3}$, in summer and winter. Differences in cold response between seasons were tested by paired t-tests. Regression analysis was used to study the relation between metabolic and insulative vasomotor response, stratified by season. Results were considered statistically significant when $p<0.05$.

\section{Results}

\section{Body composition}

Physical characteristics of the subjects are given in Table 1. Men were significantly taller, heavier and had a higher fat free mass (kg) (FFM) than women (Table 1, p<0.05). Fat mass ranged between $8.2 \%$ and $30.9 \%$ in men and between 20.7 and $36.0 \%$ in women. Mean FFM (kg) remained unchanged and fat mass (kg) (FM) was increased significantly in winter in males (Table 1). As a result, in men in winter, fat percentage was significantly higher and the percentage fat free mass was lower than in summer $(1.5 \%, p<0.05)$. The same trend occurred in the females.

Table 1. Subject characteristics

\begin{tabular}{|c|c|c|c|c|c|c|}
\hline & \multicolumn{3}{|c|}{ SUMMER } & \multicolumn{3}{|c|}{ WINTER } \\
\hline & $\begin{array}{l}\text { Mean } \\
\mathrm{n}=20\end{array}$ & $\begin{array}{l}\text { Males } \\
\mathrm{n}=10\end{array}$ & $\begin{array}{c}\text { Females } \\
\mathrm{n}=10\end{array}$ & $\begin{array}{l}\text { Mean } \\
n=20\end{array}$ & $\begin{array}{l}\text { Males } \\
\mathrm{n}=10\end{array}$ & $\begin{array}{c}\text { Females } \\
n=10\end{array}$ \\
\hline$\overline{\text { Age }(y)}$ & $26 \pm 5$ & $27 \pm 6$ & $25 \pm 3$ & & & \\
\hline Height (m) & $1.74 \pm 0.09$ & $1.82 \pm 0.04$ & $1.67 \pm 0.07^{\dagger}$ & & & \\
\hline Weight $(\mathrm{kg})$ & $71.1 \pm 14.4$ & $78.8 \pm 15.5$ & $63.3 \pm 8.1^{\dagger}$ & $72.0 \pm 14.8$ & $79.9 \pm 16.6$ & $64.2 \pm 6.9^{\dagger}$ \\
\hline FM (kg) & $16.1 \pm 7.1$ & $14.3 \pm 8.6$ & $17.9 \pm 5.1$ & $17.0 \pm 6.8^{*}$ & $15.7 \pm 8.9^{*}$ & $18.4 \pm 4.0$ \\
\hline FFM $(\mathrm{kg})$ & $55.0 \pm 12.0$ & $65.5 \pm 8.9$ & $45.4 \pm 4.8^{\dagger}$ & $55.0 \pm 11.9$ & $64.2 \pm 9.8$ & $45.8 \pm 4.2^{\dagger}$ \\
\hline $\operatorname{SMR}(\mathrm{kJ} / \mathrm{min})$ & $4.58 \pm 0.70$ & $5.10 \pm 0.46$ & $4.07 \pm 0.48^{\dagger}$ & $4.58 \pm 0.70$ & $5.08 \pm 0.58$ & $4.08 \pm 0.37^{\dagger}$ \\
\hline $\operatorname{RMR}(\mathrm{kJ} / \mathrm{min})$ & $4.74 \pm 0.72$ & $5.25 \pm 0.56$ & $4.23 \pm 0.46^{\dagger}$ & $4.75 \pm 0.73$ & $5.24 \pm 0.58$ & $4.26 \pm 0.51^{\dagger}$ \\
\hline
\end{tabular}

Values are means \pm SD. FM, Fat mass; FFM, Fat free mass; SMR, Sleeping metabolic rate; RMR, Resting metabolic rate. ${ }^{\star} p<0.05$ between summer and winter. ${ }^{\dagger} p<0.05$ between males and females.

\section{Metabolism}

Average metabolic rate (SMR and RMR) was higher in males compared to females (Table 1). Inter individual variation in SMR and RMR at $22^{\circ} \mathrm{C}$ was mainly explained by variation in FFM in both summer and winter (SMR $r^{2}=0.81, R^{2} r^{2}=0.84$ in summer and SMR $r^{2}=0.89$, RMR $r^{2}=0.81$ in winter; all $p$ values $<0.0001$ ). Including FM in multiple linear regression analysis did not result in a significant increase of explained variation. After adjustment for body composition in multiple linear regression analysis, no signifi- 
cant gender differences in SMR and RMR were found. There were no significant differences between seasons in SMR, RMR (Table 1) or $\mathrm{VO}_{2}$ max.

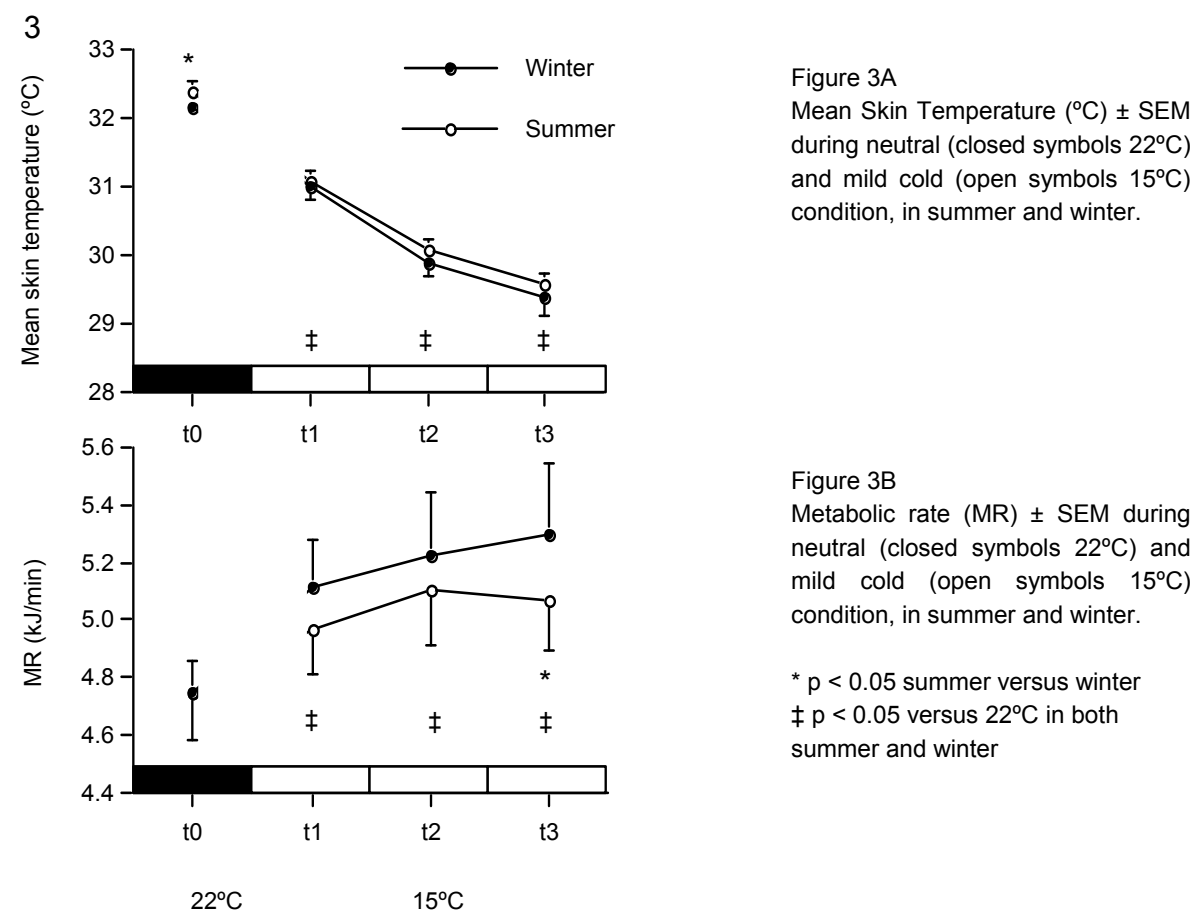

During $t_{1}-t_{3}$, no shivering was registered by EMG and the subjects did not report any sensation of shivering. In both seasons, MR was significantly increased during cold exposure $\left(t_{1}-t_{3}\right)$, compared to $t_{0}$ (Figure 3B, ANOVA for repeated measurements, $p<$ $0.001)$. In summer the average $M R$ increased from $4.7 \pm 0.7 \mathrm{~kJ} / \mathrm{min}\left(\mathrm{t}_{0}\right)$ to $5.1 \pm 0.8$ $\mathrm{kJ} / \mathrm{min}\left(\mathrm{t}_{3}\right)$ and in winter MR increased from $4.7 \pm 0.7 \mathrm{~kJ} / \mathrm{min}$ (t0) to $5.3 \pm 0.9 \mathrm{~kJ} / \mathrm{min}\left(\mathrm{t}_{3}\right)$. On average, the increase was $7.0 \pm 10.5 \%(p<0.05)$ in summer and $11.5 \pm 9.1 \%(p<$ 0.01 ) in winter, respectively (t-test: values at $t_{3}$ vs. $t_{0}$ ). The amount of cold induced thermogenesis, calculated as the incremental area under the curve (AUCinc) was slightly but not significantly higher in winter compared to summer. At $t_{3}$ however, the increase in MR $(\mathrm{kJ} / \mathrm{min})$ was significantly larger in winter than in summer (Figure $3, \mathrm{p}<0.01$ ). A large inter-individual variation in the increase in heat production was found, which was consistent throughout the seasons. The metabolic response ranged from a decrease of $4 \%$ to an increase of $30 \%$ in winter and from a decrease of $12 \%$ to an increase of $24 \%$ in summer. Cold induced thermogenesis $(\mathrm{kJ} / \mathrm{min})$ in summer was significantly related to cold induced thermogenesis in winter (Figure $4, r^{2}=0.61 p<0.001$ ). In summer and winter, approximately two thirds $(70 \%$ and $65 \%)$ of the metabolic response of $t_{3}$ was reached at $t_{1}$. If only the period was considered when subjects were exposed to the cold (i.e. $t_{1}, t_{2}$ to $t_{3}$ ), a significant increase from $t_{1}, t_{2}$ to $t_{3}$ was found, in winter, but not in summer (ANOVA repeated measures winter $p<0.01$, summer $p=0.13$ ). 


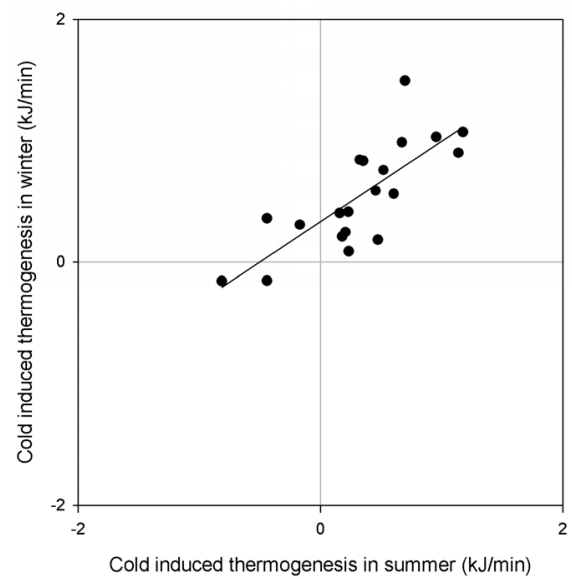

Figure 4

Cold induced thermogenesis

(change in metabolic rate during cold exposure in $\mathrm{kJ} / \mathrm{min}$ )

$(Y=0.66 X+0.33, r 2=0.61, p<0.001)$

\section{Body temperatures}

Table 2 summarizes the body temperatures measured during the experiment.

No significant difference was found between rectal and intestinal temperature in summer and winter and during thermo neutral and mild cold conditions. A small increase in rectal and intestinal temperature was found in response to the mild cold. All skin temperatures decreased significantly during exposure to mild cold $(p<0.01)$, in winter as well as in summer (Table 2, Figure 3A). The temperature gradient between rectal and mean skin temperature (Trectal-skin) at $t_{0}$ was significantly higher in winter than in summer (Table 2).

Table 2. Body temperatures and temperature gradients $\left({ }^{\circ} \mathrm{C}\right)$ during neutral $\left(22^{\circ} \mathrm{C}\right)$ and mild cold $\left(15^{\circ} \mathrm{C}\right)$ environmental conditions in summer and in winter.

\begin{tabular}{|c|c|c|c|c|c|c|c|}
\hline & & & AMER & & & JTER & \\
\hline & & $22^{\circ} \mathrm{C}$ & $15^{\circ} \mathrm{C}$ & & $22^{\circ} \mathrm{C}$ & $15^{\circ} \mathrm{C}$ & \\
\hline T core & Tintestine & $36.8 \pm 0.4$ & $36.9 \pm 0.4$ & & $36.9 \pm 0.3$ & $37.0 \pm 0.4$ & $\ddagger$ \\
\hline & Trectum & $36.8 \pm 0.3$ & $36.8 \pm 0.4$ & & $36.9 \pm 0.3$ & $37.0 \pm 0.6$ & \\
\hline T periphery & TskinR & $32.4 \pm 0.6^{*}$ & $29.6 \pm 0.8$ & $\ddagger$ & $32.1 \pm 0.5$ & $29.4 \pm 1.1$ & $\ddagger$ \\
\hline T gradients & Tintestine-skin & $4.5 \pm 0.7$ & $7.4 \pm 0.8$ & $\ddagger$ & $4.7 \pm 0.6$ & $7.6 \pm 1.2$ & $\ddagger$ \\
\hline & Trectal-skin & $4.3 \pm 0.5^{*}$ & $7.1 \pm 0.9$ & $\ddagger$ & $4.8 \pm 0.5$ & $7.4 \pm 1.1$ & $\ddagger$ \\
\hline & Tintestine-dist & $6.2 \pm 1.5$ & $13.3 \pm 2.3$ & $\ddagger$ & $6.1 \pm 1.1$ & $14.4 \pm 2.5$ & $\ddagger$ \\
\hline & Trectal-dist & $6.2 \pm 1.5$ & $14.9 \pm 2.1$ & $\ddagger$ & $6.2 \pm 1.2$ & $14.2 \pm 2.5$ & $\ddagger$ \\
\hline
\end{tabular}

Values are means \pm SD $\left({ }^{\circ} \mathrm{C}\right)$. TskinR, mean skin temperature calculated according to Ramanathan (1964). Significant difference: $\ddagger p<0.01$ between neutral ambient temperature and mild cold, ${ }^{*} p<0.05$ between summer and winter

\section{Metabolism versus insulative parameters}

The average MR ( $\mathrm{kJ} / \mathrm{min})$ was in both summer and winter negatively related to the increase in Tintestine-dist (Figure 5, summer, $r^{2}=0.38, p<0.01$; winter $r^{2}=0.31, p<$ 0.05). In summer and winter, the change in intestinal temperature from $t_{0} t_{0} t_{3}$ was positively related to $\mathrm{FM}(\%)(\mathrm{p}<0.05)$. At $\mathrm{t}_{3}$ in winter, the temperature gradient between intestine and skin was positively related to FM $(\%)(p<0.05)$. 

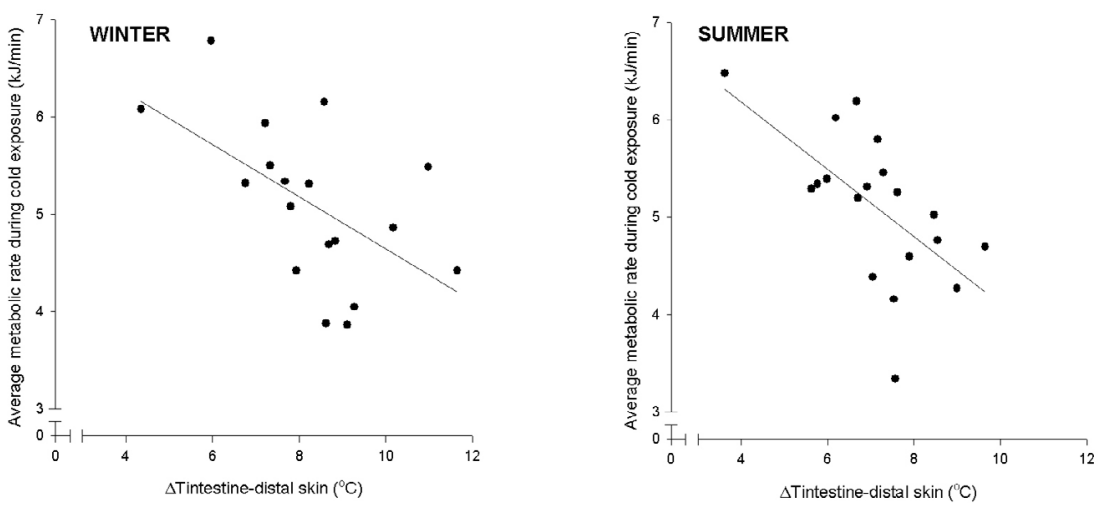

Figure 5 Average metabolic rate during cold exposure $(\mathrm{kJ} / \mathrm{min})$ versus change in intestinal-distal temperature gradient $\left({ }^{\circ} \mathrm{C}\right)$ in summer and winter.

Winter: $\quad Y=-0.27 X+7.32, r^{2}=0.31, p<0.05$

Summer: $\quad Y=-0.34 X+7.56, r^{2}=0.38, p<0.01$

\section{Discussion}

Three hours of cold exposure revealed an increase in metabolic rate of $7.0 \%$ in summer and $11.5 \%$ in winter. The increase in winter was significantly higher than in summer. In winter, metabolism was still increasing at the end of the experiment, while in summer it seemed to be stabilized. This could mean that in winter MR during the time of exposure did not reach a steady state situation, while in summer an equilibrium was reached.

Individual metabolic rates were related to fat free mass. The increase in metabolic rate however, was not related to either fat free mass or fat mass. Neither could the seasonal difference in metabolic response be attributed to changes in body composition or physical fitness. This indicates that anthropometry is not the explanation and the reason for the differences could be in autonomic or endocrinological functions. On the long term however, body composition can be affected by differences in metabolic response.

Interestingly, the average drop in mean skin temperatures during cold exposure did not differ between the seasons. Nevertheless, the combination of an equal insulative vasomotor response with a higher cold induced thermogenesis seems to point towards a smaller heat debt in winter. Earlier studies under more severe conditions show that cold acclimation is characterized by a decrease in heat debt in response to cold ${ }^{(4)}$. Therefore we conclude that even in a moderate climate cold acclimation occurred.

The study clearly shows interindividual variation in cold response. The change in intestine-distal temperature gradient implies a change in insulation, which was inversely related to the average metabolic rate during cold exposure (Figure 5). This means that some people tend to respond in a more metabolic way and others in a more insulative way. This was comparable to a study under mild cold conditions using two days of mild cold $^{(34)}$.

Interestingly, this study shows that those subjects showing a high metabolic response in summer do so again in winter (Fig 4). This suggests that the type of response indeed is 
subject specific. The variation in metabolic response is large, in winter the range was from -0.16 to $+1.49 \mathrm{~kJ} / \mathrm{min}$. The negative metabolic response could be a $Q_{10}$ effect due to the cooling of peripheral tissue. The possibility however, that the response of -0.16 $\mathrm{kJ} / \mathrm{min}$ lies within the accuracy of the measurement, should not be neglected. This variation in response between subjects has been found earlier in $24 \mathrm{~h}$ energy expenditure $^{(34)}$. The present study shows that this variation in $24 \mathrm{~h}$ energy expenditure can at least in part be explained by the change in resting metabolic rate. The magnitude of the metabolic response can have important health implications. Some people tend to be more energy efficient than others under the test circumstances. These (mild) circumstances are common in daily life. Therefore, it is possible that some people deal with the small temperature fluctuations encountered in real life in a much more efficient way than others. Those that are efficient are more prone to develop obesity ${ }^{(27)}$. This lines up with an earlier study showing reduced cold-induced metabolic response in obese as compared to lean subjects ${ }^{(7)}$.

O'Brien et al. ${ }^{(24)}$ suggested that core cooling during the adaptation period is necessary to induce an enhancement in sympathetic activation during cold exposure. In their study, exercise was applied to prevent core cooling during the experimental cold adaptation period which resulted in lower norepinephrine levels ${ }^{(24)}$. Though the exact amount and duration of cold exposure in daily life in wintertime in our subjects is not known, core cooling can hardly be expected. A peripheral or skin cooling during the adaptation period as Rintamaki (2000) described is more likely ${ }^{(28)}$.

Body composition was not related to the metabolic or temperature response. However, there are also small changes in core temperature (Tintestine). The percentage body fat was related to this change in intestinal temperature. In extreme cold stress situations, like water immersion, fat mass is known to be important in preventing core cooling, when the cutaneous blood flow is minimal ${ }^{(11)}$. Our results suggest that even in mild cold the fatness of a subject might play a role in insulation.

In several other studies describing moderate or mild cold conditions, shivering occurred $^{(16)}$. Our test conditions (air temperature, clothing) were carefully chosen in pilot studies, so that during cold exposure no shivering would take place. Indeed, in the present study increases MR without shivering as registered by EMG was measured and noted by subjects and observer. Whether humans use non-shivering thermogenesis (NST) is still under debate ${ }^{(17,22)}$. In the past it has been shown that daily cold exposure results in an increase in metabolism with a gradual decrease of shivering which indicates the existence of $\mathrm{NST}^{(10)}$. Several more recent studies point towards a significant contribution of NST in humans ${ }^{(25,37,38,42)}$. Although shivering cannot be completely ruled out from our measurements, these results make a significant contribution of ST unlikely. We recently found under more severe cold exposure, using the same experimental set up, that when shivering is evident, MR increases 30 to $60 \%$ as soon as shivering starts $(\text { Chapter } 4)^{(35)}$. Our study thus indicates that NST seems to be a serious candidate for the observed increase in MR.

In the present experiment, no change in either SMR, RMR, or $\mathrm{VO}_{2}$ max was found between seasons, independent of correction for the change in body composition. This means that a change in cold response due to a change in physical fitness can be excluded. Other studies report an effect on the metabolic response to severe cold ex- 
plained by seasonal changes in RMR and maximum oxygen uptake. In these studies however, the response is affected by higher levels of shivering thermogenesis ${ }^{(4,13,15)}$.

As a heat-loss restricting mechanism, all skin temperatures decreased significantly in response to the mild cold. The decrease in skin temperatures was not significantly different between seasons. Since test conditions were identical in summer and winter and assuming that the subjects were in heat-balance during the thermoneutral condition, the higher metabolic response to cold in winter indicates that on average the subjects showed less heat debt in winter. This has been described as an indicator for cold adaptation $^{(3,4)}$.

In summary, individual variation in cold response is observed, as shown by the inverse relation between the insulative and metabolic cold response. The significant relation of the metabolic response in winter versus the metabolic response in summer indicates that the type of cold response is subject specific. Though the pattern of the response seems to remain during acclimatization, the average magnitude of the metabolic response was increased in winter. There was no seasonal change in the insulative vasomotor response. Body heat debt thus was less during cold exposure in winter compared to summer. This means that even in a modern society (clothing, housing with central heating) in a moderate climate, cold acclimatization occurred. 


\section{References}

1 Bell DG, Tikuisis $\mathrm{P}$ and Jacobs I. Relative intensity of muscular contraction during shivering. J Appl Physiol 72: 2336-2342, 1992.

2 Bittel J. Cold adaptation - its relevance for long term exposure. In: Problems with cold work, edited by Holmer I and Kuklane K. Solna: Arbete Och Hälsa, 1998, p. 147-151.

3 Bittel J. The different types of general cold adaptation in man. Int J Sports Med 13 Suppl 1: S172-176, 1992.

4 Bittel JH. Heat debt as an index for cold adaptation in men. J Appl Physiol 62: 1627-1634, 1987.

5 Bittel JH, Nonotte-Varly C, Livecchi-Gonnot GH, Savourey GL and Hanniquet AM. Physical fitness and thermoregulatory reactions in a cold environment in men. J Appl Physiol 65: 1984-1989, 1988.

6 Blaza S and Garrow JS. Thermogenic response to temperature, exercise and food stimuli in lean and obese women, studied by $24 \mathrm{~h}$ direct calorimetry. Br J Nutr 49: 171-180, 1983.

7 Contaldo F, Scalfi L, Coltordi A and Lanzilli A. Reduced cold-induced thermogenesis in familial human obesity. Klin Wochenschr 64: 177-180, 1986.

8 Dauncey MJ. Activity and energy expenditure. Can J Physiol Pharmacol 68: 17-27, 1990.

9 Dauncey MJ. Influence of mild cold on $24 \mathrm{~h}$ energy expenditure, resting metabolism and diet-induced thermogenesis. Br J Nutr 45: 257-267, 1981.

10 Davies TRA. Chamber cold acclimatization in man. J Appl Physiol 16: 1011-1015, 1961.

11 Dulac S, Quirion A, DeCarufel D, LeBlanc J, Jobin M, Cote J, Brisson GR, Lavoie JM and Diamond P. Metabolic and hormonal responses to long-distance swimming in cold water. Int J Sports Med 8: 352-356, 1987.

12 Ellis KJ. Human body composition: in vivo methods. Physiol Rev 80: 649-680, 2000.

13 Eyolfson DA, Tikuisis P, Xu X, Weseen G and Giesbrecht GG. Measurement and prediction of peak shivering intensity in humans. Eur J Appl Physiol 84: 100-106, 2001.

14 Huttunen P, Lando NG, Meshtsheryakov VA and Lyutov VA. Effects of long-distance swimming in cold water on temperature, blood pressure and stress hormones in winter swimmers. J Therm Biol 25: 171-174, 2000.

15 Ingemann-Hansen T and Halkjaer-Kristensen J. Seasonal variation of maximal oxygen consumption rate in humans. Eur J Appl Physiol Occup Physiol 49: 151-157, 1982.

16 Inoue $\mathrm{Y}$, Nakao M, Ueda $\mathrm{H}$ and Araki T. Seasonal variation in physiological responses to mild cold air in young and older men. Int J Biometeorol 38: 131-136, 1995.

17 Jansky $P$ and Jansky L. Sites and cellular mechanisms of human adrenergic thermogenesis: a review. $J$ Therm Biol 27: 269 - 277, 2002.

18 Leonard WR, Sorensen MV, Galloway VA, Spencer GJ, Mosher MJ, Osipova L and Spitsyn VA. Climatic influences on basal metabolic rates among circumpolar populations. Am J Human Biol 14: 609-620, 2002.

19 Lesná I, Vybíral S, Jansky L and Zeman V. Human nonshivering thermogenesis. J Therm Biol 24: 63-69, 1999.

20 Levine JA, Eberhardt NL and Jensen MD. Role of nonexercise activity thermogenesis in resistance to fat gain in humans [see comments]. Science 283: 212-214, 1999.

21 Nagashima K, Yoda T, Yagishita T, Taniguchi A, Hosono T and Kanosue K. Thermal regulation and comfort during a mild-cold exposure in young Japanese women complaining of unusual coldness. J Appl Physiol 92: 1029-1035, 2002.

22 Nedergaard J, Golozoubova V, Matthias A, Asadi A, Jacobsson A and Cannon B. UCP1: the only protein able to mediate adaptive non-shivering thermogenesis and metabolic inefficiency. Biochim Biophys Acta 1504: $82-$ 106, 2001.

23 O'Brien C, Hoyt RW, Buller MJ, Castellani JW and Young AJ. Telemetry pill measurement of core temperature in humans during active heating and cooling. Med Sci Sports Exerc 30: 468-472, 1998.

24 O'Brien C, Young AJ, Lee DT, Shitzer A, Sawka MN and Pandolf KB. Role of core temperature as a stimulus for cold acclimation during repeated immersion in 20 degrees $C$ water. J Appl Physiol 89: 242-250, 2000.

25 Paolone VJ and Paolone AM. Thermogenesis during rest and exercise in cold air. Can J Physiol Pharmacol 73: 1149-1153, 1995.

26 Ramanathan NL. A new weighting system for mean surface temperature of the human body. $J$ Appl Physiol 19: 531-533, 1964.

27 Ravussin E, Lillioja S, Knowler WC, Christin L, Freymond D, Abbott WG, Boyce V, Howard BV and Bogardus C. Reduced rate of energy expenditure as a risk factor for body-weight gain. N Engl J Med 318: 467-472, 1988.

28 Rintamaki H. Human cold acclimatisation and acclimation. Int J Circumpolar Health 60: 422-429, 2001.

29 Rising R, Keys A, Ravussin E and Bogardus C. Concomitant interindividual variation in body temperature and metabolic rate. Am J Physiol 263: E730-734, 1992. 
30 Schoffelen PF, Westerterp KR, Saris WH and Ten Hoor F. A dual-respiration chamber system with automated calibration. J Appl Physiol 83: 2064-2072, 1997.

31 Scholander PF, Hammel HT, Hart JS, LeMessurier DH and Steen J. Cold adaptation in Australian Aborigines. J Appl Physiol 13: 211-218, 1958.

32 Siri WE. Body composition from fluid spaces and density: analysis of methods. In: Techniques for measuring body composition, edited by Brozek J and Henschel A. Washington DC: National Academy of Sciences, 1961, p. 223-244.

33 Tikuisis $\mathrm{P}$, Bell DG and Jacobs I. Shivering onset, metabolic response, and convective heat transfer during cold air exposure. J Appl Physiol 70: 1996-2002, 1991.

34 van Marken Lichtenbelt WD, Schrauwen P, van De Kerckhove S and Westerterp-Plantenga MS. Individual variation in body temperature and energy expenditure in response to mild cold. Am J Physiol Endocrinol Metab 282: E1077-1083, 2002.

35 van Ooijen AM, van Marken Lichtenbelt WD, van Steenhoven AA and Westerterp KR. Cold-induced heat production preceding shivering. Br J Nutr 93: 387-391, 2005.

36 van Ooijen AMJ, van Marken Lichtenbelt WD and Westerterp KR. Individual differences in body temperature and the relation to energy expenditure: the influence of mild cold. $J$ Therm Biol 26: 455-459, 2001.

37 Vybiral S, Lesna I, Jansky L and Zeman V. Thermoregulation in winter swimmers and physiological significance of human catecholamine thermogenesis. Exp Physiol 85: 321-326, 2000.

38 Warwick PM and Busby R. Influence of mild cold on $24 \mathrm{~h}$ energy expenditure in 'normally' clothed adults. $\mathrm{Br} \mathrm{J}$ Nutr 63: 481-488, 1990.

39 Webb P. The physiology of heat regulation. Am J Physiol 268: R838-850, 1995.

40 Weir JB. New methods for calculating metabolic rate with special reference to protein metabolism. 1949 [classical article]. Nutrition 6: 213-221, 1990.

41 Westerterp KR, Wouters $L$ and van Marken Lichtenbelt WD. The Maastricht protocol for the measurement of body composition and energy expenditure with labeled water. Obes Res 3 Suppl 1: 49-57, 1995.

42 Westerterp-Plantenga MS, Marken Lichtenbelt WD and Schrauwen P. Core-skin gradient of body temperature related to non-shivering thermogenesis 3 in humans at a lowered ambient temperature. J.Therm. Biol. 26: 467-472, 2001.

43 Young AJ, Muza SR, Sawka MN, Gonzalez RR and Pandolf KB. Human thermoregulatory responses to cold air are altered by repeated cold water immersion. J Appl Physiol 60: 1542-1548, 1986. 


\section{Chapter 4}

\section{Cold induced heat production preceding shivering}

Published as: A.M.J. van Ooijen, W.D. van Marken Lichtenbelt, A.A. van Steenhoven, K.R. Westerterp.

Br J Nutr (2005) 93;3, 387-391 


\begin{abstract}
Individual changes in heat production and body temperature were studied in response to cold exposure, prior to shivering. Subjects were normal weight, 10 women and 7 men age $23 \pm 3$ y and BMI $21.2 \pm 1.6 \mathrm{~kg} / \mathrm{m}^{2}$. They were lying supine under thermoneutral conditions for $30 \mathrm{~min}$ and were subsequently exposed to air of $15^{\circ} \mathrm{C}$ until shivering. Heat production was measured with a ventilated hood. Body composition was measured with underwaterweighing and deuterium dilution. Body temperatures were measured with thermistors. Heat production during cold exposure prior to shivering, increased and reached a plateau. Skin temperature decreased and did not reach a plateau during the test period. The non-shivering interval (NSI) ranged from 20 to $148 \mathrm{~min}$, was not related to body composition and was not significantly different for women (81 $\pm 15 \mathrm{~min})$ and men (84 $\pm 34 \mathrm{~min}$ ). NSI was negatively related to skin temperature $\left(r^{2}=0.44, p=0.004\right)$ and skin temperature was related to heat production, $\left(r^{2}=0.39 p=0.007\right)$. In conclusion, subjects with a relatively large heat production during cold exposure maintained a relatively high skin temperature but showed a short NSI, independent of differences in body composition.
\end{abstract}




\section{Introduction}

Upon entering a cooler environment, the body will adjust to restore heat balance. Heat balance can be restored by reducing heat loss or on the other hand, increasing heat production. Behavioural aspects can intervene at both points, clothing can reduce heat loss and activity and food intake can increase heat production. Even when behavioural aspects are taken into account, physiological reactions during resting conditions occur $^{(22)}$. The reduction of heat loss is established by vasoconstriction, which decreases heat transfer from core to the skin. This reduces the temperature of the skin and distal parts of the body ${ }^{(10)}$. On the other side of the balance, heat can be produced by several mechanisms summarized as adaptive thermogenesis. Adaptive thermogenesis during resting conditions is subdivided into non-shivering thermogenesis (NST) and shivering thermogenesis (ST). Under severe cold circumstances, shivering starts soon, but depends on the interplay between core temperature and skin temperature ${ }^{(3)}$ and the change in skin temperature ${ }^{(9)}$. Shivering is a very efficient way to produce heat and the peak shivering intensity can increase heat production up to five times basal metabolic rate $^{(8)}$. The intensity of shivering is determined by the severity of cold exposure, the amount of fat free mass, fitness of the subject ${ }^{(8)}$, and the rate of change of the skin temperature ${ }^{(9)}$. If cold exposure is not so severe, shivering does not start immediately ${ }^{(21)}$. While NST in humans preceding the onset of shivering, or in addition to shivering has been observed before ${ }^{(13,21)}$, opinions on the existence and mechanisms involved are still divided $^{(12)}$.

Though shivering is intensively studied, the period preceding shivering has hardly been described $^{(21)}$. Nevertheless, the state of being exposed to mild cold without shivering is a condition occurring frequently in daily life. In an earlier investigation, we showed an increase in heat production in response to mild cold without shivering ${ }^{(20)}$, and that the relative magnitude of NST was related to the temperature response. This can have implications for energy balance and the risk of gaining weight ${ }^{(6,15)}$. Insight in factors as body composition, body shape, resting metabolic rate and gender related to the cold induced heat production, can be of importance in treatment and prevention of obesity ${ }^{(19)}$. In our previous investigation, factors determining NST could not yet be unraveled, possibly because heat production did not reach a plateau ${ }^{(20)}$.

Therefore, in the present study, we used a protocol with mild cold exposure that was expected to last long enough to reach a metabolic plateau prior to shivering and that was cold enough to actually induce shivering. This resulted in a well-defined non-shivering interval (NSI), making it possible to study individual differences in NST and the duration of the NSI. It was hypothesized that subjects who cool down fast have a relatively low skin temperature and a relatively short non-shivering interval. If subjects cool down fast, the shivering threshold is expected to be reached earlier. Further, the question is addressed, whether subject characteristics (body fat, morphology, resting metabolic rate (RMR)) are related to NSI, NST or ST.

Summarizing, the aims of the present study were to investigate the following questions: (1) Does NST reach a plateau or does it increase until shivering starts? (2) Does skin temperature reach a plateau or does the temperature continue to drop until shivering starts? (3) Is heat production related to the NSI? (4) Is the temperature response related 
to the NSI? (5) Are the temperature response and the response in heat production related? (6) Is it possible to identify subject characteristics (e.g. body composition or $\mathrm{RMR}$ ) that are related to NST or ST?

\section{Materials and Methods}

\section{Subjects}

Ten women and 7 men participated in the study, previously approved by the Ethics Committee of Maastricht University. They volunteered and gave written consent to participate. All subjects were healthy, non-smokers and did not use any medication. Subjects were $23 \pm 3$ years old (mean \pm SD), $178 \pm 12 \mathrm{~cm}$ tall and weighed $66.9 \pm 8.4 \mathrm{~kg}$ (Table 1).

Table 1. Subject characteristics and non-shivering interval (NSI), mean \pm SD.

\begin{tabular}{lcc}
\hline & Men $(\mathrm{n}=7)$ & Women $(\mathrm{n}=10)$ \\
\hline Age $(\mathrm{y})$ & $21 \pm 2$ & $24 \pm 3$ \\
Height $(\mathrm{m})$ & $1.90 \pm 0.06$ & $1.69 \pm 0.05$ \\
Weight $(\mathrm{kg})$ & $74.8 \pm 4.1$ & $61.4 \pm 5.0$ \\
BMI $\left(\mathrm{kg} / \mathrm{m}^{2}\right)$ & $20.8 \pm 1.6$ & $21.5 \pm 1.5$ \\
FFM $(\mathrm{kg})$ & $65.7 \pm 4.5$ & $44.4 \pm 3.9$ \\
FM $(\%)$ & $12.2 \pm 1.9$ & $27.5 \pm 6.6$ \\
NSI (min) & $81 \pm 15$ & $84 \pm 34$ \\
\hline
\end{tabular}

Body mass index (BMI), Fat free mass (FFM), fat mass (FM),

\section{Design}

The experiment consisted of a cold air exposure test. Subjects were lying supine, the head slightly tilted, on a stretcher, in $15^{\circ} \mathrm{C}$ air, and covered with a duvet $(375 \mathrm{~g} / \mathrm{m} 2)$. This was the thermoneutral condition. Cold was induced after $30 \mathrm{~min}$ by removal of the duvet. The test was terminated thirty minutes after the onset of shivering. The interval between the removing of the duvet and the onset of shivering was defined as the non-shivering interval (NSI). The interval between the onset of shivering and the termination of the test was defined as the shivering interval (SI) Metabolic rate (MR), body temperatures and electromyography (EMG) were measured continuously. Body composition was determined on a separate visit within one week of the experiment.

Subjects arrived at the laboratory by car or public transport and were fasting for at least four hours in order to avoid any effects of activity or diet. They were instructed not to perform strenuous activity the day before the experiment.

The clothing had a total insulative value of 0.18 clo $\left(0.028 \mathrm{~m}^{2} .{ }^{\circ} \mathrm{C} \mathrm{W}^{-1}\right)$ and consisted of shorts $(0.1 \mathrm{clo})$, a singlet $(0.04 \mathrm{clo})$ and panties and a bra for women and briefs for men (0.04 clo).

\section{Measurements and instrumentation}

Body composition was calculated using the three-compartment model according to Siri $(1961)^{(16)}$. For this calculation, body density and total body water were determined using 
underwater weighing and deuterium dilution ${ }^{(7)}$. The latter was determined according to the Maastricht protocol ${ }^{(25)}$.

$\mathrm{O}_{2}$ consumption and $\mathrm{CO}_{2}$ production were measured with an automated respiratory gas analyzer using a ventilated hood system (Omnical, IDEE, Maastricht, The Netherlands). The equipment had been recently validated and the gas analysers were calibrated before the experiments ${ }^{(1)}$.

Heat production was calculated from these data according to Weir (1949) republished as a classical article ${ }^{(24)}$. Resting metabolic rate (RMR) was defined as heat production in a thermoneutral environment, lying still and awake in a post-absorptive state. RMR was calculated as the average of 10 minutes with the lowest SD of the last 20 minutes while the subject was covered with the duvet. NST was defined as the increase in heat production, exceeding RMR, during cooling, before subjects started shivering. NST was calculated by subtracting RMR from the total heat production during this period. Shivering thermogenesis (ST) was defined as the heat production, exceeding the sum of RMR and NST when the subjects were shivering, as registered by EMG (see below). ST was calculated by subtracting RMR and NST from the total heat production during this period. Rectal temperature was measured continuously by a thermistor-probe (YSI probes, series 402, Yellow Springs Instruments Co. Ltd., Ohio, U.S.A.) inserted $10 \mathrm{~cm}$ beyond the anal sphincter. Skin temperatures were measured by surface thermistors (YSI probes, series 409B, Yellow Springs Instruments Co. Ltd., Ohio, U.S.A.) placed on the dorsal side of the hand, forearm, upper arm, chest, abdomen, the lower back, anterior thigh, posterior calf and foot. Temperatures were registered and saved over one-minute intervals (Tiretherm, IDEE, Maastricht, The Netherlands).

Mean skin temperature was calculated according to Ramanathan (1964) and is hereafter mentioned as "skin temperature" ${ }^{(14)}$. A weighted body temperature, as a cue for thermo regulation, including rectal and skin temperatures was calculated using the formula according to Cunningham (1978) $)^{(5)}$.

$$
\text { Tbody }=\text { Tcore }+0.1 \times\left(\text { Tskin }-33^{\circ} \mathrm{C}\right)
$$

This measure combines the relative importance of skin and core temperatures for thermoregulatory adjustments.

Shivering was detected using electromyography (EMG) (Tiretherm, IDEE, Maastricht, The Netherlands). EMG electrodes were placed $3 \mathrm{~cm}$ apart on the skin at the $\mathrm{m}$. pectoralis major ${ }^{(2,18)}$. This site was chosen because in people having a normal amount of fat, shivering starts in the upper trunk region, and propagates towards the extremities ${ }^{(18)}$. In addition, every 15 minutes, subjects were asked if they felt if they were shivering and the observer checked the subjects to see if they were shivering.

\section{Treatment of data}

Data are reported as means \pm SD. Results were considered statistically significant when $p<0.05$. The SPSS program, version 6.1 (SPSS Inc., Chicago, IL, U.S.A.) was used for statistical analyses. Linear regression analysis was used to study the relation between the metabolic and insulative response. If necessary, the analysis was corrected for body composition by adding fat free mass (FFM) in the equation. Gender differences were 
tested by unpaired T-tests. The difference between men and women in NSI was tested by Mann-Whitney $U$ test.

\section{Results}

\section{Subjects}

Subjects were healthy with a normal percentage body fat, $21.2 \pm 2.2 \%$ (Table 1). As can be expected, men were significantly taller, heavier, had a higher FFM (kg) and a lower body fat percentage (FM\%) than women.

Time course of heat production, muscle activity and temperature.

A representative example of the progress of heat production, EMG signal and skin temperature is presented in Figure 1. Fifteen out of the 17 subjects showed similar trends. Three distinct phases can be recognized: thermoneutral; non-shivering interval; shivering interval. Figure $1 \mathrm{~A}$ shows heat production throughout the experiment. During the thermoneutral period, metabolic rate reached a plateau. During the NSI, heat production gradually increased and reached a plateau again. The slope of the regression line over the last 15 minutes before shivering was not significant in 11 subjects, indicating that a plateau was reached in most subjects. For the total group, the change in heat production of the mentioned interval was not significantly different from zero $(p=0.27)$. Heat production rose sharp after the onset of shivering. On average, heat production increased from $76.8 \pm 14.8(\mathrm{~W})$ during the thermoneutral phase, to $87.7 \pm 19.2(\mathrm{~W})$ during the last 15 minutes preceding shivering ( $p<0.001$ ), to $96.3 \pm 21.6(\mathrm{~W})$ during the first 15 minutes of shivering $(p<0.001)$. The change in heat production during the NSI was on average $12 \%$ ranging from $-6 \%$ to $28 \%$. After the onset of shivering, heat production increased another $12 \%$ ranging from $-2 \%$ to $29 \%$. The pattern of the EMG measurement of the same subject is shown in Figure 1B. During the thermoneutral interval and the NSI, the EMG signal showed low amplitude. The increase in signal at the start of the NSI is an artifact, caused by removal of the duvet. The SI is clearly marked by an increase in EMG amplitude.

The pattern of skin temperature of the same subject is shown in Figure $1 \mathrm{C}$. This pattern is representative for all subjects. During the thermoneutral interval, skin temperature rose marginally. The start of the NSI is marked by a steep decline that tends to level off near the end of the experiment. However, skin temperature did not reach a plateau, neither during the $\mathrm{NSI}$, nor during the shivering interval. Mean skin temperature decreased from $32.5 \pm 0.9^{\circ} \mathrm{C}$ during the thermoneutral phase to $27.2 \pm 1.4^{\circ} \mathrm{C}$ at the onset of shivering and decreased further to $27.0 \pm 1.4^{\circ} \mathrm{C}$ during the $\mathrm{SI}$ (Table 2 ).

Table 2. Metabolism and body temperature during thermoneutral phase and at the onset of shivering

\begin{tabular}{lcc}
\hline & Thermoneutral phase & Shivering onset \\
\hline Heat production $(\mathrm{W})$ & $76.8 \pm 14.8$ & $87.7 \pm 19.2$ \\
Rectal temperature $\left({ }^{\circ} \mathrm{C}\right)^{*}$ & $37.2 \pm 0.2$ & $36.9 \pm 0.3$ \\
Mean skin temperature $\left({ }^{\circ} \mathrm{C}\right)^{*}$ & $32.5 \pm 0.9$ & $27.2 \pm 1.4$ \\
Body temperature $\left({ }^{\circ} \mathrm{C}\right)^{*}$ (weighted) & $37.1 \pm 0.2$ & $36.4 \pm 0.4$ \\
\hline
\end{tabular}

" $p<0.001$ Thermoneutral phase versus shivering onset (paired T-test) 

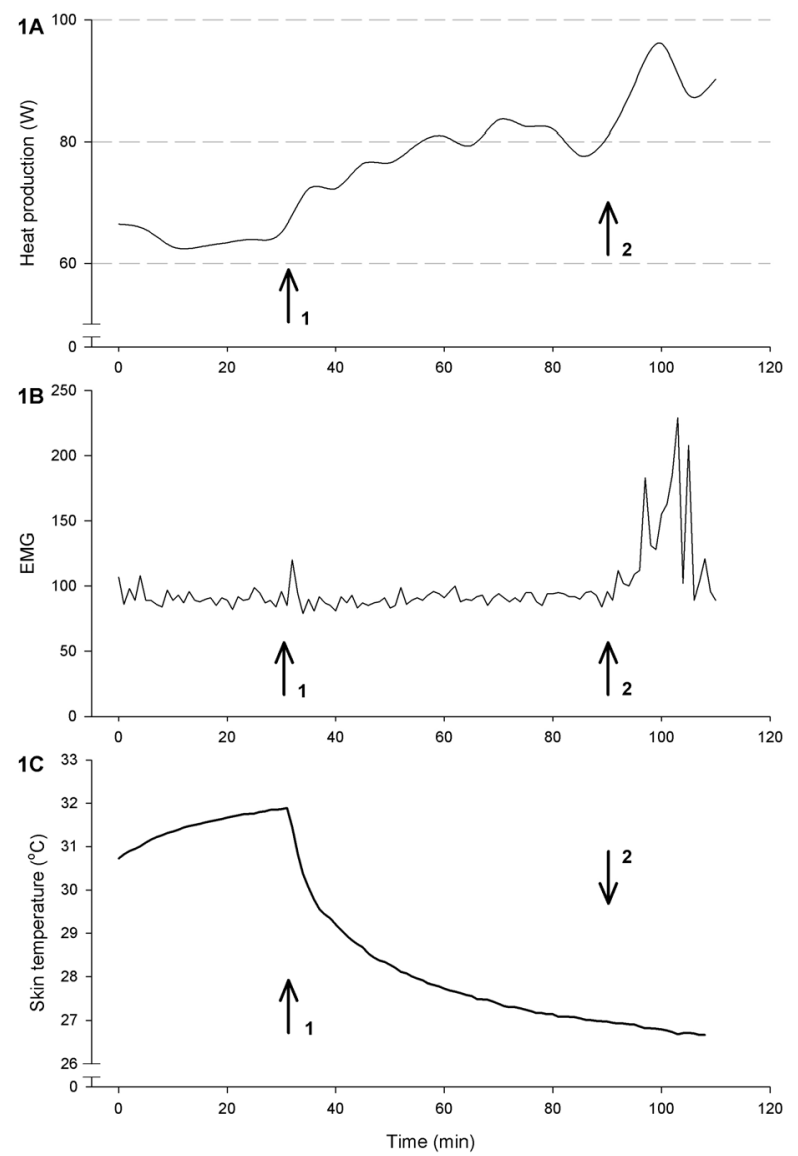

Figure 1A

Typical pattern of heat production during the experiment

(1=Duvet removed, 2=Onset of shivering)

Figure 1B

Typical pattern of an EMG measurement during the experiment

(1=Duvet removed, 2=Onset of shivering)

Figure $1 \mathrm{C}$

Typical pattern of skin temperature during the experiment

(1=Duvet removed, $2=$ Onset of shivering)

\section{Thermoneutral phase}

RMR was significantly higher in men compared to women $(p<0.001)$. RMR was related to FFM $\left(R M R(W)=13.8+1.2\right.$ FFM $(\mathrm{kg})\left(\mathrm{p}<0.001, \mathrm{r}^{2}=0.84\right)$. After correcting for FFM in multiple linear regression analysis, no significant difference between genders remained.

Body temperatures during the thermoneutral phase are presented in Table 2.

Stepwise regression did not include skin temperature in the relation between FFM and RMR.

\section{Non-shivering interval}

The NSI ranged from 20 to 148 minutes (mean $83 \pm 15$, Table 1 ). The NSI was not significantly different between men and women $(p=0.77)$. The range and SD for both groups indicates large between-subject differences in response to cold.

The length of the NSI was not related to either FFM or fat mass (FM). The duration of the $\mathrm{NSI}$ was negatively related to skin temperature during this interval $\left(r^{2}=0.44, p=0.004\right)$. 
Mean skin temperature during the NSI was positively related to heat production during the NSI $\left(r^{2}=0.39, p=0.007\right)$. When heat production is corrected for FFM $(\mathrm{kg})$, the residuals of the relation between heat production $(\mathrm{W})$ and $F F M(\mathrm{~kg})$ are still related to mean skin temperature during the NSI $\left(r^{2}=0.29, p=0.03\right)$. The change in weighted body temperature was related to NST (Watt) $\left(r^{2}=0.39, p=0.007\right)$. Furthermore, the rate of skin cooling (represented as the average change over time of skin temperature) was related to mean skin temperature at the onset of shivering $\left(r^{2}=0.32, p=0.02\right)$.

\section{Shivering interval}

During shivering, mean skin temperature was $27.9 \pm 1.3^{\circ} \mathrm{C}$ and rectal temperature was $36.9 \pm 0.3^{\circ} \mathrm{C}$.

The increase in heat production during of shivering (ST) was not significantly related to FFM, FM, RMR or NST. The SI was probably too short for the subjects to reach heat balance and these results will not be discussed any further in the discussion.

\section{Discussion}

In the present study the change in heat production and the temperature response to cold was investigated in the period before shivering. The advantage of the present study protocol was a well-defined period between the start of cooling until the onset of shivering, allowing inter-subject comparison of the NSI and temperature- and metabolic responses during this interval. The results showed on average a significant increase in heat production induced by cold, in absence of shivering. The inter-individual variation in response is large. A recent validation of the equipment showed a mean within-subject coefficient of variation in resting heat production of $3.3 \%$ on separate days ${ }^{(1)}$. It is thus unlikely that a change in heat production during our test larger than that is the result of a measurement or technical error. A possible explanation of the decrease in heat production in some of the subjects is the Q10 effect. This means that for a given decrease in temperature the enzyme activity of the tissue will decrease as well, hereby decreasing heat production ${ }^{(11)}$. If the temperature of the periphery of the subject decreases $3^{\circ} \mathrm{C}$, the Q10 effect can account for a $6 \%$ decrease in total body heat production. Subjects who do not, or not enough increase local heat production will show a net decrease in total heat production. Even when local heat production induced by shivering is not enough to compensate for the total cooling of the body, the net result in heat production can be a decrease.

During the NSI, mean skin temperature was related to heat production, even after correction for FFM. Subjects with a relatively high mean skin temperature are likely to lose more heat to the environment, although it has not been actually measured whether heat production during $\mathrm{NSI}$ is related to heat loss. In the case of shivering, such a relation has been described by Tikuisis et al. (1991). They found the intensity of shivering and the increase over the time of exposure, to be consistent with the increase in the convective heat transfer coefficient, calculated from skin temperature and heat fluxes ${ }^{(18)}$. The contribution of NST however, is small compared to ST and when heat-loss remains larger than heat-production, shivering will be induced. In our data, a plateau was reached 
for heat production before the onset of shivering, while skin temperature was still decreasing. This indicates that heat balance was not reached during the NSI and therefore, shivering started.

$\mathrm{NSI}$ and mean skin temperature during NSI were negatively related. In contrast to our expectations, subjects with a relatively high mean skin temperature have an early onset of shivering. A relatively high skin temperature means that a relatively large amount of heat is lost to the environment.

The present study shows that a large heat production is related to a relatively high mean skin temperature and a relatively high mean skin temperature is related to a short NSI. This means indirectly that a relatively high heat production is related to a short NSI. On the other side of the balance, the lower the skin temperature during the non-shivering interval, the longer it takes to start shivering. This means that, on the one hand, less heat is dissipated to the environment and that further cooling is restricted, but also that these subjects tolerate relatively low peripheral body temperatures. This contradicts what we expected and what can be expected based on previous literature ${ }^{(3)}$. Namely that, a low body temperature results in an early shivering onset and not a relatively high body temperature as we found in the present study. It should be noted that the present study investigates inter individual differences in contrast with previous literature. These results fit the concept of heat regulation as described by Webb (1995) and Tikuisis (2003), as opposed to temperature regulation in a more classical sense ${ }^{(17,23)}$.

The present study also showed that the rate of skin cooling during NSI was related to skin temperature at the onset of shivering. Subjects with fast skin cooling had higher skin temperatures at the onset of shivering. This confirms that body temperature is not the only important factor in thermoregulation but also the change in body temperature or the change in heat content of the body ${ }^{(9)}$. The subjects with fast skin cooling and high mean skin temperatures at the onset of shivering were also the subjects with a relatively high mean skin temperature during the $\mathrm{NSI}$ and a relatively short NSI.

The change in weighted body temperature during NSI was related to NST, reflecting that subjects having a relatively high heat production response have relatively small decrease in body temperature. This is in line with results from our previous study ${ }^{(20)}$ and others ${ }^{(4)}$. These inter-individual differences can have the following consequences. Subjects responding to the cold with a relatively large decrease in temperature can be more energy efficient and could have a higher risk of gaining weight ${ }^{(15)}$. A relatively high heat production combined with in an early onset of shivering could be an advantage in preventing obesity through a change in energy balance. It should be noted that this reaction can be a disadvantage for survival in severe cold circumstances.

No relations were found between RMR and NST. NST does not depend on the size of FFM but possibly on the morphology of the subject, the activity of the tissues that FFM consists of or genetic variation.

\section{Conclusions}

To summarize, we found that (1) NST reaches a plateau during the NSI, while (2) body temperature does not. Both (3) heat production during cold exposure and (4) skin temperature were related to the duration of the NSI. (5) NST and the change in weighted 
body temperature were related and (6) no subject characteristics were found that predict NST or ST.

The present study shows that normal weight subjects show inter-individual variation in heat production in the response to cold. The relatively high response in heat production found in some subjects as opposed to those with a relatively large response in skin temperature can have consequences for energy balance and therefore for weight maintenance. This is confirmed by the result that the subjects having a relatively high heat production during the $\mathrm{NSI}$ seem to start shivering at an earlier stage in contrast with hypotheses based on previous studies within subjects. This implies that a high heat production before shivering results in a high overall heat production during cold exposure including a relatively early onset of shivering. 


\section{References}

1 Adriaens MP, Schoffelen PF and Westerterp KR. Intra-individual variation of basal metabolic rate and the influence of daily habitual physical activity before testing. Br J Nutr 90: 419-423, 2003.

2 Bell DG, Tikuisis $\mathrm{P}$ and Jacobs I. Relative intensity of muscular contraction during shivering. $J$ Appl Physiol 72: 2336-2342, 1992.

3 Benzinger TH. Heat regulation: homeostasis of central temperature in man. Physiol Rev 49: 671-759, 1969.

4 Contaldo F, Scalfi L, Coltordi A and Lanzilli A. Reduced cold-induced thermogenesis in familial human obesity. Klin Wochenschr 64: 177-180, 1986.

5 Cunningham DJ, Stolwijk JA and Wenger CB. Comparative thermoregulatory responses of resting men and women. J Appl Physiol 45: 908-915, 1978.

6 Dauncey MJ. Influence of mild cold on $24 \mathrm{~h}$ energy expenditure, resting metabolism and diet-induced thermogenesis. Br J Nutr 45: 257-267, 1981.

7 Ellis KJ. Human body composition: in vivo methods. Physiol Rev 80: 649-680, 2000.

8 Eyolfson DA, Tikuisis P, Xu X, Weseen G and Giesbrecht GG. Measurement and prediction of peak shivering intensity in humans. Eur J Appl Physiol 84: 100-106, 2001

9 Fiala D, Lomas KJ and Stohrer M. Computer prediction of human thermoregulatory and temperature responses to a wide range of environmental conditions. Int J Biometeorol 45: 143-159., 2001.

10 Frank SM, Raja SN, Bulcao CF and Goldstein DS. Relative contribution of core and cutaneous temperatures to thermal comfort and autonomic responses in humans. J Appl Physiol 86: 1588-1593., 1999.

11 Gordon CJ. The therapeutic potential of regulated hypothermia. Emerg Med J 18: 81-89, 2001.

12 Nedergaard J, Golozoubova V, Matthias A, Asadi A, Jacobsson A and Cannon B. UCP1: the only protein able to mediate adaptive non-shivering thermogenesis and metabolic inefficiency. Biochim Biophys Acta 1504: 82 106, 2001.

13 Paolone VJ and Paolone AM. Thermogenesis during rest and exercise in cold air. Can J Physiol Pharmacol 73: 1149-1153, 1995.

14 Ramanathan NL. A new weighting system for mean surface temperature of the human body. $J$ Appl Physiol 19: 531-533, 1964.

15 Ravussin E, Lillioja S, Knowler WC, Christin L, Freymond D, Abbott WG, Boyce V, Howard BV and Bogardus C. Reduced rate of energy expenditure as a risk factor for body-weight gain. N Engl J Med 318: 467-472, 1988.

16 Siri WE. Body composition from fluid spaces and density: analysis of methods. In: Techniques for measuring body composition, edited by Brozek J and Henschel A. Washington DC: National Academy of Sciences, 1961, p. 223-244.

17 Tikuisis $\mathrm{P}$. Heat balance precedes stabilization of body temperatures during cold water immersion. $J$ Appl Physiol 95: 89-96, 2003.

18 Tikuisis $\mathrm{P}$, Bell DG and Jacobs I. Shivering onset, metabolic response, and convective heat transfer during cold air exposure. J Appl Physiol 70: 1996-2002, 1991.

19 Van Marken Lichtenbelt WD and Daanen HA. Cold-induced metabolism. Curr Opin Clin Nutr Metab Care 6: 469-475, 2003.

20 Van Ooijen AM, Van Marken Lichtenbelt WD, Van Steenhoven AA and Westerterp KR. Seasonal changes in metabolic and temperature responses to cold air in humans. Physiol Behav 82: 545-553, 2004

21 Vybiral S, Lesna I, Jansky $L$ and Zeman V. Thermoregulation in winter swimmers and physiological significance of human catecholamine thermogenesis. Exp Physiol 85: 321-326, 2000.

22 Warwick PM and Busby R. Influence of mild cold on $24 \mathrm{~h}$ energy expenditure in 'normally' clothed adults. $\mathrm{Br} \mathrm{J}$ Nutr 63: 481-488, 1990.

23 Webb P. The physiology of heat regulation. Am J Physiol 268: R838-850, 1995.

24 Weir JB. New methods for calculating metabolic rate with special reference to protein metabolism. 1949 [classical article]. Nutrition 6: 213-221, 1990.

25 Westerterp KR, Wouters $L$ and van Marken Lichtenbelt WD. The Maastricht protocol for the measurement of body composition and energy expenditure with labeled water. Obes Res 3 Suppl 1: 49-57, 1995. 


\section{Chapter 5}

\section{Heat production and body temperature during cooling and rewarming in overweight and lean men}

Published as: A.M.J. van Ooijen, K.R. Westerterp, L. Wouters, P.F.M. Schoffelen, A.A. van Steenhoven, W.D. van Marken Lichtenbelt.

Obesity (2006) 14; 1914-1920 


\begin{abstract}
Objective:

Comparison between overweight and lean subjects with respect to thermogenesis and physiological insulation in response to mild cold and rewarming.

Research Methods and Procedures: Ten overweight (Body Mass Index $29.2 \pm 2.8 \mathrm{~kg} / \mathrm{m}^{2}$ ) and ten lean men (BMI $21.1 \pm 2.0 \mathrm{~kg} / \mathrm{m}^{2}$ ) were exposed to one hour cold air, followed by one hour of rewarming. Body composition was determined by hydrodensitometry and deuterium dilution. Heat production and body temperatures were measured continuously by indirect calorimetry and thermistors respectively. Muscle activity was recorded using electromyography.

Results:

In both groups, heat production increased significantly during cooling (lean, $p=0.004$; overweight, $p=0.006$ ). The increase was larger in the lean group compared to overweight $(p=0.04)$. During rewarming, heat production returned to baseline in the overweight group and stayed higher compared to baseline in the lean group $(p=0.003)$. The difference in heat production between rewarming and baseline was larger in the lean ( $p$ $=0.01)$ than in the overweight subjects.

Weighted body temperature of both groups decreased during cold exposure (lean, $p=$ 0.002 ; overweight $p<0.001$ ) and did not return to baseline during rewarming.

Discussion and conclusion:

Overweight subjects showed a blunted mild cold induced thermogenesis. The insulative cold response was not different between groups. The energy efficient response of the overweight subjects can have consequences for energy balance in the long term. Secondly, the results support the concept of a dynamic heat regulation model instead of temperature regulation around a fixed set point.
\end{abstract}




\section{Introduction}

Adaptive thermogenesis, the dissipation of energy in the form of heat in response to diet or cold, has been implicated in the regulation of energy balance and body temperature. Most studies focus on diet induced thermogenesis. However, cold induced thermogenesis is also of interest with respect of weight regulation, since it is shown to be highly variable between individuals. Humans can respond to cold by increasing metabolism, decreasing peripheral body temperature (insulation) or hypothermia. Under mild cold conditions hypothermia is unlikely to occur. Under severe cold conditions it has been shown that individuals differ in the relative contributions of the metabolic and insulative response ${ }^{(4)}$. Under mild cold conditions such inter-individual variation has also been reported in a $24 \mathrm{~h}$ cold exposure ${ }^{(20)}$. The observed increase in $24 \mathrm{~h}$ energy expenditure varied from $0.15-1.45 \mathrm{MJ} / \mathrm{d}$. During a short term study (3 hour mild cold exposure), we also showed large variation ${ }^{(22)}$, ranging from -4 to $+30 \%$ in winter ${ }^{(21)}$. Interestingly, by repeating the experiment in another season, we were able to show that the relative contribution of metabolic and insulative response was subject specific ${ }^{(21)}$.

We posed the question whether overweight people can be characterized by an "overweight" specific cold response. Differences between overweight and lean might be due to: the insulation properties of body fat ${ }^{(1,2,9,14)}$, surface to volume ratio ${ }^{(11)}$, or skin vasoconstrictive reaction to cold ${ }^{(19)}$. These three properties are involved in reducing body heat loss from the skin. Lean and obese can also differ in cold induced thermogenesis, possibly through differences in autonomic responsiveness ${ }^{(12,13)}$.

Indeed, some studies indicate reduced cold-induced thermogenesis, high level of insulation in obesity under severe cold conditions ${ }^{(4,5)}$ and decreased autonomic responsiveness $^{(12,13)}$. However, with respect to moderate temperature differences hardly any studies on obesity have been performed. Therefore, we investigated whether lean and overweight subjects differ in cold induced thermogenesis under mild cold conditions. We are focusing on mild cold, since small changes in ambient temperature occur in daily life in most modern societies in temperate zones. We seldom shiver nowadays, but during wintertime people do experience cold, when leaving our comfortable warm room, walking to our car, waiting for public transport, etc. Mild cold exposure is a common daily occurrence.

We tested the hypothesis that during a short term mild cold exposure of one hour and rewarming, overweight subjects show a blunted thermogenic and an enlarged insulative response compared to their lean counterparts.

\section{Research methods and procedures}

\section{Subjects}

Two groups of ten healthy, non-smoking male volunteers were recruited. A lean group with BMI $21.1 \pm 2.0 \mathrm{~kg} / \mathrm{m}^{2}$ (range $17.9-23.4 \mathrm{~kg} / \mathrm{m}^{2}$ and an overweight group, BMI $29.2 \pm$ $2.8 \mathrm{~kg} / \mathrm{m}^{2}$ (range $24.7-33.2 \mathrm{~kg} / \mathrm{m}^{2}$ ). The present study was approved by the Ethics Committee of Maastricht University. Detailed information concerning purpose and 
methods used in the study was given before written consent was obtained. Subject characteristics are presented in Table 1.

Table 1. Subject characteristics, average \pm SD

\begin{tabular}{llll}
\hline & Group & Lean & Overweight \\
$\mathrm{n}=20$ & $\mathrm{n}=10$ & $\mathrm{n}=10$ \\
\hline Age $(\mathrm{yr})$ & $25 \pm 6$ & $23 \pm 4$ & $27 \pm 7$ \\
Height $(\mathrm{m})$ & $1.81 \pm 0.07$ & $1.82 \pm 0.08$ & $1.80 \pm 0.06$ \\
${ }^{*}$ Weight $(\mathrm{kg})$ & $82.1 \pm 14.5$ & $69.7 \pm 7.1$ & $94.5 \pm 6.8$ \\
${ }^{*} \mathrm{BMI}\left(\mathrm{kg} / \mathrm{m}^{2}\right)$ & $25.2 \pm 4.8$ & $21.1 \pm 2.0$ & $29.2 \pm 2.8$ \\
${ }^{*} \mathrm{FM}(\%)$ & $20.6 \pm 7.2$ & $14.9 \pm 4.2$ & $27.0 \pm 5.3$ \\
"FFM $(\mathrm{kg})$ & $64.4 \pm 7.7$ & $58.8 \pm 5.0$ & $70.0 \pm 5.5$ \\
\hline
\end{tabular}

${ }^{*} p<0.05$ Lean versus overweight

Body mass index (BMI), Fat mass (FM), Fat free mass (FFM)

\section{Design}

The experiment consisted of a cold air exposure test followed by rewarming. Subjects were lying on a chair with supported legs in $15^{\circ} \mathrm{C}$ air, and covered with a duvet $(375$ $\left.\mathrm{g} / \mathrm{m}^{2}\right)$. This was the thermoneutral condition and the duvet was removed after 60 minutes of baseline measurement. The moment the duvet was removed, was the start of cold exposure. After 60 minutes of cold exposure, the duvet was replaced and this was the start of the rewarming phase. The test was terminated after 60 minutes of rewarming. The subjects were wearing standard clothing with an insulative value of $0.71 \mathrm{clo}$ ( $\mathrm{lcl}=$ $\left.0.109 \mathrm{~m}^{2} \cdot{ }^{\circ} \mathrm{C} / \mathrm{W}\right)$, consisting of sweatpants $(0.28 \mathrm{clo})$, a sweater $(0.37 \mathrm{clo})$, socks that cover only the feet $(0.02 \mathrm{clo})$ and briefs $(0.04 \mathrm{clo})$. The face, hands and ankles were exposed directly to the environment. Heat production and body temperatures were measured continuously (see below).

Subjects arrived at the lab by car or public transport after overnight fasting in order to avoid any effects of activity or diet. They were instructed not to perform any strenuous activities the day before the experiment.

Body composition was determined on a separate visit within one week of the experiment.

\section{Measurements and instrumentation}

Body composition was calculated using the three-compartment model according to Siri $(1961)^{(16)}$. For this calculation, body density and total body water were determined using underwater weighing and deuterium dilution ${ }^{(7)}$. The latter was determined according to the Maastricht protocol ${ }^{(27)}$.

Oxygen $\left(\mathrm{O}_{2}\right)$ consumption and Carbondioxide $\left(\mathrm{CO}_{2}\right)$ production were measured with an automated respiratory gas analyzer using a ventilated hood system (Omnical, IDEE, Maastricht, The Netherlands). Gas analyzers were calibrated before the experiments. Heat production was calculated from these data according to Weir (1949) ${ }^{(26)}$.

Rectal temperature was measured continuously by a thermistor-probe (YSI probes, series 402, Yellow Springs Instruments Co. Ltd., Ohio, U.S.A.) inserted $10 \mathrm{~cm}$ beyond the anal sphincter.

Skin temperatures were measured by surface thermistors (YSI probes, series 409B, Yellow Springs Instruments Co. Ltd., Ohio, U.S.A.) placed on the dorsal side of the hand, 
forearm, upper arm, chest, abdomen, the lower back, anterior thigh, posterior calf and dorsal side of the foot. Temperatures were registered and saved over one-minute intervals (Tiretherm, IDEE, Maastricht, The Netherlands).

Mean skin temperature was calculated according to Ramanathan $(1964)^{(15)}$. Weighted body temperature (WBT) was calculated as a measure of rectal and mean skin temperature according to Cunningham $(1978)^{(6)}$. This value provides an estimate of total body temperature as a possible drive for heat production. In order to study temperature distribution, trunk and distal skin temperature were calculated. Trunk temperature was calculated as the average of the skin temperature measured at the lower back, the abdomen and the chest. Distal skin temperature was calculated as the average of hand and foot.

Possible shivering was detected using electromyography (EMG) (Tiretherm, IDEE, Maastricht, The Netherlands). EMG electrodes were placed $3 \mathrm{~cm}$ apart on the skin at the $m$. pectoralis major as described before ${ }^{(3,18,21)}$. This site was chosen because in people having a normal amount of fat, shivering starts in the upper trunk region, and propagates towards the extremities ${ }^{(18)}$.

Baseline values were calculated over minutes 21 to 50 of the first hour. During cold exposure and rewarming minutes 11 to 60 were used for calculations to avoid influence of removing or replacing the duvet.

\section{Data treatment}

Data are reported as means \pm SD. Results were considered statistically significant when $\mathrm{p}<0.05$. The SPSS program, version 11.5.0 (SPSS Inc., Chicago, IL, U.S.A.) was used for statistical analyses.

Between group differences were tested by unpaired t-tests. Within group changes were tested by paired t-tests. Linear regression analysis was used to study the relation between skin temperatures and fat percentage.

Table 2. Heat production and body temperatures at baseline, during cooling and rewarming. Average \pm SD.

\begin{tabular}{|c|c|c|c|c|}
\hline & & Baseline & Cooling & Rewarming \\
\hline Heat production & Lean & $44.7 \pm 3.1$ & $53.4 \pm 7.2^{\dagger}$ & $50.0 \pm 4.2^{\dagger}$ \\
\hline$\left(\mathrm{W} / \mathrm{m}^{2}\right)$ & Overweight & $44.7 \pm 3.9$ & $47.5 \pm 4.5^{\dagger}$ & $45.9 \pm 4.7$ \\
\hline Rectal & Lean & $36.8 \pm 0.2$ & $36.9 \pm 0.2$ & $36.8 \pm 0.2$ \\
\hline temperature $\left({ }^{\circ} \mathrm{C}\right)$ & Overweight & $36.9 \pm 0.2$ & $36.9 \pm 0.2$ & $36.9 \pm 0.2$ \\
\hline Mean skin & Lean & $32.4 \pm 0.4$ & $29.6 \pm 0.8^{\dagger}$ & $30.5 \pm 0.6^{\dagger}$ \\
\hline temperature $\left({ }^{\circ} \mathrm{C}\right)$ & Overweight & $32.6 \pm 0.6$ & $29.9 \pm 0.7^{\dagger}$ & $30.6 \pm 0.7^{\dagger}$ \\
\hline Trunk skin & Lean & $34.6 \pm 0.2^{*}$ & $32.7 \pm 0.4^{\dagger *}$ & $34.3 \pm 0.3^{\dagger *}$ \\
\hline temperature $\left({ }^{\circ} \mathrm{C}\right)$ & Overweight & $33.9 \pm 0.8$ & $32.0 \pm 0.6^{\dagger}$ & $33.5 \pm 0.8$ \\
\hline Distal skin & Lean & $30.5 \pm 0.8$ & $26.6 \pm 1.2^{\dagger}$ & $27.0 \pm 1.1^{\dagger}$ \\
\hline temperature $\left({ }^{\circ} \mathrm{C}\right)$ & Overweight & $31.5 \pm 1.3$ & $28.0 \pm 1.9^{\dagger}$ & $28.2 \pm 1.9^{\dagger}$ \\
\hline Weighted & Lean & $36.8 \pm 0.2$ & $36.5 \pm 0.2^{\dagger}$ & $36.5 \pm 0.3^{\dagger}$ \\
\hline temperature $\left({ }^{\circ} \mathrm{C}\right)$ & Overweight & $36.9 \pm 0.2$ & $36.6 \pm 0.2^{\dagger}$ & $36.6 \pm 0.3^{\dagger}$ \\
\hline
\end{tabular}




\section{Results}

During baseline, there were no significant differences between lean and overweight subjects in energy expenditure (expressed in $\mathrm{W} / \mathrm{m}^{2}$ ), and most temperatures (Table 2). Only trunk temperature was lower in the overweight men $(p=0.02)$.

Heat production increased significantly during the hour of cold exposure in both groups $(p=0.004$ and $p=0.006$ for lean and overweight respectively, Table 2, Figure 1). During rewarming heat production decreased in both groups and returned to baseline in the overweight group. In the lean group, heat production during rewarming remained significantly higher compared to baseline $(p=0.003$, Table 2). Shivering did not occur during any of the stages of the experiment.

At baseline, during cooling and during rewarming, heat production was not significantly different between groups (Table 2). However, the increase in heat production during cooling was significantly larger in the lean group compared to the overweight $(p=0.04)$. The difference in heat production between rewarming and baseline was significantly larger in the lean group compared to the overweight as well $(p=0.01)$.

Rectal temperature was not significantly different between groups at any stage of the experiment and did not change significantly compared to baseline (Table 2). Trunk temperature was significantly lower in the overweight group compared to the lean group during the three stages of the test $(p=0.02, p=0.007, p=0.006$, respectively, Table 2). Within groups, trunk temperature decreased significantly during cold exposure $(p<0.001$ in both groups). During rewarming trunk temperature was not significantly different from baseline in the overweight group, and stayed significantly lower compared to baseline in the lean group ( $p=0.03$, Table 2$)$.

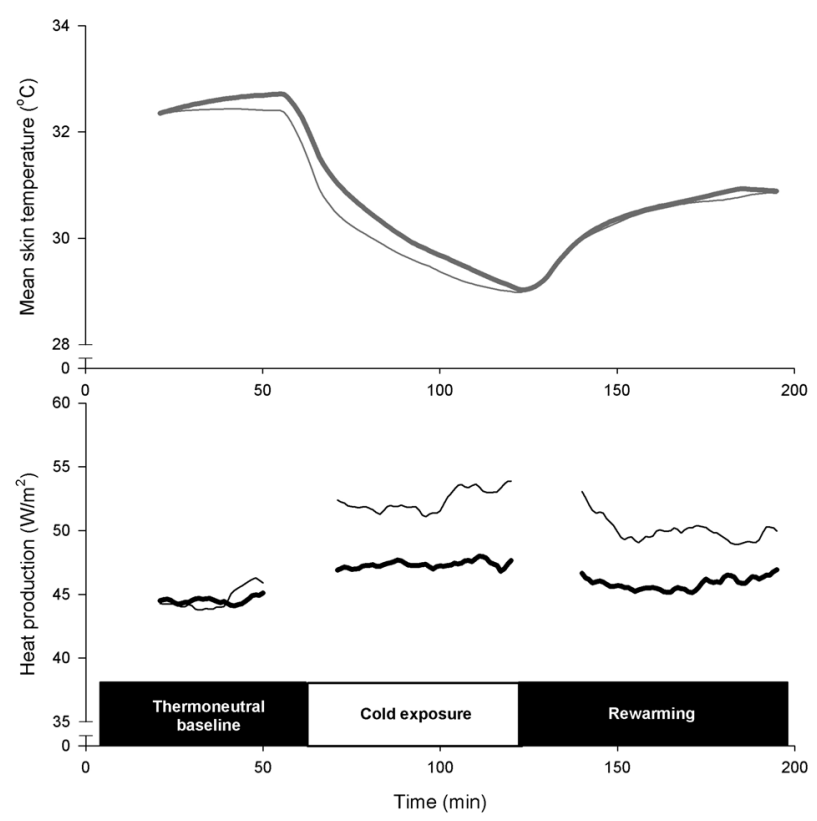

Figure 1

Course of mean heat production $\left(\mathrm{W} / \mathrm{m}^{2}\right)$ and mean skin temperature $\left({ }^{\circ} \mathrm{C}\right)$ in overweight (fat line) and lean (thin line) subjects. 
Mean skin temperature decreased significantly during cold exposure $(p<0.001)$ in both groups. During rewarming, mean skin temperature did not return to baseline in the two groups ( $p<0.001$ compared to baseline). Weighted body temperature decreased significantly during cold exposure $(p=0.002$ and $p<0.001$ for lean and overweight respectively) in both groups. During rewarming, weighted body temperature increased again but did not return to baseline $(p=0.01$ and $p=0.003$ compared to baseline in the lean and overweight group respectively).

Distal skin temperature decreased significantly during cold exposure $(p<0.001)$ and increased again during rewarming. Distal skin temperature did not return to baseline values in both groups ( $p<0.001$ for both groups compared to baseline).

Trunk temperature was negatively related to fat percentage at baseline (Figure $2 \mathrm{~A}, \mathrm{r}^{2}=$ $0.32, p=0.009)$. A similar relation was evident during cold exposure and rewarming $\left(r^{2}=\right.$ $0.40, p=0.003 ; r^{2}=0.36, p=0.005$, respectively). Distal skin temperature was positively related to fat percentage at baseline, (Figure $2 B, r^{2}=0.28, p=0.02$ during cold exposure and rewarming $\left(r^{2}=0.25, p=0.03 ; r^{2}=0.29, p=0.01\right.$, respectively)
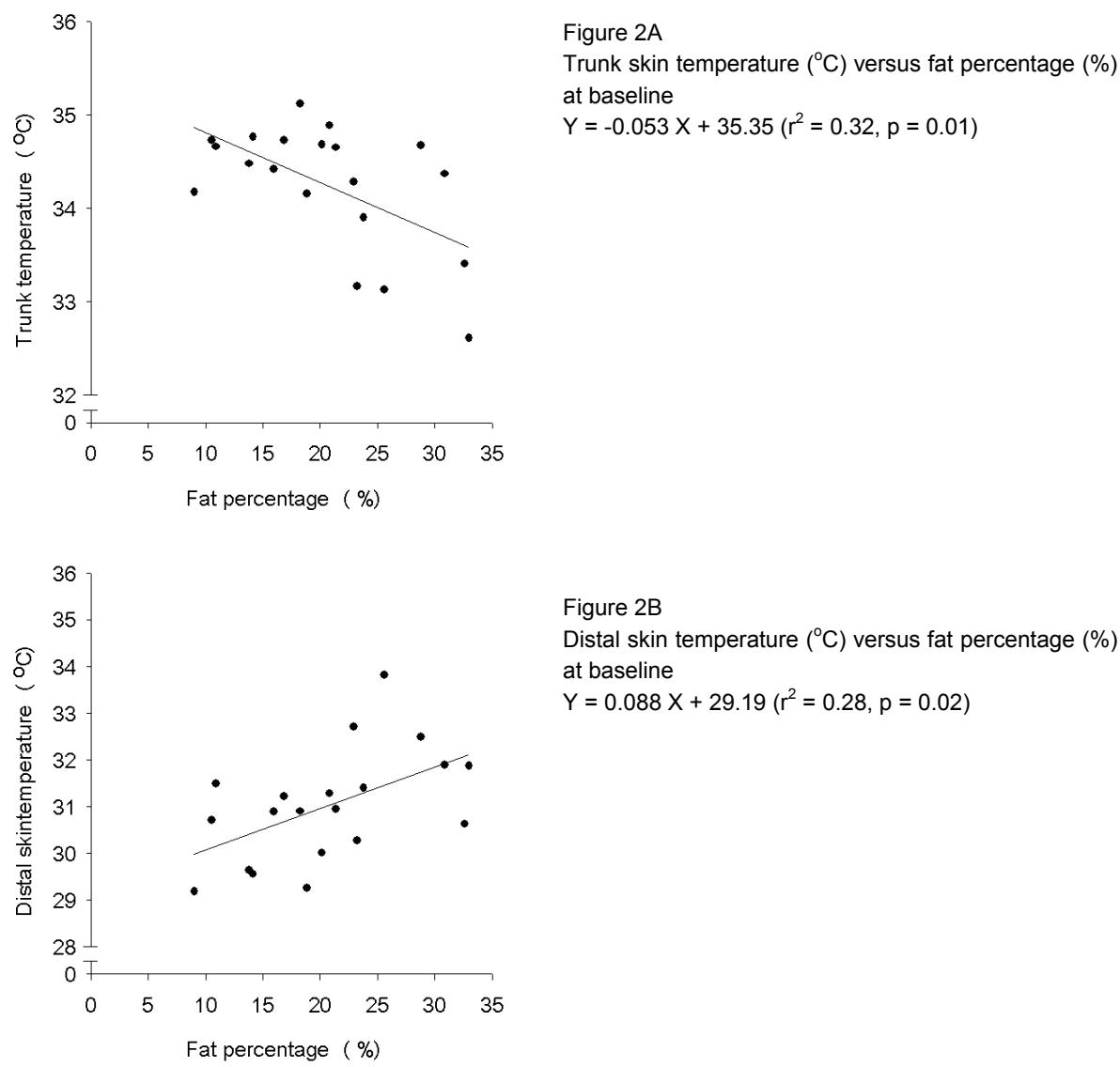

Figure 2B

Distal skin temperature $\left({ }^{\circ} \mathrm{C}\right)$ versus fat percentage (\%) at baseline $Y=0.088 X+29.19\left(r^{2}=0.28, p=0.02\right)$ 


\section{Discussion}

This study tested whether overweight subjects, relative to their lean counterparts, show a low (mild) cold induced thermogenesis and a high insulative cold response. Heat production corrected for body surface area indeed increased significantly less in the overweight compared to lean during one hour of mild cold exposure. Moreover, energy expenditure of the overweight subjects returned to baseline during the period of rewarming, while energy expenditure in the lean still remained elevated during that hour. Cold induced changes in core-skin temperature gradients were not significantly different between lean and overweight. Therefore, this study shows that overweight subjects show a blunted cold induced thermogenesis, but there was no difference in the insulative cold response between lean and obese.

The extra heat production in lean relative to the overweight subjects must have been dissipated and should be reflected in an elevated skin temperature. Most likely during cold exposure, vasoconstriction of the extremities occurred in both groups. Indeed, there were no differences in distal temperatures between groups. One would expect increased skin temperatures at other skin sites, but there were not differences between lean and overweight at the measured sites. Only mean trunk temperature was significantly higher in the lean subjects, but this occurred during all stages of the experiment including baseline. It is possible that temperature distribution changes differs between the groups $^{(25)}$. To this end the results indicate that the overweight subjects preserved heat more efficiently through a smaller heat loss compared to body size.

On average heat production increased with $11.8 \%$ during cold exposure. For the lean group, the average increase was $17.2 \%$ and for the overweight group the increase was $6.4 \%$. The increase in heat production during cold exposure was three times as large in lean as compared to overweight subjects. Since heat production during rewarming was still relatively high in the lean only, the total effect of temporary cold exposure is even larger. This has consequences for the energy balance ${ }^{(24)}$. We do not know whether this energy efficient response of the overweight subjects has played a role in the development of the overweight, but it will have consequences for long term energy balance and weight maintenance.

We calculated weighted body temperatures in order to evaluate whether temperature or heat was regulated during cold exposure. Weighted body temperature can be used as a possible drive for heat production ${ }^{(6)}$. During cold exposure and rewarming weighted body temperature decreased in both groups and increased again. However, in both groups the WBT during rewarming remained low compared to baseline. Apparently, one hour of rewarming was not sufficient to return WBT to baseline. On the other hand in both groups heat production decreased already during rewarming. In the overweight group, mean heat production even returned to baseline level. This suggests that heat production is not exclusively regulated by body temperature, but most likely heat loss is involved.

The concept of heat regulation as opposed to the classical concept of temperature regulation was suggested before by Glaser and Newling and Webb $(1993,1995)^{(8,23,24)}$ Webb $(1995)^{(24)}$ showed that heat balance occurs at many levels of activity. These activities range from sleep to intense sustained exercise, and at every level of heat 
balance there is a resultant body temperature that is directly proportional to heat production $^{(23)}$. In addition, body heat content returns to the same starting point every day and after exercise ${ }^{(23)}$. This was recently affirmed by Tikuisis (2003) who found that heat balance precedes the stabilization of body temperatures during cold water immersions $^{(17)}$. At the moment that heat debt reversed and started to decrease, heat production remained at the same level while core temperature was still decreasing ${ }^{(17)}$. In the present experiment, heat production was already decreasing while body temperature was still below baseline values. These observations support the concept of a dynamic model of heat regulation instead of temperature regulation around a fixed set point.

The only significant difference between groups in body temperature was found in trunk temperature. Trunk temperature was significantly lower in the overweight group during all stages of the experiment. The negative relation of trunk temperature versus fat percentage $\left(r^{2}=0.32, p=0.009\right)$ suggests that local fat might be involved. A thicker layer of fat might be responsible for reduced heat transfer to the skin ${ }^{(10)}$. The positive relation between distal skin temperatures and body fat percentage underlines the relative importance of distal body sites for heat dissipation in overweight subjects.

In conclusion, overweight subjects showed a blunted cold induced thermogenesis. The study did not show a difference in insulative cold response between lean and overweight. The increase in heat production in response to a mild cold stimulus was three times as large in lean compared to overweight subjects. Since during rewarming heat production was still increased in the lean, the total effect of temporary cold exposure is even larger. Our observations support the concept of a dynamic model of heat regulation instead of temperature regulation around a fixed set point. Because we choose mild cold conditions as encountered in everyday life, it is likely that the observed blunted cold induced thermogenesis in the overweight will have consequences for energy balance and weight maintenance in the long term. 


\section{Literature}

1 Anderson GS and Martin AD. Calculated thermal conductivities and heat flux in man. Undersea Hyperb Med 21: 431-441, 1994.

2 Bar-Or O, Lundegren HM and Buskirk ER. Heat tolerance of exercising obese and lean women. J Appl Physiol 26: 403-409, 1969.

3 Bell DG, Tikuisis P and Jacobs I. Relative intensity of muscular contraction during shivering. J Appl Physiol 72: 2336-2342, 1992.

4 Bittel JH. Heat debt as an index for cold adaptation in men. J Appl Physiol 62: 1627-1634, 1987.

5 Contaldo F, Scalfi L, Coltordi A and Lanzilli A. Reduced cold-induced thermogenesis in familial human obesity. Klin Wochenschr 64: 177-180, 1986.

6 Cunningham DJ, Stolwijk JA and Wenger CB. Comparative thermoregulatory responses of resting men and women. J Appl Physiol 45: 908-915, 1978.

7 Ellis KJ. Human body composition: in vivo methods. Physiol Rev 80: 649-680, 2000.

8 Glaser EM and Newling PS. The control of body temperature in thermal balance. J Physiol 137: 1-11, 1957.

9 Haymes EM, McCormick RJ and Buskirk ER. Heat tolerance of exercising lean and obese prepubertal boys. J Appl Physiol 39: 457-461, 1975.

10 Kasai T, Hirose M, Matsukawa T, Takamata A and Tanaka Y. The vasoconstriction threshold is increased in obese patients during general anaesthesia. Acta Anaesthesiol Scand 47: 588-592, 2003.

11 Kurz A, Sessler DI, Christensen R and Dechert M. Heat balance and distribution during the core-temperature plateau in anesthetized humans. Anesthesiology 83: 491-499, 1995.

12 Matsumoto T, Miyawaki C, Ue H, Kanda T, Yoshitake $\mathrm{Y}$ and Moritani T. Comparison of thermogenic sympathetic response to food intake between obese and non-obese young women. Obes Res 9: 78-85, 2001.

13 Matsumoto T, Miyawaki T, Ue H, Kanda T, Zenji C and Moritani T. Autonomic responsiveness to acute cold exposure in obese and non-obese young women. Int J Obes Relat Metab Disord 23: 793-800, 1999.

14 Otte JW, Merrick MA, Ingersoll CD and Cordova ML. Subcutaneous adipose tissue thickness alters cooling time during cryotherapy. Arch Phys Med Rehabil 83: 1501-1505, 2002.

15 Ramanathan NL. A new weighting system for mean surface temperature of the human body. J Appl Physiol 19: 531-533, 1964.

16 Siri WE. Body composition from fluid spaces and density: analysis of methods. In: Techniques for measuring body composition, edited by Brozek J and Henschel A. Washington DC: National Academy of Sciences, 1961 , p. 223-244.

17 Tikuisis $\mathrm{P}$. Heat balance precedes stabilization of body temperatures during cold water immersion. J Appl Physiol 95: 89-96, 2003.

18 Tikuisis P, Bell DG and Jacobs I. Shivering onset, metabolic response, and convective heat transfer during cold air exposure. J Appl Physiol 70: 1996-2002, 1991.

19 Valensi P, Smagghue O, Paries J, Velayoudon P, Lormeau B and Attali JR. Impairment of skin vasoconstrictive response to sympathetic activation in obese patients: influence of rheological disorders. Metabolism 49: 600-606, 2000.

20 van Marken Lichtenbelt WD, Schrauwen P, van De Kerckhove S and Westerterp-Plantenga MS. Individual variation in body temperature and energy expenditure in response to mild cold. Am J Physiol Endocrinol Metab 282: E1077-1083, 2002.

21 Van Ooijen AM, Van Marken Lichtenbelt WD, Van Steenhoven AA and Westerterp KR. Seasonal changes in metabolic and temperature responses to cold air in humans. Physiol Behav 82: 545-553, 2004.

22 van Ooijen AMJ, van Marken Lichtenbelt WD and Westerterp KR. Individual differences in body temperature and the relation to energy expenditure: the influence of mild cold. J Therm Biol 26: 455-459, 2001.

23 Webb P. Daily activity and body temperature. Eur J Appl Physiol Occup Physiol 66: 174-177, 1993.

24 Webb P. The physiology of heat regulation. Am J Physiol 268: R838-850, 1995.

25 Webb P. Temperatures of skin, subcutaneous tissue, muscle and core in resting men in cold, comfortable and hot conditions. Eur J Appl Physiol 64: 471-476, 1992.

26 Weir JB. New methods for calculating metabolic rate with special reference to protein metabolism. 1949 [classical article]. Nutrition 6: 213-221, 1990.

27 Westerterp KR, Wouters $L$ and van Marken Lichtenbelt WD. The Maastricht protocol for the measurement of body composition and energy expenditure with labeled water. Obes Res 3 Suppl 1: 49-57, 1995. 


\section{Chapter 6}

\section{Adaptive thermogenesis, skin blood flow and sympathetic activity in lean and overweight men: Effects of cold exposure}

W.D. van Marken Lichtenbelt. 


\begin{abstract}
The relevance of adaptive thermogenesis (AT) in the etiology of obesity is still inconclusive. Therefore, we investigated whole body and local cold exposure in lean and overweight subjects on AT, serum thyroid hormones, plasma catecholamines, and skin blood flow.

Ten overweight men BMl $29.2 \pm 2.8 \mathrm{~kg} / \mathrm{m}^{2}$ and ten lean men, BMl $21.1 \pm 2.0 \mathrm{~kg} / \mathrm{m}^{2}$ participated. Energy expenditure, catecholamines and thyroid hormones (T3 and T4) were measured before and during one hour whole body cooling (air temperature $15^{\circ} \mathrm{C}$ ) and one hour of rewarming. In addition in a cold pressor test (CPT) fingertip skin blood flow and plasma catecholamines were measured.

During whole body cooling, thermogenesis increased significantly in both groups (lean baseline: $44.7 \pm 3.1$, cold: $53.4 \pm 7.2, p<0.01$; overweight baseline: $44.7 \pm 3.9$, cold: $47.5 \pm 4.5, p<0.01)$, but increased more in lean than in overweight subjects $(p<0.05)$. During both tests, norepinephrine increased significantly $(p<0.05)$ in the overweight group. Overweight subjects showed a decrease in blood flow $(p<0.05)$ in the CPT. In contrast, no significant changes in norepinephrine and blood flow were found in lean subjects.

This study demonstrates that during both whole body and local cooling the overweight subjects conserve more heat and show lower cold-induced thermogenesis compared to their lean controls. The observed larger increase in cold-induced norepinephrine levels in overweight subjects indicates that the SNS plays a role in the AT differences between lean and overweight. The higher energy efficiency can contribute to weight gain and troublesome weight loss in overweight subjects.
\end{abstract}




\section{Introduction}

The sympathetic nervous system (SNS) plays an important role in the regulation of adaptive thermogenesis (the regulated production of heat or regulated energy expenditure) and heat loss. Important stimuli for SNS activity are food and cold ${ }^{(23)}$. In this study we focused on the effect of cold exposure. The SNS exerts its effects through the catecholamines, norepinephrine and epinephrine, binding to both $\alpha$ and $\beta$-adrenoceptors $\left(\alpha 1-, \alpha 2-, \beta 1-, \beta 2-\right.$, and $\beta 3$ ) located on target cells ${ }^{(20)}$. In general, stimulation of $\beta$ adrenoceptors increases thermogenesis. Stimulation of $\alpha$-receptors does not increase thermogenesis, but increases vasoconstriction. Important with respect to regulating skin blood flow is vasoconstriction of the arteriovenous anastomoses ${ }^{(4)}$.

Because of its role in energy balance and thermoregulation, the SNS is a relevant physiological system to be studied in relation to overweight. Differences in thermogenesis between lean and overweight have been shown with respect to $\beta$-adrenoceptor mediated thermogenesis. For instance the $\beta 2$-adrenoceptor mediated thermogenesis is impaired in overweight subjects compared to lean controls ${ }^{(25)}$. The effect of cold has been compared between obese and non-obese showing thermogenic sympathetic response is reduced in obese $e^{(14)}$

In extreme cold obese subjects may lose relatively less heat compared to lean, because of the insulative capacity of body fat and the small surface to volume ratio. However, thermoregulatory control in a mild cold situation is mainly established through skin perfusion. Though some studies suggest blunted vasoconstriction response to mild cold in obese ${ }^{(8)}$, from anaesthetized patients it has recently been shown that intra-operative thermoregulatory vasoconstriction is greater in obese patients ${ }^{(8)}$. Therefore core temperature in obese subjects under anesthesia is maintained because their vasoconstriction threshold to a low environmental temperature is high (i.e. vasoconstriction is initiated at a higher core temperature $)^{(8)}$. From the scarce data available, the hypothesis can be drawn that in obese cold-induced thermogenesis (CIT) is blunted with a relatively high cold-induced vasoconstriction threshold. This indicates enlarged heat (energy) conservation in obese compared to lean. More data are necessary to confirm this.

Apart from the catecholamines, the thyroid hormones are important in the regulation of thermogenesis. Thyroid activity is known to be related to $\operatorname{RMR}^{(19,27)}$ and is upregulated in a cold environment ${ }^{(5,27)}$. The effects of thyroid hormones are usually found as a result of long term exposure to cold. Sympathetic mediated thermogenesis interacts with thyroid hormones and requires minimum levels of thyroid activity ${ }^{(22)}$. Taken together, in normal weight subjects after a single cold-air exposure, serum thyroid hormone, thyroidstimulating hormone, and epinephrine remain unchanged, while serum norepinephrine levels increase ${ }^{(11,30)}$.

In previous studies we documented an increase in thermogenesis without shivering during a short term ( 3 hours) and midterm ( 2 days) mild cold exposure ${ }^{(35,36)}$. There were large inter-individual differences with respect to the relative contributions of thermogenesis and heat loss. We therefore compared overweight and lean subjects and we found that overweight subjects showed a significantly smaller increase in thermogenesis in response to mild cold (Chapter 5$)^{(3)}$. 
Here we report on the effect of mild cold on thermogenesis in lean and overweight in combination with serum thyroid hormones and plasma catecholamines. In order to obtain information on heat loss (i.e. vasoconstriction of arteriovenous anastomoses) we additionally studied the effect of a cold pressor test in the same individuals on changes in plasma catecholamines and vasoconstriction in the finger. We hypothesize that overweight subjects show a blunted CIT, a reduced SNS activation, and a relatively high cold induced vasoconstriction.

\section{Materials and Methods}

\section{Subjects}

Two groups of ten healthy, non-smoking sedentary male volunteers were recruited. A lean group with BMI $21.1 \pm 2.0 \mathrm{~kg} / \mathrm{m}^{2}$ and an overweight group, BMI $29.2 \pm 2.8 \mathrm{~kg} / \mathrm{m}^{2}$. Subject characteristics are presented in Table 1.The present study was approved by the Ethics Committee of Maastricht University. Detailed information concerning purpose and methods used in the study was provided before written consent was obtained.

Table 1. Subjects' characteristics

\begin{tabular}{lcc}
\hline & Lean & Overweight \\
& $\mathrm{n}=10$ & $\mathrm{n}=10$ \\
\hline Age $(\mathrm{yr})$ & $23 \pm 4$ & $27 \pm 7$ \\
Height $(\mathrm{m})$ & $1.82 \pm 0.08$ & $1.80 \pm 0.06$ \\
Weight $(\mathrm{kg}){ }^{*}$ & $69.7 \pm 7.1$ & $94.5 \pm 6.8$ \\
BMl $(\mathrm{kg} / \mathrm{m} 2)^{*}$ & $21.1 \pm 2.0$ & $29.2 \pm 2.8$ \\
FM $(\%)^{*}$ & $14.9 \pm 4.2$ & $27.0 \pm 5.3$ \\
FFM $(\mathrm{kg})^{*}$ & $58.8 \pm 5.0$ & $70.0 \pm 5.5$ \\
\hline
\end{tabular}

Values are means \pm SD. BMI, body mass index; FM, fat mass; FFM, fat free mass. Significant difference between lean and overweight: ${ }^{*} \mathrm{P}<0.05$.

\section{Design}

A whole-body cooling test in the respiration chamber was used to study thermogenesis and the catecholamine response to cold. Subsequently a cold pressor test (CPT) was carried out to study the vasoconstriction and catecholamine response. The cold pressor test is also described as a hand cooling test with the intention to induce sympathetic activation $^{(12,17)}$.

The tests were conducted at separate days within one week. In the same week body composition was determined.

\section{Body composition}

Body composition was calculated using the three-compartment model according to Siri $(1961)^{(28,34)}$. For this calculation, body density and total body water were determined using underwater weighing and deuterium dilution, according to the Maastricht protocol (38). 


\section{Whole-body cooling test}

Subjects arrived at the lab by car or public transport after overnight fasting in order to avoid any effects of activity or diet. They were instructed not to perform any strenuous activities the day before the experiment.

Subjects were lying on a chair with supported legs, in $15^{\circ} \mathrm{C}$ air, and covered with a duvet $\left(375 \mathrm{~g} / \mathrm{m}^{2}\right)$. This was the thermoneutral condition and the duvet was removed after 60 minutes of baseline measurement. The moment the duvet was removed, was the start of cold exposure. After 60 minutes of cold exposure, the duvet was replaced and this was the start of the rewarming phase. The test was terminated after 60 minutes of rewarming. The subjects were wearing standard clothing with an insulative value of $0.71 \mathrm{clo}$ (Icl = $\left.0.109 \mathrm{~m}^{2} \cdot{ }^{\circ} \mathrm{C} / \mathrm{W}\right)$, consisting of sweatpants $(0.28 \mathrm{clo})$, a sweater $(0.37 \mathrm{clo})$, socks that cover only the feet $(0.02 \mathrm{clo})$ and briefs $(0.04 \mathrm{clo})$. The face, hands and ankles were exposed directly to the environment. Thermogenesis was measured continuously (see below).

$\mathrm{O}_{2}$ consumption and $\mathrm{CO}_{2}$ production were continuously measured with an automated respiratory gas analyzer using a ventilated hood system (Omnical, IDEE, Maastricht, The Netherlands). Gas analyzers were calibrated before the experiments. Thermogenesis was calculated from these data according to Weir (1949).

Shivering was detected using electromyography (EMG) (Tiretherm, IDEE, Maastricht, The Netherlands). EMG electrodes were placed $3 \mathrm{~cm}$ apart on the skin at the $\mathrm{m}$. pectoralis major as described before ${ }^{(1,31,36)}$. This site was chosen because in people having a normal amount of fat, shivering starts in the upper trunk region, and propagates towards the extremities ${ }^{(31)}$.

Baseline values were calculated over minutes 21 to 50 of the first hour. During cold exposure and rewarming minutes 11 to 60 were used for calculations to avoid influence of removing or replacing the duvet.

For blood sampling, an intravenous cannula was inserted into the antecubital vein at least 30 minutes before the tests commenced. At the end of the baseline measurement blood samples were drawn in order to analyze thyroid hormones and catecholamines. For the analyses of catecholamines the sampling was repeated at the end of cold exposure and at the end of rewarming.

\section{Cold pressor test}

Subjects arrived at the lab by car or public transport after at least 3 hours fasting and they refrained from caffeine on that day.

Subjects were lying on a bed in a room kept at $22^{\circ} \mathrm{C}$ in comfortable clothing. Before the test started, the subjects rested on the bed lying still for 30 minutes. The test consisted of 5 minutes baseline skin blood flow measurement followed by 3 minutes of immersing the left hand up to the wrist in a jar of ice water of $0-4^{\circ} \mathrm{C}$ and ten minutes of rewarming in baseline conditions ${ }^{(9)}$.

Fingertip blood flow of the right middle finger was measured continuously by laser Doppler flowmetry (Periflux PF3, Perimed, Sweden), with the hand at heart level. Finger blood flow was expressed as (arbitrary) perfusion units (PU). Reference values (zero $\mathrm{PU}$ ) were obtained by placing the probe to a white reflecting surface and calibration was 
performed using the Periflux motility standard. An intravenous cannula was inserted into the antecubital vein at least 30 minutes before the tests commenced. Blood samples for catecholamines were taken at baseline, at the end of the cold water exposure and at the end of rewarming.

\section{Hormone analyses}

The blood samples for serum concentrations of thyroxine (T4) and triiodotironine (T3) immediately centrifuged for $10 \mathrm{~min}$ at $800 \mathrm{~g}$ at $4^{\circ} \mathrm{C}$. Serum was transferred into test tubes and stored until further analyses. Serum T3 and T4 concentrations were determined by competitive immunoassay using an ADVIA Centaur T3- and T4-test respectively (Bayer Diagnostics, Leverkusen, Germany).

Samples for plasma norepinephrine and epinephrine concentrations were collected in tubes on ice, containing heparin and glutathione $(1.5 \% \mathrm{w} / \mathrm{v})$. Blood samples were immediately centrifuged for $10 \mathrm{~min}$ at $800 \mathrm{~g}$ at $4^{\circ} \mathrm{C}$. Plasma was transferred into test tubes, and stored until further analysis. Plasma catecholamine levels were determined by high performance liquid chromatography according to the method of Alberts et al. using a ClinPrep kit (Recipe, Munich, Germany).

\section{Data treatment}

Data are reported as mean $\pm S D$. Results were considered statistically significant when $p$ $<0.05$. The SPSS program, version 11.5.0 (SPSS Inc., Chicago, IL, U.S.A.) was used for statistical analyses.

Between group differences were tested by unpaired t-tests. To test the difference in increase of thermogenesis between the groups, delta's between baseline and cold were calculated and unpaired t-tests were used. Within group changes were tested by paired t-tests. Between group differences in blood flow measured by laser Doppler flowmetry, were tested by Mann-Whitney test. Within group differences in blood flow were tested by Wilcoxon signed ranks test. Multiple linear regression analysis was used to study the relation between baseline thermogenesis and thyroid hormones.

\section{Results}

\section{Whole body cooling}

Baseline. Baseline thermogenesis (in $\mathrm{W} / \mathrm{m}^{2}$ ), catecholamines, thyroid hormones and blood flow were not significantly different between groups (Table 2 ).

Baseline thermogenesis $(\mathrm{kJ} / \mathrm{min})$ was significantly related to fat free mass $\left(r^{2}=0.50, p<\right.$ $0.001)$, T4 $\left(r^{2}=0.29, p=0.015\right)$ and the ratio of T3/T4 $\left(r^{2}=0.41, p=0.002\right)$ but not to T3. Multiple linear regression showed a significant contribution of T3/T4 in addition to fat free mass $\left(r^{2}=0.78, p<0.001\right)$.

Baseline thermogenesis $(\mathrm{kJ} / \mathrm{min})=0.06 \mathrm{FFM}(\mathrm{kg})+1.72$

Baseline thermogenesis $(\mathrm{kJ} / \mathrm{min})=92.77 \mathrm{T3} / \mathrm{T} 4+0.05$ FFM $(\mathrm{kg})-0.08$ 
Table 2. Whole body cooling. Thermogenesis, epinephrine, and norepinephrine at baseline, after cold exposure and after rewarming and T3 and T4 at baseline.

\begin{tabular}{|c|c|c|c|c|}
\hline & & $\begin{array}{l}\text { Baseline } \\
\text { Mean SD }\end{array}$ & $\begin{array}{c}\text { Cold } \\
\text { Mean SD }\end{array}$ & $\begin{array}{l}\text { Rewarming } \\
\text { Mean SD }\end{array}$ \\
\hline Thermogenesis & Lean & $44.7 \pm 3.1$ & $53.4 \pm 7.2^{* *}$ & $50.0 \pm 4.2^{\star \star}$ \\
\hline$\left(\mathrm{W} / \mathrm{m}^{2}\right)$ & Overweight & $44.7 \pm 3.9$ & $47.5 \pm 4.5^{\star *}$ & $45.9 \pm 4.7$ \\
\hline Epinephrine & Lean & $0.4 \pm 0.3$ & $0.2 \pm 0.1^{*}$ & $0.2 \pm 0.1^{*}$ \\
\hline$(\mathrm{nmol} / \mathrm{l})$ & Overweight & $0.3 \pm 0.1$ & $0.2 \pm 0.1^{*}$ & $0.2 \pm 0.1$ \\
\hline Norepinephrine & Lean & $1.7 \pm 0.3$ & $1.9 \pm 0.4$ & $1.8 \pm 0.6$ \\
\hline$(\mathrm{nmol} / \mathrm{l})$ & Overweight & $1.3 \pm 0.3$ & $1.7 \pm 0.5^{*}$ & $1.5 \pm 0.4$ \\
\hline T3 & Lean & $2.2 \pm 0.3$ & & \\
\hline$(\mathrm{nmol} / \mathrm{l})$ & Overweight & $2.2 \pm 0.2$ & & \\
\hline $\mathrm{T} 4$ & Lean & $92.9 \pm 13.2$ & & \\
\hline$(\mathrm{nmol} / \mathrm{l})$ & Overweight & $88.3 \pm 10.3$ & & \\
\hline
\end{tabular}

\section{Cold-induced thermogenesis.}

During the whole body cooling test, thermogenesis corrected for body surface area increased significantly during the hour of cold exposure in both groups $(p=0.004$ and $p$ $=0.006$ for lean and overweight respectively, Table 2). Shivering did not occur during any of the stages of the experiment.

During rewarming, thermogenesis decreased in both groups and returned to baseline in the overweight group. In the lean group, thermogenesis during rewarming remained significantly higher compared to baseline $(p=0.003$, Table 2$)$.

There were no significant differences in thermogenesis between lean and overweight subjects. However, the increase in thermogenesis during cooling was significantly larger in the lean group compared to the overweight $(p=0.04)$. The difference in thermogenesis between rewarming and baseline was significantly larger in the lean group compared to the overweight as well $(p=0.01)$.

\section{Epinephrine response.}

Epinephrine was significantly decreased after the hour of cold exposure in both groups $(p=0.04$ and $p=0.01$ in lean and overweight respectively, Table 2). The response was not significantly different between the groups. After rewarming epinephrine was not significantly different from baseline values in the overweight group, but stayed significantly lower than baseline in the lean group $(p=0.03$, Table 2$)$.

\section{Norepinephrine response.}

Norepinephrine in the overweight group was significantly increased after the hour of cold exposure compared to baseline $(p=0.014$, Table 2$)$ and had returned to baseline values after rewarming. The increase in norepinephrine in the lean group was not significant. There were no significant differences between groups. 
Baseline values of blood flow, epinephrine and norepinephrine were not significantly different between lean and overweight.

Blood flow decreased significantly during hand immersion in the overweight group $(p=$ 0.005 , Table 3 ) and returned to baseline during rewarming ( $p=0.013$ rewarming vs. cold). No significant changes were found in the lean group.

Epinephrine did not change significantly in both groups (Table 3).

In the overweight group norepinephrine increased significantly during cold exposure $(p=$ 0.001 , Table 3 ) and stayed significantly higher compared to baseline during rewarming $(p=0.047$, Table 3$)$. No significant change was observed in the lean group.

Table 3. Cold pressor test. Blood flow, epinephrine, and norepinephrine at baseline, after cold exposure and after rewarming

\begin{tabular}{llccc}
\hline & & $\begin{array}{l}\text { Baseline } \\
\text { Mean } \pm \text { SD }\end{array}$ & $\begin{array}{l}\text { Cold } \\
\text { Mean } \pm \text { SD }\end{array}$ & $\begin{array}{l}\text { Rewarming } \\
\text { Mean } \pm \text { SD }\end{array}$ \\
\hline Blood flow & Lean & $57.7 \pm 23.9$ & $43.8 \pm 37.4$ & $57.4 \pm 24.0$ \\
(perfusion units) & Overweight & $49.5 \pm 33.8$ & $22.6 \pm 12.7^{* *}$ & $38.5 \pm 22.0$ \\
\hline Epinephrine & Lean & $0.2 \pm 0.2$ & $0.3 \pm 0.1$ & $0.2 \pm 0.0$ \\
(nmol/l) & Overweight & $0.2 \pm 0.1$ & $0.2 \pm 0.1$ & $0.2 \pm 0.0$ \\
Norepinephrine & Lean & $3.0 \pm 1.3$ & $3.4 \pm 0.9$ & $2.9 \pm 1.3$ \\
(nmol/l) & Overweight & $1.9 \pm 0.8$ & $2.8 \pm 0.8^{\star * *}$ & $2.2 \pm 0.8^{*}$ \\
\hline
\end{tabular}

Significant difference versus baseline: ${ }^{*}=\mathrm{P}<0.05,{ }^{* *}=\mathrm{P}<0.01,{ }^{* \star *}=\mathrm{P}<0.001$

\section{Discussion}

This study showed significant differences between overweight and lean subjects in response to local and whole body cold exposure. Both thermogenesis and heat loss responses indicated more energy conservation in the overweight group, i.e. a relatively small increase in thermogenesis during one hour of cold air exposure and relatively large decrease in finger skin blood flow during the cold pressor test. In both tests overweight subjects showed significant increases in norepinephrine while the lean did not.

The first two results (blunted CIT and high Cl-vasoconstriction in overweight) are in line with our hypotheses. Our third hypothesis (a reduced SNS activity in overweight) is not confirmed by the measurement of serum nor-epinephrine. This can be explained by differences in sensitivity to $\beta$-adrenergic stimulation between lean and overweight (see below).

Looking at baseline (comfortable temperatures) thyroid values first, this study confirms that thyroid activity is significantly related to RMR. Changes in thyroid hormones are usually found as a result of long term exposure to cold ${ }^{(5,27)}$ and cold-air exposures in the laboratory conditions have to be long and intense to lead to measurable changes in thyroid hormones ${ }^{(10)}$. Therefore in this study including 1 hour of cold exposure, only baseline thyroid values are relevant to study. Especially triiodothyronine (T3) is of interest, since most studies show increased T3-levels in a cold environment, while TSH and thyroxine (T4) remain unchanged ${ }^{(21)}$. The T3/T4 ratio is indicative for the amount of conversion of T4 to $T 3^{(24)}$. Indeed, it is mainly T3 that has been found to have an effect on thermogenesis ${ }^{(26,32)}$ Our study is in line with these observations, showing that the T3/T4 ratio significantly relates to baseline RMR in addition to fat free mass. Baseline 
thyroid activity may be relevant in short term cold exposure studies because sympathetically mediated thermogenesis has an absolute requirement for thyroid hormone ${ }^{(22)}$. However, we did not detect a relation between the thyroid hormone levels and catecholamines or thermogenesis during cold exposure.

Baseline serum catecholamine concentrations were not different between lean and overweight, which is in line with earlier observations ${ }^{(13,25)}$

Mean thermogenesis increased as a result of cold exposure (Table 2). The increase was significantly higher in the lean subjects than in the overweight subjects. The question is whether this can be related to the catecholamine response as measured by changes in plasma epinephrine and norepinephrine. Plasma epinephrine levels decreased during the whole body cooling test. It was expected that epinephrine levels would remain unchanged $^{(6,11,29,30,37)}$. Although the subjects were lying quietly for at least 30 minutes before the onset of the test, the decrease could be caused by the continuous rest during the hours that followed.

The observed increase in norepinephrine in response to cold is in line with many other studies $^{(7,16,18,29)}$. Even within the comfort range of the environmental temperature, a small reduction in temperature stimulates the sympathetic nervous system in normal subjects $^{(14)}$. In our whole body cooling experiment, norepinephrine increased in both groups but reaches statistical significance only in the overweight subjects during cold exposure. The increase is also larger in the overweight group. In contrast to norepinephrine, the response in thermogenesis was smaller in overweight than in lean subjects. This corresponds to earlier studies that show that lean subjects are more sensitive to $\beta$-adrenergic stimulation $^{(33)}$, and that the increase in thermogenesis as result of $\beta 2$-adrenergic stimulation was reduced in obese subjects ${ }^{(25)}$. In addition, Blaak and co-workers. found that weight reduction significantly improved the thermogenic response to $\beta$-adrenoceptor stimulation and lowered basal plasma norepinephrine in men ${ }^{(2)}$.

Just as during whole body cooling, during the cold pressor test norepinephrine increased significantly in the overweight group only. It is known that thermoregulatory vasoconstriction of arterio-venous anastomoses is mediated by local release of norepinephrine rather than alterations in systemic catecholamine concentration. Circulating catecholamine concentrations thus reflect spill-over from the arterio-venous anastomoses. Although spillover levels usually are small, circulating catecholamine concentrations may not be a very sensitive marker. However, blood flow did decrease significantly in the overweight subjects only. In this situation it is therefore very likely that the overweight subjects have a larger vasoconstriction response, as a result of norepinephrine induced $\alpha$-adrenergic vasoconstriction. On the other hand two other studies should be mentioned. First, it has been shown that obese women have a reduced autonomic responsiveness during acute cold compared to lean, associated with thermoregulation ${ }^{(14)}$ Secondly, somewhat contradictory, it has been shown that obese may show increased local sympathetic neuronal responsiveness, at least in forearm microcirculation ${ }^{(15)}$. The larger vasoconstriction response in the overweight group that we observe can thus be caused by both increased norepinephrine release and/or raised responsiveness of the microcirculation. Both sensitivity and amount of adrenoceptors could be involved in responsiveness. To study regional sympathetic neural function, tracer techniques for the measurement of norepinephrine spillover into the plasma could be used in future experiments ${ }^{(33)}$. Finally, an 
alternative interpretation is that alpha-adrenergic receptor sensitivity is not affected by the overweight state, instead the larger vasoconstriction may be due to decreased endothelial function and/or other local vasodilatory signals ${ }^{(39)}$. Finger blood flow was not measured during whole body cooling. The results from the cold pressor test cannot simply be translated to the longer term whole body test. Indeed during that test, the skin temperature of the hands was higher in the overweight group, which reflects higher levels of perfusion. During longer tests heat loss gradually needs to be balanced with thermogenesis forcing the overweights with their relatively small surface to volume ration to dissipate extra heat through their extremities.

In conclusion, this study shows that during both whole body cooling and local cooling the overweight subjects conserve more heat and show lower cold-induced thermogenesis compared to their lean controls. From this study it is also evident that the SNS plays a crucial role in cold-induced thermogenesis differences between the groups. In contrast to lean subjects, during cooling, norepinephrine increased significantly in the overweight group, and during local cooling. Overweight subjects showed a decrease in blood flow. Since during the whole body test we used a mild cold condition that is representative for our daily life, the lower cold-induced thermogenesis in the overweight can have important consequences. The higher energy efficiency in the overweight can contribute to body weight gain and troublesome weight loss. 


\section{Literature}

1 Bell DG, Tikuisis $\mathrm{P}$ and Jacobs I. Relative intensity of muscular contraction during shivering. J Appl Physiol 72: 2336-2342, 1992.

2 Blaak EE, van Baak MA, Kester AD and Saris WH. Beta-adrenergically mediated thermogenic and heart rate responses: effect of obesity and weight loss. Metabolism 44: 520-524, 1995.

3 Claessens-van Ooijen AM, Westerterp KR, Wouters L, Schoffelen PF, van Steenhoven AA and van Marken Lichtenbelt WD. Heat production and body temperature during cooling and rewarming in overweight and lean men. Obesity (Silver Spring) 14: 1914-1920, 2006.

4. Daanen HA. Finger cold-induced vasodilation: a review. Eur J Appl Physiol 89: 411-426, 2003.

5 Eastman CJ, Ekins RP, Leith IM and Williams ES. Thyroid hormone response to prolonged cold exposure in man. J Physiol 241: 175-181, 1974.

6 Frank SM, Higgins MS, Fleisher LA, Sitzmann JV, Raff H and Breslow MJ. Adrenergic, respiratory, and cardiovascular effects of core cooling in humans. Am J Physiol 272: R557-562, 1997.

7 Goldstein DS. Catecholamines and stress. Endocr Regul 37: 69-80, 2003.

8 Kasai T, Hirose M, Matsukawa T, Takamata A and Tanaka Y. The vasoconstriction threshold is increased in obese patients during general anaesthesia. Acta Anaesthesiol Scand 47: 588-592, 2003.

9 Kelly CB, McAree S, Cooper SJ and Stevenson M. The effects of reboxetine, a noradrenaline reuptake inhibitor, on the plasma noradrenaline response to a cold pressor test in healthy volunteers. J Psychopharmacol 16: 333-336, 2002.

10 Leppaluoto J, Korhonen I and Hassi J. Habituation of thermal sensations, skin temperatures, and norepinephrine in men exposed to cold air. J Appl Physiol 90: 1211-1218, 2001.

11 Leppaluoto J, Korhonen I, Huttunen P and Hassi J. Serum levels of thyroid and adrenal hormones, testosterone, TSH, LH, GH and prolactin in men after a 2-h stay in a cold room. Acta Physiol Scand 132: 543-548, 1988.

12 Lovallo W. The cold pressor test and autonomic function: a review and integration. Psychophysiology 12: 268282, 1975.

13 Marques-Lopes I, Forga L and Martinez JA. Thermogenesis induced by a high-carbohydrate meal in fasted lean and overweight young men: insulin, body fat, and sympathetic nervous system involvement. Nutrition 19: 25-29, 2003.

14 Matsumoto T, Miyawaki T, Ue H, Kanda T, Zenji C and Moritani T. Autonomic responsiveness to acute cold exposure in obese and non-obese young women. Int J Obes Relat Metab Disord 23: 793-800, 1999.

15 Nestel PJ, Yamashita T, Sasahara T, Chin-Dusting JP, Esler MD, Dart AM and Jennings GL. Control of the forearm microcirculation: interactions with measures of obesity and noradrenaline kinetics. Clin Sci (Lond) 95: 203-212, 1998.

16 Pacak K, Palkovits M, Yadid G, Kvetnansky R, Kopin IJ and Goldstein DS. Heterogeneous neurochemical responses to different stressors: a test of Selye's doctrine of nonspecificity. Am J Physiol 275: R1247-1255, 1998.

17 Pascualy M, Petrie EC, Brodkin K, Peskind ER, Veith RC and Raskind MA. Effects of advanced aging on plasma catecholamine responses to the cold pressor test. Neurobiol Aging 20: 637-642, 1999.

18 Pasquali R, Baraldi G, Casimirri F, Mattioli L, Capelli M, Melchionda N, Capani F and Labo G. Seasonal variations of total and free thyroid hormones in healthy men: a chronobiological study. Acta Endocrinol (Copenh) 107: 42-48, 1984.

19 Plasqui G, Kester AD and Westerterp KR. Seasonal variation in sleeping metabolic rate, thyroid activity, and leptin. Am J Physiol Endocrinol Metab 285: E338-343, 2003.

20 Rang H, Dale M and Ritter J. Pharmacology. Edinburgh: Chruchill Linvingstone, 1999.

21 Reed HL, Burman KD, Shakir KM and O'Brian JT. Alterations in the hypothalamic-pituitary-thyroid axis after prolonged residence in Antarctica. Clin Endocrinol (Oxf) 25: 55-65, 1986.

22 Ribeiro MO, Carvalho SD, Schultz JJ, Chiellini G, Scanlan TS, Bianco AC and Brent GA. Thyroid hormone-sympathetic interaction and adaptive thermogenesis are thyroid hormone receptor isoform--specific. J Clin Invest 108: 97-105, 2001.

23 Rothwell NJ. CNS regulation of thermogenesis. Crit Rev Neurobiol 8: 1-10, 1994.

24 Sawhney RC, Malhotra AS, Nair CS, Bajaj AC, Rajan KC, Pal K, Prasad R and Basu M. Thyroid function during a prolonged stay in Antarctica. Eur J Appl Physiol Occup Physiol 72: 127-133, 1995.

25 Schiffelers SL, Saris WH, Boomsma F and van Baak MA. beta(1)- and beta(2)-Adrenoceptor-mediated thermogenesis and lipid utilization in obese and lean men. J Clin Endocrinol Metab 86: 2191-2199, 2001.

26 Silva JE. The thermogenic effect of thyroid hormone and its clinical implications. Ann Intern Med 139: 205213, 2003. 
27 Silva JE. Thyroid hormone control of thermogenesis and energy balance. Thyroid 5: 481-492, 1995.

28 Siri WE. Body composition from fluid spaces and density: analysis of methods. In: Techniques for measuring body composition, edited by Brozek J and Henschel A. Washington DC: National Academy of Sciences, 1961, p. 223-244.

29 Sramek P, Simeckova M, Jansky L, Savlikova J and Vybiral S. Human physiological responses to immersion into water of different temperatures. Eur J Appl Physiol 81: 436-442, 2000.

30 Thomas JR, Ahlers ST, House JF, Schrot J, Van Orden KF, Winsborough MM, Hesslink RL, Jr. and Lewis SB. Adrenergic responses to cognitive activity in a cold environment. J Appl Physiol 68: 962-966, 1990.

31 Tikuisis $\mathrm{P}$, Bell DG and Jacobs I. Shivering onset, metabolic response, and convective heat transfer during cold air exposure. J Appl Physiol 70: 1996-2002, 1991.

32 Toubro S, Sorensen TI, Ronn B, Christensen NJ and Astrup A. Twenty-four-hour energy expenditure: the role of body composition, thyroid status, sympathetic activity, and family membership. J Clin Endocrinol Metab 81: 2670-2674, 1996.

33 van Baak MA. The peripheral sympathetic nervous system in human obesity. Obes Rev 2: 3-14, 2001.

34 van Marken Lichtenbelt WD, Hartgens F, Vollaard NB, Ebbing S and Kuipers H. Body composition changes in bodybuilders: a method comparison. Med Sci Sports Exerc 36: 490-497, 2004

35 van Marken Lichtenbelt WD, Schrauwen P, van De Kerckhove S and Westerterp-Plantenga MS. Individual variation in body temperature and energy expenditure in response to mild cold. Am J Physiol Endocrinol Metab 282: E1077-1083, 2002.

36 Van Ooijen AM, Van Marken Lichtenbelt WD, Van Steenhoven AA and Westerterp KR. Seasonal changes in metabolic and temperature responses to cold air in humans. Physiol Behav 82: 545-553, 2004.

37 Vybiral S, Lesna I, Jansky L and Zeman V. Thermoregulation in winter swimmers and physiological significance of human catecholamine thermogenesis. Exp Physiol 85: 321-326, 2000.

38 Westerterp KR, Wouters $L$ and van Marken Lichtenbelt WD. The Maastricht protocol for the measurement of body composition and energy expenditure with labeled water. Obes Res 3 Suppl 1: 49-57, 1995.

39 Williams IL, Chowienczyk PJ, Wheatcroft SB, Patel AG, Sherwood RA, Momin A, Shah AM and Kearney MT. Endothelial function and weight loss in obese humans. Obes Surg 15: 1055-1060, 2005. 


\section{Chapter 7}

\section{Validation of an individualized model of human thermoregulation for predicting responses to cold air}

Published as: W.D. van Marken Lichtenbelt, A.J.H. Frijns, A.M.J. van Ooijen, D. Fiala, A.M.Kester, A.A. van Steenhoven.

Int J Biometeorol (2007) 51:169-179 


\begin{abstract}
Abstract Most computer models of human thermoregulation are population based. Here, we individualized the Fiala model ${ }^{(4)}$ with respect to anthropometrics, body fat, and metabolic rate. The predictions of the adapted multisegmental thermoregulatory model were compared with measured skin temperatures of individuals. Data from two experiments, in which reclining subjects were suddenly exposed to mild to moderate cold environmental conditions, were used to study the effect on dynamic skin temperature responses. Body fat was measured by the three-compartment method combining underwater weighing and deuterium dilution. Metabolic rate was determined by indirect calorimetry. In experiment 1 , the bias (mean difference) between predicted and measured mean skin temperature decreased from $1.8^{\circ} \mathrm{C}$ to $-0.15^{\circ} \mathrm{C}$ during cold exposure. The standard deviation of the mean difference remained of the same magnitude (from $0.7^{\circ} \mathrm{C}$ to $0.9^{\circ} \mathrm{C}$ ). In experiment 2 the bias of the skin temperature changed from $2.0 \pm 1.09^{\circ} \mathrm{C}$ using the standard model to $1.3 \pm 0.93^{\circ} \mathrm{C}$ using individual characteristics in the model. The inclusion of individual characteristics thus improved the predictions for an individual and led to a significantly smaller systematic error. However, a large part of the discrepancies in individual response to cold remained unexplained. Possible further improvements to the model accomplished by inclusion of more subject characteristics (i.e. body fat distribution, body shape) and model refinements on the level of (skin) blood perfusion, and control functions, are discussed.
\end{abstract}

\title{
Acknowledgements
}

The authors thank Paul Schoffelen and Loek Wouters for technical assistance during data collection. 


\section{Introduction}

Various detailed models of the human thermal system, predicting human thermoregulatory responses to the environment, clothing and/or different levels of activity, have been developed in the past three decades. Most of the models available today are based on the work of Stolwijk, who modelled the body as a composite of several cylinders representing the head, the corpus, and the upper and lower extremities ${ }^{(19)}$. Useful refinements of this model have been implemented, among others by Gordon (1974), Lotens (1993), and Huizinga et al. (2001), and new thermoregulatory models have also been developed, e.g. by Wissler (1985) and Fiala et al. $(1999)^{(3,7,9,11,32)}$. However, virtually all models are population based, i.e. they predict an average response of the population or use an average subject with standardized body characteristics.

In recent years, there has been growing interest in 'personalized' models capable of predicting the thermal behavior of individuals or specific groups of populations. The fields of application for such models include indoor climate and thermal comfort research (e.g. air conditioning systems in buildings and cars), biometeorology, textile research by the military (e.g. to assess exposure limits and the performance of protective clothing systems), health sciences (e.g. study of factors determining metabolic efficiency), risks under stressful conditions (e.g. heat stress, cold stress, strenuous exercise), and in clinical environment (e.g. neuroprotection, surgery, anaesthetics, recovery, accidental hypothermia).

Recently, some models that incorporate individual human characteristics have emerged $^{(6,8,33)}$ but, although promising, the validation results remain limited. Such models predicted core temperatures during hot stress using an extended twonode model and concluded that, although model individualization did improve the predictions, substantial error still remained. Zhang et al. (2001) used a multi-segmental model and implemented individualized body composition and energy expenditure characteristics ${ }^{(33)}$. Body fat and resting metabolic rate (RMR) were derived from body length and weight ${ }^{(33)}$. However, it is important that the development and validation of individualized models is based on actually measured subjective characteristics such as body composition and RMR.

Even in modern western societies, humans are frequently exposed to environments that deviate from thermo-neutral conditions. Moreover, transient changes in ambient temperature, air velocity, and other environmental parameters are typical. Disturbances from thermo-neutral conditions lead to temporal changes in body heat content and to adjustments of the thermoregulatory system. In this respect, large differences between subjects have been documented ${ }^{(23,26)}$. Despite the fact that moderate conditions appear to be more relevant to our daily lives, most studies have focused on extreme (severe cold or heat stress) conditions. Inter-individual differences in thermoregulatory responses to severe cold have been linked to age, body composition and gender ${ }^{(10,12,27)}$. Comparatively little information is available on thermoregulatory responses under mild cold; however, even under such conditions, individuals may differ considerably in their physiological response $\mathrm{e}^{(1,23,24,26)}$. Recent research seems to indicate that body composition is a factor contributing to these individual differences ${ }^{(26)}$.

The purpose of this study is to examine to what extent a 'personalized' multi-segmental mathematical model can improve the capability of predicting the temperature responses of individuals. For this purpose we used a detailed computer model of human thermo- 
regulation $^{(3,4)}$, which is based on the analysis of a large number of independent experimental data. The original model was developed to simulate a 'standard' person with a body weight of $73.5 \mathrm{~kg}, 1.71 \mathrm{~m}$ in height (Dubois area $1.86 \mathrm{~m} 2$ ), body fat content of $14.4 \% \mathrm{wt}$, and basal metabolism of $87.1 \mathrm{~W}$. Experimental data, collected when reclining subjects were suddenly exposed to a moderate cold environment, were used to study the effect on dynamic skin temperature responses. Two different experiments were designed: one used mild cold conditions with an air temperature of $15^{\circ} \mathrm{C}$, where no shivering was observed ${ }^{(22,26)}$. In the other study, the subjects were exposed to the same ambient temperature but with less clothing, which caused shivering after 83 min on average ${ }^{(25)}$. In this trial the focus was on body temperature and metabolic responses as well as the duration of the non-shivering interval (NSI).

After carrying out a sensitivity analysis using the original model, the above-mentioned data sets were used to validate both the original and the individualized model incorporating the independently measured subject characteristics, i.e. body composition and metabolic rate.

\section{Materials and methods}

\section{Model}

The thermoregulatory responses of the test subjects were modeled using the Fiala model $^{(3-5)}$. In the original model used in this study, the human body was subdivided into 14 cylinders representing the lower and upper torso, neck, shoulders, and the lower and upper extremities, and a combination of a cylinder for the face and a sphere for the head (Figure 1). Every cylinder and sphere was built of five (face, thorax and abdomen) or four layers (other body elements) that represented different tissue materials: brain, lung, viscera, bone, muscle, fat, and skin. Furthermore, the cylinders were divided spatially into three sectors (anterior, posterior, and interior) by which asymmetric boundary conditions can be modeled (such as inhomogeneous radiant fields, or extra insulation caused e.g. by an operating-room table). The body elements exchanged heat with each other via arterial blood delivered from the central blood pool located in the thorax. After passing counter-current heat exchanges, heat was delivered to local tissues via blood perfusion $^{(3,7,9,11,32)}$.

The dynamic model consisted of passive and active components. The passive component modeled heat transfer phenomena and heat redistribution within the body, including the thermal effects of blood circulation, heat generation, accumulation and conduction in tissue layers. The model interacted with the environment by convection, (short-wave and long-wave) radiation, respiration, skin evaporation and water vapor diffusion. In this original model, the insulative effect of clothing was considered by adapting local heat transfer coefficient $U^{*} \mathrm{cl}$ according to the method described in Fiala et al. (1999) ${ }^{(3)}$ :

$$
U * c l=\frac{1}{\sum_{j=1}^{n} I * c l+\frac{1}{f *{ }_{c l}\left(h_{c, \text { mix }}+h_{R}\right)}}
$$


where $j$ and $n$ represent the running and total number of clothing layers covering a body part, respectively, $I_{c l}{ }_{c l}$ is the local insulation value, $f^{*}{ }_{c l}$ the area of the body element covered by clothing, and $h_{c, \text { mix }}$ and $h_{R}$ the local values predicted for convection and radiation, respectively. The values for $I_{c l}^{*}$ were derived by converting overall clothing characteristics obtained from the literature ${ }^{(13,14)}$ by accurately simulating the experimental procedures $^{(3)}$. A similar approach was also used to calculate the clothing's local evaporative resistance ${ }^{(3)}$.
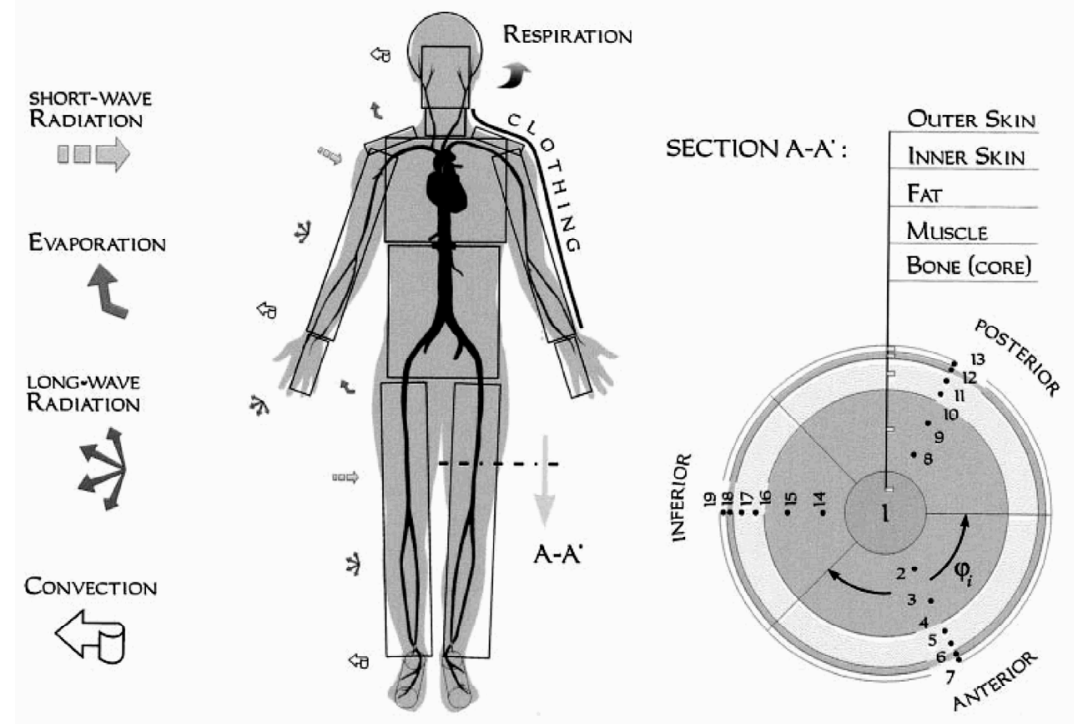

Figure 1. Schematic view of the human body model (3).

The active component represents the actual thermoregulatory system. The body responds to temperatures and changes in temperature by extra heat production produced by shivering, sweating and vasomotion. The thermoregulatory system was developed based on regression analysis of measured responses using a large number of published experiments with volunteers. The model mimics the response of a standard healthy, unacclimatized person.

\section{Individualization}

In this research we compared the results of the "standardized" person with predictions from the individualized model in which the anthropometric and basal metabolism data were adjusted according to the personal characteristics obtained from test-subjects in our experiments. Except for the head, the length of the body elements was scaled by a factor, $f$, which was the ratio of the height of the individual to the height of the average person. The head was scaled by the square root of $f$. The thickness of the skin layers of all body parts was kept unchanged. The radii of the core, bone, muscle, and fat layers of the modified model were adjusted to reflect the measured total mass and body fat content of the individual test subjects. The heat generation rates of the model were converted from the measured whole body metabolic rates. 


\section{Sensitivity analysis}

To obtain information on how body temperatures are affected by individual characteristics (body height, body weight, fat percentage and metabolic rate), we first compared the results of the standard human model of Fiala et al. (1999) with temperatures predicted by an adapted model representing an average Dutch man and woman (Visscher and Seidell $2004)^{(3,28)}$. The data for the mass, height and body mass index (BMI) are listed in Table 1.

Table 1. Literature values: mean (standard deviation) for Dutch men and women aged 20-59 yr.

\begin{tabular}{lcc}
\hline & Man & Woman \\
\hline Mass (kg) 1) & $80.9(12.2)$ & $67.7(11.7)$ \\
Height (m) 1) & $178.3(7.4)$ & $165.7(6.8)$ \\
BMI (kg/m2) 1) & $25.4(3.6)$ & $24.7(4.3)$ \\
BF (\%) 2) & $24.6(4.3)$ & $34.6(5.2)$ \\
RMR (MJ/d) 3) & $7.53(0.59)$ & $5.84(0.40)$ \\
\hline BMI, body mass index; BF, body fat; RMR, resting metabolic rate. From: (Visscher\& Seidell, 2004); Body fat \\
percentage From: (Deurenberg et al. 1991) From: (WHO 2004)
\end{tabular}

The body fat percentage (BF\%) was calculated by:

$$
B F \%=1.20 \times B M I+0.23 \times \text { age }-10.8 \times \text { sex }-5.4
$$

where age $=45$ years, sex $=1$ for males and 0 for females ${ }^{(2)}$.

The RMR (in MJ/day) was obtained as in WHO (2004) ${ }^{(31)}$ :

$$
\begin{array}{ll}
R M R=0.048 \times \text { weight }+3.653 & \text { for men } \\
R M R=0.034 \times \text { weight }+3.538 & \text { for women }
\end{array}
$$

In the simulations, the subjects wore sweatpants $(0.28 \mathrm{clo})$, a sweater $(0.37 \mathrm{clo})$, socks (0.02 clo), and underwear $(0.04 \mathrm{clo})$. The simulations were carried out for the following boundary conditions: thermo-neutral initial conditions (according to Fiala et al. 2001), followed by a $100-\mathrm{min}$ exposure to ambient temperature of $21.5^{\circ} \mathrm{C}$ and $200 \mathrm{~min}$ to $16.5^{\circ} \mathrm{C}^{(4)}$. The simulation was run with an air speed of $0.1 \mathrm{~m} / \mathrm{s}$ and relative humidity of $50 \%$. These conditions were similar to the conditions of experiment 1 described below. The simulation results are shown in Table 2.

In the simulations, the onset of shivering was predicted to occur after 170 to $300 \mathrm{~min}$ of exposure. We therefore chose to analyse skin temperatures at $t=160 \mathrm{~min}$, i.e. just before any shivering occurred. The simulations showed that the mean skin temperatures of an average man or woman would differ from the standard person by up to $1.5^{\circ} \mathrm{C}$ (Table 2 ). This indicates the importance of the actual body composition and RMR on predicted skin temperatures.

Table 2. Simulated time to shiver and temperatures $(T)$ at $160 \mathrm{~min}$ for the standard man according to Fiala (1999), and the average Dutch man and the average Dutch woman (Visscher\& Seidell, 2004).

\begin{tabular}{lccccccc}
\hline & $\begin{array}{c}\text { Time to } \\
\text { shiver } \\
(\mathrm{min})\end{array}$ & $\begin{array}{c}\text { Mean Tskin } \\
\left({ }^{\circ} \mathrm{C}\right)\end{array}$ & $\begin{array}{c}\text { Trectal } \\
\left({ }^{\circ} \mathrm{C}\right)\end{array}$ & $\begin{array}{c}\text { Tleg } \\
(\text { anterior }) \\
\left({ }^{\circ} \mathrm{C}\right)\end{array}$ & $\begin{array}{c}\text { Thand } \\
(\text { posterior }) \\
\left({ }^{\circ} \mathrm{C}\right)\end{array}$ & $\begin{array}{c}\text { Tfoot } \\
(\text { anterior }) \\
\left({ }^{\circ} \mathrm{C}\right)\end{array}$ & $\begin{array}{c}\text { Tchest } \\
(\text { anterior })\end{array}$ \\
\hline Standard man & 230 & 30.0 & 36.73 & 30.06 & 28.40 & 24.41 & 32.94 \\
Average man & 240 & 29.3 & 36.66 & 28.92 & 27.83 & 24.47 & 32.18 \\
Average woman & 260 & 28.5 & 36.01 & 28.14 & 26.92 & 23.43 & 31.46 \\
\hline
\end{tabular}


In order to evaluate the effect of individual body composition parameters and RMR relevant to the population under study, these parameters were then changed keeping the other parameters in the model constant. The time of onset of shivering, the rectal temperature and some skin temperatures were compared for both the 5 th percentile and the 95th percentile of Dutch men with the values obtained for the average person. The body composition and RMR values for the 5th percentile and the 95th percentile of Dutch men were defined as their mean values plus or minus twice their standard deviation, respectively (Table 1). The simulation results are listed in Table 3.

Table 3. Time to shiver and temperatures $(T)$ for the average man and the 5th percentile and 95th percentile man with respect to mass, height, body fat percentage and basal metabolism. When the parameter is changed to the 5th or 95th percentile value, all other parameters are kept at the average value. Temperatures are at $\mathrm{t}=160 \mathrm{~min}$.

\begin{tabular}{|c|c|c|c|c|c|c|c|c|}
\hline & & $\begin{array}{l}\text { Time to } \\
\text { shiver } \\
\text { (min) }\end{array}$ & $\begin{array}{l}\mathrm{T}_{\text {skin }} \\
\left({ }^{\circ} \mathrm{C}\right)\end{array}$ & $\begin{array}{c}\mathrm{T}_{\text {rectal }} \\
\left({ }^{\circ} \mathrm{C}\right)\end{array}$ & $\begin{array}{c}\mathrm{T}_{\text {leg }} \\
\text { (anterior) } \\
\left({ }^{\circ} \mathrm{C}\right)\end{array}$ & $\begin{array}{c}\mathrm{T}_{\text {hand }} \\
\text { (posterior) } \\
\left({ }^{\circ} \mathrm{C}\right)\end{array}$ & $\begin{array}{c}\mathrm{T}_{\text {foot }} \\
\text { (anterior) } \\
\left({ }^{\circ} \mathrm{C}\right)\end{array}$ & $\begin{array}{c}\mathrm{T}_{\text {chest }} \\
\text { (anterior) } \\
\left({ }^{\circ} \mathrm{C}\right)\end{array}$ \\
\hline \multicolumn{2}{|c|}{ Average man } & 240 & 29.3 & 36.66 & 28.92 & 27.83 & 24.47 & 32.18 \\
\hline \multirow[t]{2}{*}{ Mass } & $5^{\text {th }} \%$ & 300 & 29.5 & 36.04 & 28.85 & 28.30 & 24.05 & 31.96 \\
\hline & $95^{\text {th }} \%$ & 170 & 28.0 & 37.74 & 24.88 & 26.47 & 22.05 & 33.65 \\
\hline \multirow[t]{2}{*}{ Height } & $5^{\text {th }} \%$ & 260 & 29.5 & 36.87 & 29.05 & 28.04 & 24.55 & 32.32 \\
\hline & $95^{\text {th }} \%$ & 230 & 29.1 & 36.48 & 28.77 & 27.65 & 24.09 & 32.06 \\
\hline \multirow[t]{2}{*}{ Fat $\%$} & $5^{\text {th }} \%$ & 240 & 29.9 & 36.92 & 29.59 & 28.39 & 25.00 & 32.90 \\
\hline & $95^{\text {th }} \%$ & 250 & 28.7 & 36.31 & 28.22 & 27.25 & 23.83 & 31.69 \\
\hline \multirow[t]{2}{*}{ RMR } & $5^{\text {th }} \%$ & 210 & 28.3 & 36.98 & 25.68 & 26.91 & 22.63 & 32.92 \\
\hline & $95^{\text {th }} \%$ & 280 & 29.5 & 36.75 & 29.35 & 28.00 & 24.10 & 32.31 \\
\hline
\end{tabular}

RMR, resting metabolic rate

The analysis revealed that the impacts of body mass, body fat percentage and RMR on the mean skin temperature are of comparable order of magnitude $\left(1.2^{\circ} \mathrm{C}\right.$ to $\left.1.5^{\circ} \mathrm{C}\right)$ whereas the impact of body height is less pronounced $\left(0.4^{\circ} \mathrm{C}\right)$. The effect on local skin temperatures in the extremities was found to be even more significant, again clearly indicating the importance of actual body composition and RMR in the response of the individuals to be modeled.

\section{Experimental investigations}

Two types of experiments were carried out to validate the model. Experiment 1 involved subjects resting for $1 \mathrm{~h}$ at a comfortable temperature followed by a 3-h exposure to mild cold. Mild cold means that no shivering occurred during the entire duration of the test. In experiment 2, cold exposure was enhanced by using less clothing. Also, this experiment started with a1-h exposure to thermally comfortable conditions followed by cold exposure until shivering occurred. The tests were terminated $30 \mathrm{~min}$ after the onset of shivering.

\section{Measurements}

The volunteers in both experiments were given detailed information regarding the purpose and the methods used in the study, before written consent was obtained. The Ethics Committee of Maastricht University approved the studies.

The body composition of all subjects was determined in a separate session, which took place within 1 week before the actual trials. Body composition was calculated using the 
three-compartment model according to Siri (1956) ${ }^{(18)}$. For this calculation, the body density and the total body water content were determined using underwater weighing and deuterium dilution ${ }^{(30)}$.

During the tests, $\mathrm{O} 2$ consumption and $\mathrm{CO} 2$ production were measured by indirect calorimetry, using a ventilated hood system. Metabolic rate was calculated from these data according to Weir $(1949)^{(29)}$. RMR was defined as the metabolic rate of subject who were awake and lying still while exposed to thermoneutral conditions.

Rectal temperature was measured continuously using a thermistor-probe (YSI probes, series 402, Yellow Springs Instruments, Ohio) inserted for $10 \mathrm{~cm}$. Skin temperatures were measured using surface thermistors (YSI probes, series 409B, Yellow Springs Instruments) at the hand posterior, upper arm posterior, chest at the $\mathrm{m}$. pectoralis, abdomen anterior, back sub scapula, thigh anterior, and foot posterior. In experiment 2 measurements of skin temperature of the posterior forearm and the calf were also included. Temperatures were recorded continuously for $50 \mathrm{~s}$ out of each minute and saved every minute. The mean skin temperature was calculated as proposed by Ramanathan (1964) and Mitchell and Wyndham $(1969)^{(15,16)}$.

Shivering was detected using electromyography (EMG) (Tiretherm, Maastricht Instruments, Maastricht University, The Netherlands) placed on the skin above the m. pectoralis major. This site was chosen based on earlier findings of Tikuisis et al. (1991), who found that shivering starts in the upper trunk region in people with a normal amount of fat and in the upper trunk and leg regions in lean people, before propagating towards the extremities $^{(20)}$. In addition, the subjects were asked every $15 \mathrm{~min}$ if they felt they were shivering, and this condition was also checked visually by the investigator.

The subjects arrived at the laboratory by car or public transport and had fasted for at least $4 \mathrm{~h}$ in order to avoid any effects of activity or diet. They were instructed not to perform any strenuous activity the day before the experiment.

\section{Experiment 1}

Ten male and ten female subjects, all healthy non-smokers, participated in these tests. Participants were between 19 and 36 years of age, with an average height of $1.74 \pm 0.09$ $\mathrm{m}$ (mean $\pm \mathrm{SD}$ ), weight $71.1 \pm 14.4$ (range $51.2-107.2$ ) $\mathrm{kg}$, and a BF\% of $22.5 \pm 8.4$ (range 8.2-36). Their average basal metabolic rate was $6.59 \pm 1.01 \mathrm{MJ} / \mathrm{day}$.

The trials took place at the end of the summer, in August and September. The subjects attended the laboratory for an overnight stay including the following morning to participate in the experiment. The subjects were instructed to perform no exercise the day before the measurement and they fasted from the moment they entered the chamber for the whole duration of the experiment. They stayed quietly in the laboratory for $1.5-2 \mathrm{~h}$ at $22^{\circ} \mathrm{C}$ before the actual measurements started. The measurements took place in the morning. Metabolic rate (MR), intestinal, rectal and skin temperatures were measured for $1 \mathrm{~h}$ at an ambient temperature of $22^{\circ} \mathrm{C}$ followed by $3 \mathrm{~h}$ during which the subjects were exposed to $15^{\circ} \mathrm{C}$. The subjects were lying supine on a stretcher. The clothing consisted of sweatpants ( $0.28 \mathrm{clo})$, a sweater $(0.37 \mathrm{clo})$, socks $(0.02 \mathrm{clo})$, and panties and a bra for women and briefs for men (0.04 clo). During the experiment, the face, hands and ankles were uncovered. 


\section{Experiment 2}

Ten women and seven men participated in this study. All were healthy and non-smokers. The subjects were 19- 31 years old, $1.78 \pm 0.12 \mathrm{~m}$ tall, weighed $66.9 \pm 8.4$ (range 54.7 $79.5) \mathrm{kg}$, and had a BF\% of $21.2 \pm 2.2(9.6-40.4)$. Their basal metabolic rate averaged $6.64 \mathrm{v} \pm 1.28 \mathrm{MJ} /$ day.

In the experiment the subjects were lying supine, the head slightly tilted, on a stretcher, in an environment with an air temperature of $15^{\circ} \mathrm{C}$. Other environmental parameters were the same as in experiment 1 . The clothing had a total estimated insulative value of 0.18 clo $\left(0.028 \mathrm{~m}^{2 \circ} \mathrm{C} \mathrm{W}-1\right)$ and consisted of pants $(0.1 \mathrm{clo})$, a singlet $(0.04 \mathrm{clo})$ and panties and a bra for women and briefs for men (0.04 clo). Subjects stayed quietly in the laboratory for $1.5-2 \mathrm{~h}$ at $22^{\circ} \mathrm{C}$ before the actual measurements started. The measurements took place in the morning. The subjects were initially covered with a duvet (375 $\mathrm{g} / \mathrm{m}^{2}$ ) to simulate thermoneutral conditions. Cold was then induced after $30 \mathrm{~min}$ by removing the duvet. The test was terminated $30 \mathrm{~min}$ after the onset of shivering. The interval between removing the duvet and the onset of shivering was defined as the nonshivering interval $(\mathrm{NSI})$. The interval between the onset of shivering and the termination of the test was termed the shivering interval $(\mathrm{SI})$. MR, body temperatures and EMG were measured continuously.

\section{Model-measurement comparisons and statistical analysis}

We initially compared the predictions obtained using the standard subject with measured individual thermoregulatory responses to mild cold. In the second stage, the model was adapted by including the individualized body composition (BC) data (i.e. height, weight and $\mathrm{BF} \%$ ) and/or RMR or actual measured MR to simulate the cold exposure tests.

We calculated the differences between predicted and measured results for each 1-min interval for each individual. These data were used to calculate the mean differences and standard deviations. In Tables 4 and 5, the results averaged over the whole group are given as mean \pm SD over 30 -min time intervals, i.e. the last $30 \mathrm{~min}$ or $10 \mathrm{~min}$ in comfort (exp 1: 31- $60 \mathrm{~min}$; exp 2: 21-30 min), during early cold exposure (exp 1: 91-120 min; exp 2: 51-80 $\mathrm{min}$ ), and the last $30 \mathrm{~min}$ in the cold (exp 1: 211-240 $\mathrm{min}$; exp 2: 81-110 $\mathrm{min})$. The 30 -min mean values were used to test significance by two-tailed paired t-tests between model predictions and measurements with and without inclusion of subject characteristics. The t-tests were calculated using the absolute differences between model and measurements. Absolute values are used because positive and negative change in errors should not cancel each other out.

Linear regression analyses was employed to evaluate the relationship between the predicted and observed times between the start of cold exposure and the onset of shivering. Any differences were considered statistically significant at $\mathrm{P}<0.05$. 


\section{Results}

\section{Experiment 1}

A typical example of measured results is shown in Figure 2a. The data refers to a female subject. During the first hour of comfort the rectal and chest temperatures were constant and the temperatures of the thigh, hand and foot showed a small decline. During the $3 \mathrm{~h}$ of cold exposure, all measured temperatures decreased, except for the rectal temperature, which exhibited a slight increase as the exposure continued. The most prominent decrease in temperature was observed for the hands and feet. The individualized model (with body composition and the metabolic rate adjusted) showed very similar trends (Figure 2b) including all skin temperatures as well as rectal temperature. In the model, the slight increase in the rectal temperature resulted from a massive peripheral vasoconstriction predicted as a response to the cool environment.
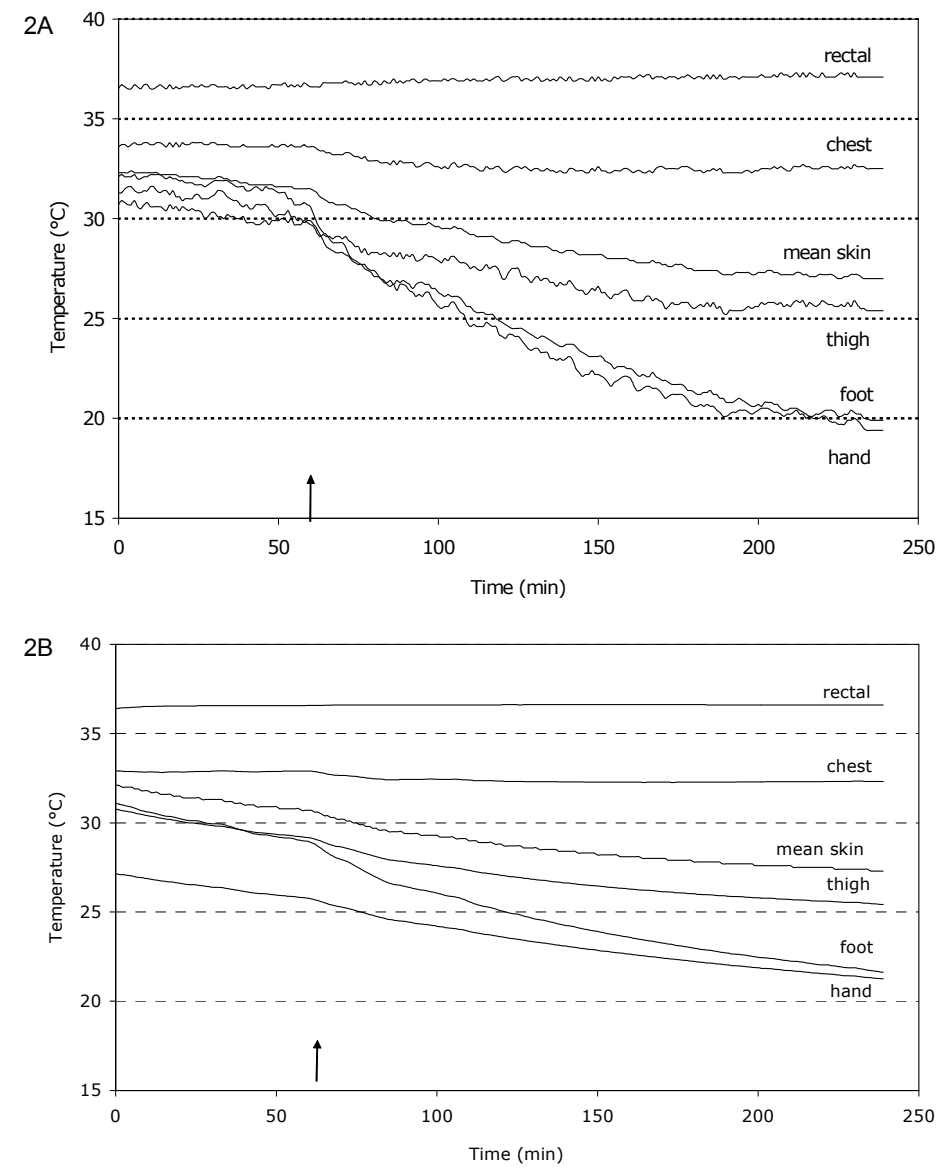

Figure 2

A. Example of temperature measurements of experiment 1. Data from one subject.

B. Example of temperature model results of experiment 1. Data from the same subject as in Figure $2 \mathrm{~A}$ 
Considering the skin temperatures from all subjects (Table 4), the differences between predictions using the standard person model and actual measurements were substantial, i.e. during the final 30 min interval, the prediction-measurement discrepancy of the mean skin temperature was $1.78 \pm 0.67^{\circ} \mathrm{C}$, and that of the back of the hand $5.3 \pm 2.8^{\circ} \mathrm{C}$. The mean deviation between the predicted and measured mean skin temperature is plotted over time in Figure 3 (line A). Adopting individual body composition characteristics and the actual MR of the subjects in the model notably improved the predictions of skin temperature for most body parts. The error decreased from $1.8^{\circ} \mathrm{C}$ to $-0.15^{\circ} \mathrm{C}(\mathrm{P}<0.001)$ and $5.26^{\circ} \mathrm{C}$ to $1.98^{\circ} \mathrm{C}(\mathrm{P}<0.001)$ for the mean skin temperature and the back of the hand skin temperature, respectively, during the final $30 \mathrm{~min}$ of exposure (Table 4; for $\mathrm{T}$ skin Figure 3 line B).

The most significant improvements in skin temperature predictions were achieved when both BC and MR data were adopted. In contrast, the effect of RMR on predicted skin temperatures was relatively small.

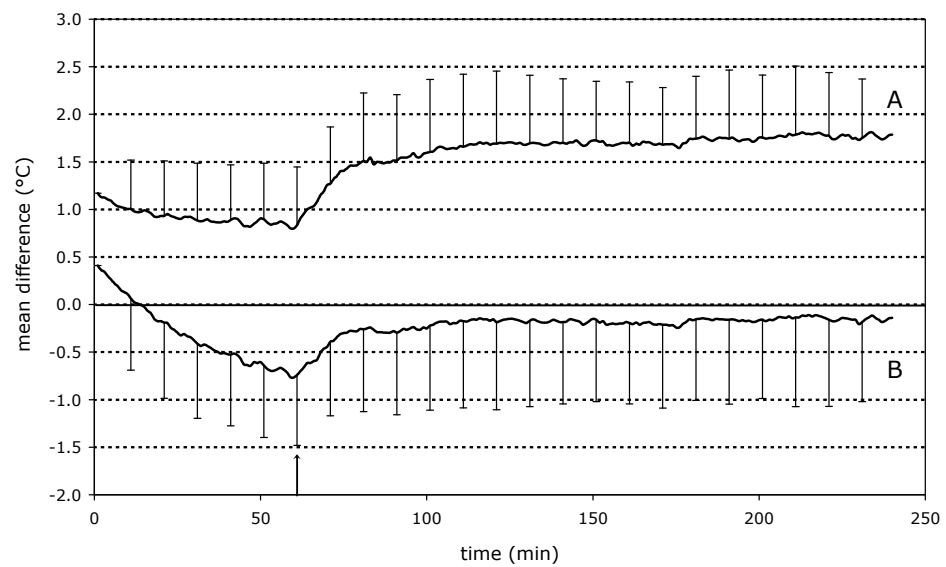

Figure 3 Comparison of model predictions and measurements of experiment 1.

Mean difference (bold lines) with SD (vertical lines) between modeled and measured skin temperatures plotted against time, using the standard subject in the model (line A), and with input in the model of subject characteristics (body composition and metabolic rate) (line $\mathrm{B}$ ). The arrow indicates the change the air temperature from $22^{\circ} \mathrm{C}$ to $15^{\circ} \mathrm{C}$.

The predicted skin temperature of the chest was found to be less sensitive to variations of individual characteristics (Table 4). The results for the posterior thorax and the anterior abdomen showed similar results (data not shown). During the state of comfort (time interval: $31-60 \mathrm{~min}$ ) the predictions were not much improved by adopting individual characteristics, except for hand skin temperature. However, for some subjects the differences between predicted and measured skin temperatures (see e.g. foot in Table 4) increased during this interval as a result of the inclusion of personal characteristics. Overall, considering all subjects and body parts, the standard deviation was not decreased significantly by the introduction of individual characteristics (compare Figure 3 , standard deviations of lines $A$ and $B$ ). 


\section{Experiment 2}

In this experiment, shivering was elicited, on average, after about 83 min of cold exposure. Since we were only interested in metabolic and temperature responses prior to shivering, only data from 11 subjects and for times up to $110 \mathrm{~min}$ of exposure was analyzed, thus excluding subjects $(n=12)$ who started shivering earlier. There were generally considerable inter-individual differences in the measured times of onset of shivering, which ranged from 20 to $148 \mathrm{~min}$.

Analysis of the results indicated that the differences between predictions obtained using the standard model and actual measurements were only slightly larger than those obtained for experiment 1 (Table 5, Figure 4a for T skin). The discrepancies ranged from $2.0 \pm 1.1^{\circ} \mathrm{C}$ for the mean skin temperature to $7.6 \pm 1.0^{\circ} \mathrm{C}$ for the hand skin temperature during the final 30 min interval. Introducing individual characteristics led to better agreement with measurements to some extent for all measured body sites during the final 30 min of cold exposure (Table 5). In contrast to experiment 1, however, the improvement was rather limited and there were virtually no differences between predictions obtained by including the measured RMR or including the actual measured MR. Nevertheless, the inclusion of both measured MR and BC data showed significant improvements with experimental observations (Table 5; T skin: Figure 4).

During the 'comfort' state (baseline values from 21- $30 \mathrm{~min}$ ) the adapted model also showed improved predictions for all body parts when both BC and MR data were included. Here, however, it was mainly the input of the personal BC data that provided the largest improvements. As already observed in experiment 1, the standard deviations of predicted skin temperatures were only marginally affected by the introduction of individual subject characteristics (Table 5; Figure 4).

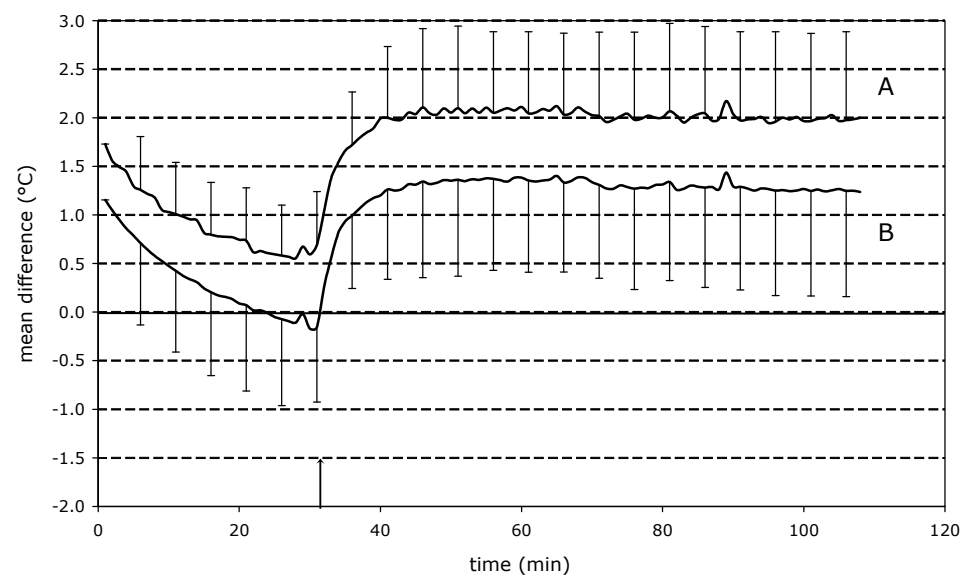

Figure 4.

Comparison of model predictions and measurements of experiment 2. Mean difference (bold lines) with SD (vertical lines) between modeled and measured skin temperatures plotted against time, using the standard subject in the model (line A), and with input in the model of subject characteristics (body composition and metabolic rate) (line B). The arrow indicates the change the air temperature from $22^{\circ} \mathrm{C}$ to $15^{\circ} \mathrm{C}$.

Finally, the predicted and measured times of the onset of shivering correlated significantly (with inclusion of both $B C$ and resting metabolic values: $R^{2}=0.47$ and $P<0.05$ ). 
However, the modeled time intervals ranged from 130 to 150 min (range $20 \mathrm{~min}$ ), while the actual observed range amounted to 80-190 min (range $110 \mathrm{~min}$ ).

\section{Discussion}

\section{Adapted versus standard model}

The predictions of the multisegmental thermoregulatory model of Fiala et al. (2001) were compared with measured skin temperatures of individuals during exposure to thermally comfortable and (mild) cold conditions ${ }^{(4)}$. Analysis of the results showed that the deviations between the predictions and individual measurements were substantial, but that the agreement with measured data improved significantly on a group level (bias decreased) when individual characteristics were incorporated. The deviations on an individual level (standard deviations), however, remained large. The inclusion of individual characteristics thus improved the predictions for an individual and led to a smaller systematical error. However, a large part of the discrepancies in individual response to cold remained unexplained.

\section{Individual characteristics}

The effect of the following individual characteristics was studied: body composition, resting metabolic rate, and actual measured metabolic rate. All three characteristics did improve the predictions; however, this study did not clarify which of these characteristics is the most important for predicting skin body temperature.

The sensitivity analysis of the model indicated that variations in the body composition of the Dutch population (range $5^{\text {th }}$ and $95^{\text {th }}$ percentile) caused changes in the mean skin temperature of up to $3.1^{\circ} \mathrm{C}$. The normal range of RMR in the Dutch population resulted in a variation in the mean skin temperature of $1.2^{\circ} \mathrm{C}$. It follows that the effect of body composition is two to three times as large as the effect of adapted metabolic rates.

Considering the results of both experiments, the difference between measured and predicted temperatures was indeed decreased much more by the input of body composition characteristics than by the input of the metabolic rate. As expected, individualization of body composition plus the resting metabolic rate reduced the differences between measured and predicted skin temperatures even more.

It appeared that, in experiment 1 , the model predictions agreed best with measured data when body composition and actual metabolic rate instead of RMR were incorporated. One reason for this might be that by using the measured MR the model was dynamically adapted as exposure progressed. The model would thus benefit from improved predictions of metabolic responses to mild cold. In experiment 2, inclusion of both RMR and MR provided comparable improvements.

Finally, the model shows a much smaller variation in the time interval between the start of cold exposure and the onset of shivering than did actual measurements. Once model individualizations can provide higher accuracy in predicting skin temperatures, then individual differences in the time of onset of shivering may be better predicted. In the current model, shivering thermogenesis is governed by skin temperature, and the rate of change in skin temperature, and is affected, to a lesser degree, by the level of the body 
core temperature. However, different formulations have been proposed ${ }^{(21)}$. The influence of peripheral and central thermoreception on shivering might, however, not be simply additive as implied in the original model. There is some experimental indication for possible cross-correlations, when the strength of signals from one body side (body core) could affect the sensitivity of the central nervous system to signals from other body sites (skin) when eliciting shivering. Such cross-correlations could have important implications for modeling metabolic responses to cold in obese and lean subjects, who typically show notable differences in their core/skin-temperature ratios.

\section{Model time response}

It was expected that, during the comfort period, subjects would have reached thermal steady state. During the experiments this was almost the case, but the model predictions still showed a gradual decline in skin temperature even during the last minutes of comfort in both experiments. This explains that the bias was not constant during comfort (see Figures 3 and 4). During exposure to cold, the measurements showed a faster temperature response than that predicted by the model in both experiments, explaining the large shift in the mean difference between model and measurement at the onset of cold exposure. After 10-20 min the bias then leveled off.

The time response may also explain the deviations between model prediction and measurement in experiment 2 , which were generally larger than in experiment 1 . The important difference between the two experiments was the severity of the exposure. That the model responded slower to changes in environmental conditions is in line with the relatively large deviations between model and measurements during the shorter and colder exposure in experiment 2.

\section{Comparison with other individualized models}

This study considered individual characteristics such as anthropometrical data, body fat content, and resting metabolic rate. Other individualized models include "Scenario", which includes anthropometrical, VO2max, menstrual cycle and circadian rhythm data ${ }^{(6)}$, the "Berkeley comfort model", which includes anthropometrics, body fat, gender, skin color, and resting metabolic rate data ${ }^{(9,33)}$, and the model described by Havenith $(2001)^{(8)}$, which includes information on the anthropometrics, body fat layer thickness, VO2max, and the acclimatization state.

Only Havenith (2001) published a validation study of his model, using independently measured characteristics ${ }^{(8)}$. The results from that study focused on rectal temperatures, which were predicted with and without incorporating subjective characteristics. No skin temperature results were presented. Compared to our study on skin temperatures, the inclusion of individual characteristics decreased the systematic error of the rectal temperature predictions during heat exposure. In contrast to our results, the mean squared error also decreased significantly. Havenith concludes however, just as we do, that a substantial part of the differences of individual responses remains unexplained ${ }^{(8)}$. 
These results indicate that knowledge of the inter-individual differences is still limited and that (1) further characteristics may play a role and/or (2) further model refinements and/or development might be necessary to better represent individuals or population groups.

\section{Further characteristics}

Further subjective characteristics, in addition to total body fat content, height, weight and MR, might be important. Here, the most influential characteristics could include, e.g., the distribution of body fat specific to individuals, training status, and gender. Cold acclimatization could play a role, although experiment 1 took place at the end of the summer and thus any acclimatization effects to cold were expected to be at a minimum at that time of year in the Netherlands. Individual differences in sympathetic nervous system function and its sensitivity might be important, causing individual variations in the metabolic response and, importantly, in the heat distribution over the body controlled by the peripheral vasoconstriction. It is furthermore assumed that skeletal muscles might play an important role in cold-induced thermogenesis, apart from shivering. Therefore, muscle mass (in addition to the effect of training) could be a further variable that needs closer consideration.

\section{Model refinements and further development}

With respect to the above mentioned subjective characteristics (body fat distribution, training status, gender) only body fat distribution can be modeled in some detail using the original Fiala et al. (2001) model ${ }^{(4)}$. Further refinements, such as those incorporated in the latest model version, i.e. the introduction of further cylinders for upper and lower legs and arms, will improve the prediction of local skin temperatures regarding personal differences in the distribution of body fat and/or muscle mass.

Another improvement could involve connecting the different blood pathways in their natural order. In the current circulatory model, the blood pathways to individual body segments are linked to the central blood pool via counter-current heat exchangers. This approach recognizes the fact that even the arterial blood temperature is not homogeneous over the body. A more realistic approach would be to link, e.g., the hands with lower arms, rather than with the central blood pool.

With respect to the thermoregulatory component, the model was developed based on regression analysis using a large number of published experiments to mimic 'average' human thermoregulatory behavior. The simulation of the thermoregulatory behaviors of individuals and/or specific groups of the population will require further modeling research efforts. To this end, the prediction of the above mentioned vasomotor responses to cold might be of paramount importance. To this end, a model implementing individualized, physiological principles of human thermoregulation should, at least in part, replace the original statistical regression approach of predicting an average response. Aspects such as training status and gender would also have to be included in the definition of a new, personalized thermoregulatory system. 
We conclude that inclusion of individual characteristics can substantially improve model predictions but a significant error remains. The objectives for future research are therefore to improve the models and gain more knowledge of the physiological processes and individual characteristics. Individual characteristics could include more detailed anatomy. On the other hand the model can be improved, e.g., by introducing a more detailed treatment of blood vessels and pathways in the extremities, further subdivisions of the extremities, and the development of individualized, physiologically based controlmechanisms in the model.

As our knowledge of the causes of inter-individual differences is still scant, further research employing both modeling and experiment seems to be necessary to enhance our understanding of the nature of the individual characteristics and physiological principles governing human thermoregulation. 


\section{References}

1 Dauncey MJ. Influence of mild cold on $24 \mathrm{~h}$ energy expenditure, resting metabolism and diet-induced thermogenesis. Br J Nutr 45: 257-267, 1981.

2 Deurenberg P, Weststrate JA and Seidell JC. Body mass index as a measure of body fatness: age- and sexspecific prediction formulas. Br J Nutr 65: 105-114, 1991.

3 Fiala D, Lomas KJ and Stohrer M. A computer model of human thermoregulation for a wide range of environmental conditions: the passive system. J Appl Physiol 87: 1957-1972, 1999.

4Fiala D, Lomas KJ and Stohrer M. Computer prediction of human thermoregulatory and temperature responses to a wide range of environmental conditions. Int J Biometeorol 45: 143-159., 2001.

5 Fiala D, Lomas KJ and Stohrer M. First principles modeling of thermal sensation responses in steady-state and transient conditions. ASHRAE 109: 143-159, 2003.

6 Gonzalez RR. SCENARIO revisited: comparison of operational and rational models in predicting human responses to the environment. J Therm Biol 29: 515-527, 2004.

7 Gordon RG. The response fo human thermoregulatory system in the cold. PhD Thesis: University of California, 1974.

8 Havenith G. Individualized model of human thermoregulation for the simulation of heat stress response. J Appl Physiol 90: 1943-1954., 2001.

9 Huizinga $\mathrm{C}$, Zang $\mathrm{H}$ and Arens $\mathrm{E}$. A model of human physiolog yand comfort for assessing complex thermal environments. Build Environ 36: 1943-1954, 2001.

10 Kaciuba-Uscilko H and Grucza R. Gender differences in thermoregulation. Curr Opin Clin Nutr Metab Care 4: 533-536, 2001.

11 Lotens WA. Heat transfer from humans wearing clothing. PhD Thesis: Delft University of Technology, 1993.

12 Matsumoto T, Miyawaki T, Ue H, Kanda T, Zenji C and Moritani T. Autonomic responsiveness to acute cold exposure in obese and non-obese young women. Int J Obes Relat Metab Disord 23: 793-800, 1999.

13 McCulloch RG, Jones BW and Huck A. Comprehensive data base for determining the evaporative resistance of clothing. ASHRAE Trans: 95, 1989.

14 McCulloch RG, Jones BW and Huck A. Comprehensive data base for extimating clothing insulation. ASHRAE Trans: 29-47, 1985.

15 Mitchell $\mathrm{D}$ and Wyndham $\mathrm{CH}$. Comparison of weighting formulas for calculating mean skin temperature. $J$ Appl Physiol 26: 616-622, 1969.

16 Ramanathan NL. A new weighting system for mean surface temperature of the human body. $J$ Appl Physiol 19: 531-533, 1964.

17 Reeves MM, Davies PS, Bauer J and Battistutta D. Reducing the time period of steady state does not affect the accuracy of energy expenditure measurements by indirect calorimetry. J Appl Physiol 97: 130-134, 2004.

18 Siri WE. The gross composition of the body. Adv Biol Med Physiol 4: 239-280, 1956.

19 Stolwijk JA and Wexler I. Peripheral nerve activity in response to heating the cat's skin. J Physiol 214: 377 392, 1971.

20 Tikuisis P, Bell DG and Jacobs I. Shivering onset, metabolic response, and convective heat transfer during cold air exposure. J Appl Physiol 70: 1996-2002, 1991.

21 Tikuisis P, Gonzalez RR, Oster RA and Pandolf KB. Role of body fat in the prediction of the metabolic response for immersion in cold water. Undersea Biomed Res 15: 123-134, 1988.

22 Van Marken Lichtenbelt WD, Frijns AJH, Fiala D, Janssen FEM, Van ooijen AMJ and Van Steenhoven AA. Individual characteristics and mathematical modeling of human thermoregulation. $J$ Therm Biol 29: 577 - 581, 2004.

23 van Marken Lichtenbelt WD, Schrauwen P, van De Kerckhove S and Westerterp-Plantenga MS. Individual variation in body temperature and energy expenditure in response to mild cold. Am J Physiol Endocrinol Metab 282: E1077-1083, 2002.

24 van Marken Lichtenbelt WD, Westerterp-Plantenga MS and van Hoydonck P. Individual variation in the relation between body temperature and energy expenditure in response to elevated ambient temperature. Physiol and Behavior 73: 235-242, 2001.

25 van Ooijen AM, van Marken Lichtenbelt WD, van Steenhoven AA and Westerterp KR. Cold-induced heat production preceding shivering. Br J Nutr 93: 387-391, 2005.

26 Van Ooijen AM, Van Marken Lichtenbelt WD, Van Steenhoven AA and Westerterp KR. Seasonal changes in metabolic and temperature responses to cold air in humans. Physiol Behav 82: 545-553, 2004.

27 Van Someren EJ, Raymann RJ, Scherder EJ, Daanen HA and Swaab DF. Circadian and age-related modulation of thermoreception and temperature regulation: mechanisms and functional implications. Ageing Res Rev 1: 721-778, 2002. 
28 Visscher TL and Seidell JC. Time trends (1993-1997) and seasonal variation in body mass index and waist circumference in the Netherlands. Int J Obes Relat Metab Disord 28: 1309-1316, 2004.

29 Weir JB. New methods for calculating metabolic rate with special reference to protein metabolism. 1949 [classical article]. Nutrition 6: 213-221, 1990.

30 Westerterp KR, Wouters $L$ and van Marken Lichtenbelt WD. The Maastricht protocol for the measurement of body composition and energy expenditure with labeled water. Obes Res 3 Suppl 1: 49-57, 1995.

31 WHO. Interim report FAONHO/UNU Expert Consulation Report onHuman Energy Requirements. Geneva: WHO, 2004.

32 Wissler EH. Mathematical simulation of human thermal behavior using whole body models. In: Heat transfer in medicine and biology : analysis and applications, edited by Shitzer A and Eberhart RC. New York: Plenum press, 1985.

33 Zhang $\mathrm{H}$, Huizinga $\mathrm{C}$, Arens $\mathrm{E}$ and $\mathrm{Yu}$ T. Considering individual physiological differences in a human thermal model. J Therm Biol 26: 401-408, 2001. 


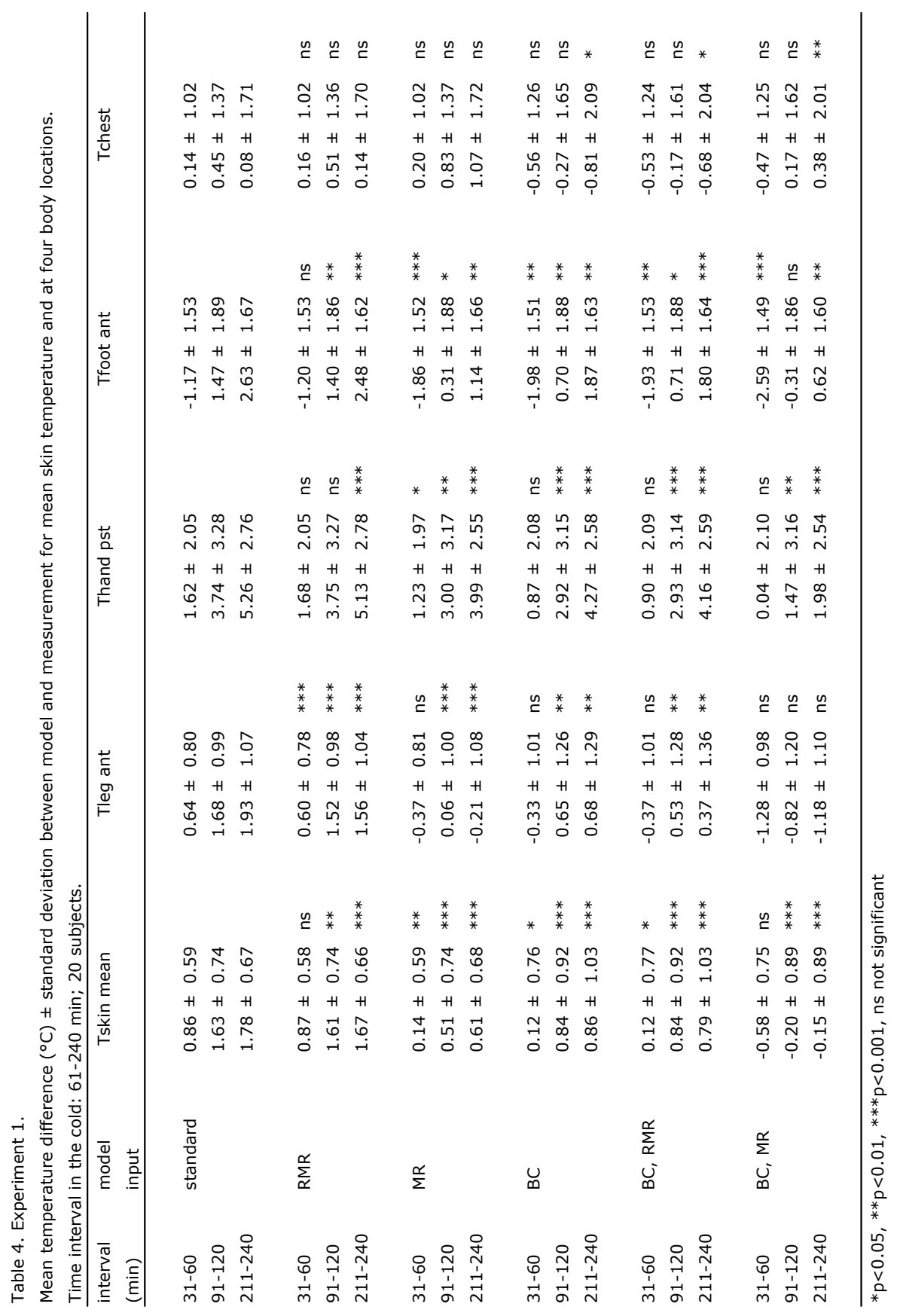




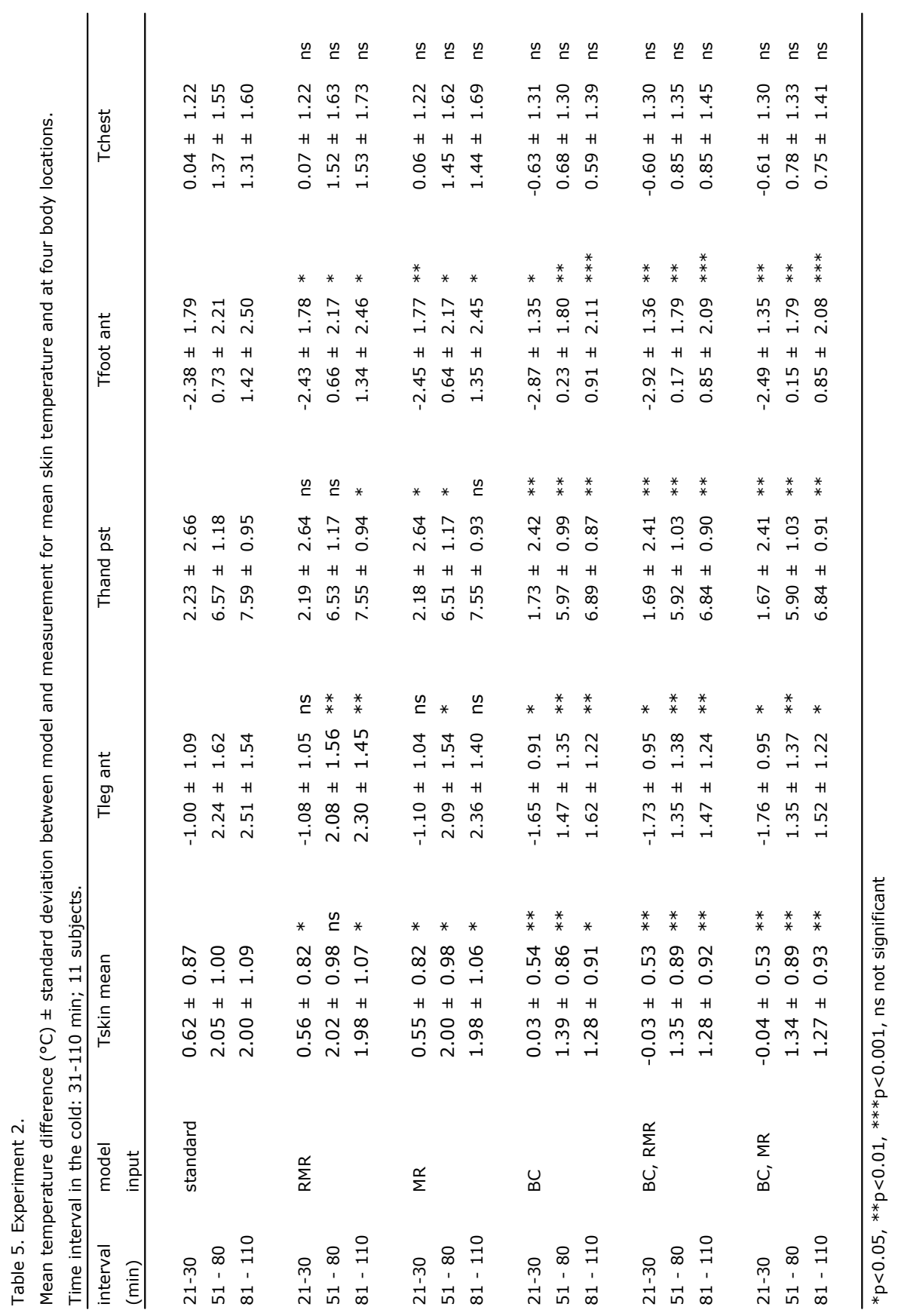




\section{Chapter 8}

General Discussion 
The main objective of this thesis was to study the variability in human metabolic and temperature responses to mild cold. More specifically, can the variation in cold induced thermogenesis be explained by body composition and the activity of the sympathetic nervous system? Essential in these studies is that the cold exposure was mild, reflecting environmental temperature changes as observed regularly in daily life.

\section{Summary of results}

It was shown repeatedly that heat production increases as a result of mild cold while shivering was absent (Chapter 2 to 5 ). The non-shivering component was clearly shown in Chapter 4 with a period of cold-induced non-shivering thermogenesis before shivering is initiated. The variation in cold-induced non-shivering thermogenesis between individuals is illustrated in Figure 1, showing cold-induced non-shivering thermogenesis in percentage of resting metabolic rate (RMR) of 20 individuals measured in winter (Chapter 3).

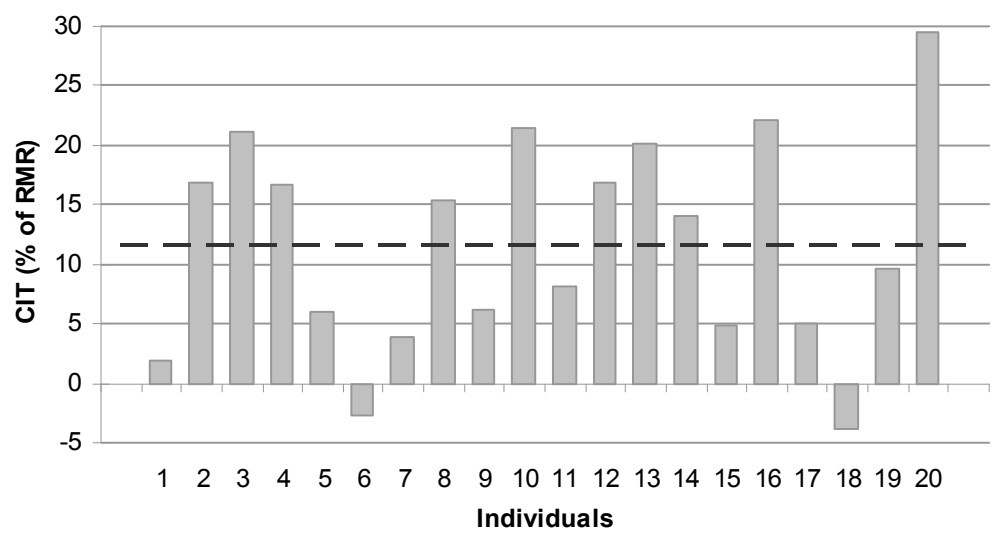

Figure 1. Cold-induced thermogenesis (CIT) in percentage of RMR, 20 subjects measured in winter. The dotted line represents the mean value of all subjects

The range of cold-induced thermogenesis in the subjects ranged from 0 to $20 \%$ of RMR, with extremes of $30 \%$ (Figures 1 and 2).

Comparing the different studies described in this thesis, the $1^{\text {st }}$ and $2^{\text {nd }}$ box in Figure 2 (data from Chapter 2 and 3) show a potentially normal range of variation in metabolic response with variation caused by season.

The $3^{\text {rd }}$ and $4^{\text {th }}$ box in Figure 2 (data from Chapter 5 and 6 ) show a larger range of coldinduced thermogenesis in lean men (BMI <24) compared to overweight men (BMI >24). The $5^{\text {th }}$ box in Figure 2 (data from Chapter 4 ) shows a relatively small range of variation, the data for this box was collected during the first 15 minutes of cold exposure, on this moment, the first subject started to shiver. 


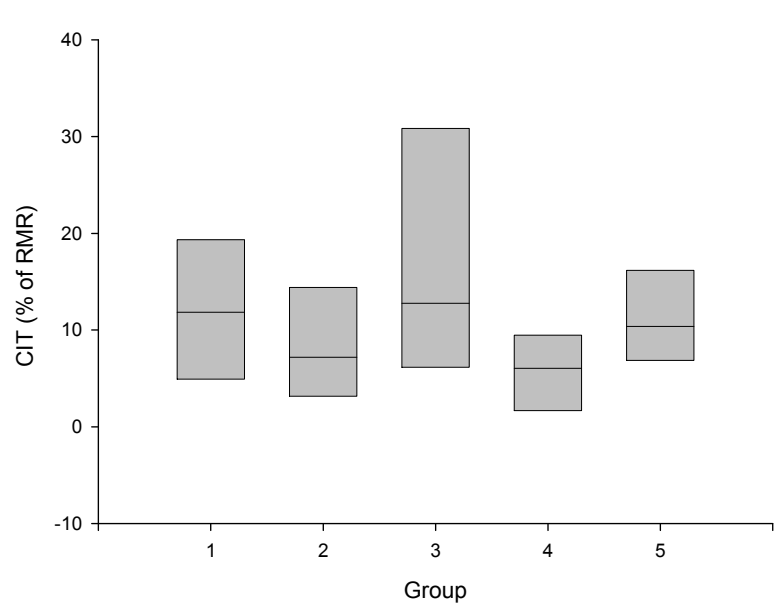

Figure 2

Range of cold-induced thermogenesis (CIT) between individuals over 5 subject groups / situations as measured and described in Chapters 2-5.

1: winter, 2: summer (1,2: 20 subjects men and women, $1 \mathrm{hr}$ of cold exposure), 3: lean, 4 : overweight $(3,4$ : 10 men, $1 \mathrm{hr}$ cold exposure ), 5: during first 15 minutes of nonshivering interval (17 subjects men and women, $15 \mathrm{~min}$ cold exposure). Graph shows median, $25^{\text {th }}$ and $75^{\text {th }}$ percentile

The magnitude of the cold response varies due to cold acclimatization, but the relative contribution of metabolic and temperature response was subject specific and consistent throughout the seasons (Chapter 3 ). Subjects that show a typical metabolic response, represent a small insulative response and vice versa (Chapter 3-6) ${ }^{(42)}$.

In Chapter 4 individual changes in heat production and body temperature were studied in response to cold exposure until shivering occurred. Clearly non-shivering thermogenesis reaches a plateau (possibly a maximum) during the non-shivering interval, while body temperature does not. Subjects with a relatively large heat production during cold exposure maintained a relatively high skin temperature but showed a short non-shivering interval, independent of differences in body composition. This implies that a high heat production before shivering results in a high overall heat production during cold exposure including a relatively early onset of shivering. The combination of these responses however was opposite expectations based on literature describing measurements within subjects.

Whole body cooling showed a larger cold-induced thermogenesis in lean versus overweight subjects (Figure 2) (Chapter 5). During both local and whole body cooling, noradrenalin increased significantly in the overweight group. In contrast, no significant changes in noradrenalin and blood flow were observed in lean subjects (Chapter 6).

Finally, the data collected for the studies as described in Chapter 3 and 4 were successfully applied to validate a dynamic thermoregulation model for the prediction of individual body temperatures over time (Chapter 7 ).

\section{Metabolic implications}

The results from Chapter 5 and 6 show a difference in cold induced thermogenesis between lean and overweight subjects. Both whole body and local cooling showed that the overweight subjects conserve more heat and showed lower cold-induced thermogenesis (an insulative response) compared to their lean controls. The energy efficient response of the overweight subjects can have consequences for energy balance in the long term ${ }^{(34)}$. As an example, a person with $11.5 \%$ NST over a RMR of $4.75 \mathrm{~kJ} / \mathrm{min}$ 
(average of the group measured in winter) would spend enough energy comparable to approximately $200 \mathrm{gr}$ of body weight if exposed to $1 \mathrm{hr}$ cold a day over half a year. This is similar to the difference between the average lean and overweight subject in Chapter 5 . The difference between the non-responders and maximum responders measured throughout our experiments could add up to over three times this amount.

Results from Tikuisis et al. (1999) are in line with this thesis also showing a wide range of inter-individual differences in response to cold, although cold exposure was more extreme. The duration of extreme cold exposure was positively related to both body fatness and shivering intensity, indicating that both a metabolic and an insulative response can be effective ${ }^{(25,41,42)}$. Interestingly, subjects with a relatively high percentage of body fat could all stay relatively long in the cold and keep up a relatively high rectal temperature.

Apart from gaining more insight in the variability and regulation of cold-induced thermogenesis, which can be used for the development of pharmacological and diet interventions, future studies will reveal whether long term living in the thermoneutral zone promotes adiposity, as suggested by Keith et al. ${ }^{(18)}$. They investigated plausible contributors to the increasing obesity incidence of the last years in addition to the two most well-known contributors, decreased physical activity and increased food intake. Living in the thermoneutral zone, artificially created by e.g. heating and air-conditioning systems is one of the possible additional contributors ${ }^{(18)}$.

\section{Suggested Mechanisms of cold-induced thermogenesis}

Adaptive thermogenesis protects the body from cold exposure or regulates energy balance after changes in diet. Possible mechanisms in both humans and small mammals are mitochondrial uncoupling, protein turnover, futile cycling, and non exercise activity thermogenesis ${ }^{(21,23)}$. With respect to regulation, it is clear that the sympathetic nervous system plays an important role in these processes. Indeed, Chapter 5 and 6 describe differences between lean and overweight subjects in blood noradrenaline levels during mild cold exposure, confirming the role of the sympathetic nervous system. Wijers et al. (2007) found a relation between cold-induced thermogenesis and dietary induced thermogenesis, indicating that inter-individual differences in activity or sensitivity of the sympathetic nervous system are responsible for the differences in adaptive thermogene$\operatorname{sis}^{(46)}$. Besides the sympathetic nervous system a second neuro-hormonal pathway for the regulation of cold-induced thermogenesis is the hypothalamic-pituitary-thyroid axis $^{(23)}$. Cold-induced thermogenesis is activated by the sympathetic nervous system but is modulated by $\mathrm{TH}$. The type II iodothyronine deiodinase plays a critical role in modulating the amount of the active $\mathrm{TH}, \mathrm{T} 3$, in BAT, thereby modulating the responses to the sympathetic nervous system ${ }^{(37)}$. Here the discussion will be restricted to the sympathetic nervous system.

Cold-induced thermogenesis is mediated by the sympathetic nervous system, and, in rodents, is accomplished by the three known adrenergic receptors ( $\beta 1-A R, \beta 2-A R$, and $\beta 3-A R)$. The main target organ for $\beta$-adrenergic stimulation of cold-induced thermogenesis is brown adipose tissue. In humans both $\beta 1-A R$ and $\beta 2-A R$ are known to contribute to thermogenesis. Furthermore, it has been shown that in adult humans $\beta 3$ mRNA is 
present in both BAT and white adipose tissue ${ }^{(19)}$ and recent studies indicate that $\beta 3-A R$ may be located in skeletal muscle as well ${ }^{(6)}$.

In small mammals (e.g. rodents and human infants), brown adipose tissue (BAT) serves as a thermogenic organ, in which mitochondrial respiration is being uncoupled to dissipate energy using the uncoupling protein $\mathrm{UCP}-1^{(9)}$. The thermogenic activity is primarily mediated by a mitochondrial protein (UCP1) which allows protons to leak back across the inner mitochondrial membrane ${ }^{(5)}$. This results in dissipation of the proton electrochemical gradient (also referred to as proton leak) allowing substrate oxidation to occur without concomitant capture of some of the useful energy via the synthesis of ATP. This means that, during activation of UCP (by cold or diet), substrate oxidation is effectively uncoupled from phosphorylation with a resultant increase in heat production.

Several papers ${ }^{(2,20,47)}$ showed a role for the sympathetic nervous system in the regulation of thermogenesis in humans. However, until recently, the relevance of brown adipose tissue was believed to be marginal in most adult humans ${ }^{(14)}$, and focus has been on skeletal muscle. Indeed skeletal muscle can account for approximately $40 \%$ of the adrenalin infusion-induced thermogenesis ${ }^{(38)}$, and results from our laboratory just showed that mitochondrial uncoupling in human skeletal muscle relates to cold-induced thermogenesis after mild cold exposure ${ }^{(47)}$. Nevertheless, very recently, unrelated pursuits within nuclear medicine indicated that brown adipose tissue is present and active in adult humans and may thus be an organ of physiological and pharmaceutical importance even in adults ${ }^{(28)}$.

Studies on UCP1 polymorphisms indicate the role BAT plays in cold-induced thermogenesis in humans. Especially the functional $-3826 \mathrm{~A} / \mathrm{G}$ UCP-1 polymorphism is associated with weight and fat gain, resistance to weight loss, increased susceptibility to obesity, less pronounced recovery from overfeeding, and lower expression of UCP-1 mRNA in intraperitoneal depot ${ }^{(7,29,30)}$

Generally, compared to lean subjects, obesity is characterized by an increased level of sympathetic nervous system activity in most tissues, while responsiveness is blunted.

Results from plasma and urine levels of catecholamines are variable ${ }^{(24)}$, but whole body noradrenaline spill-over measurements appear to be positively correlated to body fatness ${ }^{(33)}$. Recent microneurographic studies also showed higher sympathetic neural activation in obese compared to lean controls ${ }^{(1,45)}$, and analyses of heart rate variability in obese subjects suggests that they have increased sympathetic nervous system activity $^{(17)}$. On the other hand, evidence pointed out that in obese subjects the response of the sympathetic nervous system to physiological stimuli is blunted, e.g. by cold $^{(25)}$. In obese subjects the increase in thermogenesis is impaired during noradrenaline or isoprenaline infusion, although some studies found conflicting results.

The observed larger increase in cold-induced noradrenalin levels in overweight subjects combined with a relative low cold-induced thermogenesis (Chapter 6), supports the above described blunted sympathetic nervous system sensitivity in the obese subjects.

Besides uncoupling, other potential thermogenic biochemical reactions involve futilecycles and ATPases oxidation ${ }^{(16,23)}$.This is a well characterized mechanism for coldinduced thermogenesis in skeletal muscle cells in fish and in birds ${ }^{(3)}$. The thermogenic potential for $\mathrm{Ca} 2+$ cycling in mammals is evident from the pathological syndrome of malignant hyperthermia, a dominant genetic disorder in humans and pigs ${ }^{(8,31)}$. 
To what extend the sympathetic nervous system mediates Ca-cycling in skeletal muscle is not known.

\section{Temperature versus thermoregulation}

Body temperature is not the only important factor in thermoregulation (Chapter 4). Also the change in body temperature or the change in heat content of the body contributes. $A$ relatively high heat production and consequently high heat loss (skin temperature) is accompanied with an early onset of shivering heat production. While heat content is balanced, temperature is in this situation kept above the usual core temperature level indicating a fluctuating body temperature. This is comparable to the findings of Webb (1995), who argued that it is heat balance that is regulated, not temperature ${ }^{(44)}$. Changes in heat loss are balanced by changes in heat production and the other way around. This results in a body temperature that is not kept constant but fluctuates within a certain range.

So, is it really temperature or is it actually heat content that is regulated, the latter allowing body core temperature to fluctuate within a certain range?

Different concepts have been suggested regarding the manner in which temperature is regulated. The question whether temperature is regulated around a fixed or fluctuating set-point was addressed in several studies ${ }^{(12,27,40,44)}$. Historically the fixed set-point model has been used, especially for didactic and modeling tools. The term set-point is still in use although the definition has evolved with respect to the fact that often it is assumed that the set-point can fluctuate, for instance during fever. Results to support the fixed setpoint theory were presented by Cabanac et al. ${ }^{(4)}$. They revealed that the cessation of sweating and onset of shivering occurred at a common core temperature. In the design however, core temperature reflected peripheral temperature. Mekjavic et al. ${ }^{(26)}$ used a cold bath, starting with exercise to recreate the warm core-temperature, followed by cooling in the same bath. Peripheral temperature was thus kept constant. Core threshold temperatures for sweating and shivering did not coincide, but established a zone in which neither effectors are active. This was termed the "null zone or interthreshold zone or thermoeffector threshold zone". The term balance point has been suggested by others $^{(35)}$.

\section{Thermal modeling}

Individual differences in the regulation of body temperature can result in inaccuracies in the prediction of temperature. Knowledge of factors that influence cold-induced thermogenesis and body temperature may help to improve thermal models.

Thermal models are increasingly used for indoor climate and thermal comfort research, biometeorology, the textile and military research, in health sciences, risks under stressful conditions, and in clinical environment. 
The most widely used thermal comfort model is developed by Fanger ${ }^{(10)}$. This model links the body heat balance to comfort under different environmental conditions (including clothing) and activity levels. However no physiological processes are included and standard population characteristics are used. Therefore such models can be used under static environments only and individual responses cannot be predicted. One of the first contributions to a more physiological approach came from Pennes in 1948. Pennes formulated a mathematical relation between heat flow and blood to tissues. The Pennes model is thus suited for examining heat flow within a local region ${ }^{(32)}$.

Dynamic whole body models were developed in the seventies, with the pioneering work of Stolwijk ${ }^{(39)}$. Stolwijk produced a thermoregulatory model describing the human as a 25 compartment body with control functions for blood flow, metabolism and sweating. Unlike the Pennes model, the Stolwijk model includes physiological thermoregulatory mechanisms. Useful refinements of this model have been implemented, among others by Gordon, Lotens and Huizinga ${ }^{(13,15,22)}$, and also new thermoregulatory models have been developed e.g. by Wissler and Fiala ${ }^{(11,48)}$. However, virtually all models are population based, i.e. they predict an average response of the population or use an average subject with standardized body characteristics.

Here, the development of a dynamic individual specific model was described (Chapter 7). This is an extended version of the model by Fiala which is based on the Stolwijk model ${ }^{(11,12,39)}$. This model was extended by facilitating input of individual (body composition and metabolic) parameters. Recently, new submodels were developed facilitating the use of the model under clinical environment (open heart surgery, anesthesia and recovery ${ }^{(36)}$. The data from physiological measurements described in Chapter $3^{(43)}$ were used to validate the individualized model. The analysis of the model showed that the inclusion of individual characteristics improved the predictions for an individual and led to a smaller systematical error in comparison to those for an average person. However, a large part of the discrepancies in individual response to cold remained unexplained.

In subsequent studies it appeared that the description of the perfusion needs improvement. Vasoconstriction in the model is determined by a fixed weighing system. A more physiologically based approach is needed. One adaptation can be replacement of the fixed factor for the constriction by factors that depend on local tissue temperatures. Furthermore, in the model non-shivering thermogenesis is not included. Our studies clearly showed the significant contribution of cold-induced thermogenesis. The problem is the highly variable contribution of cold induced thermogenesis depending on the individual and on the level of acclimatization. Physiological experiments are needed in search for subject characteristics that predict the magnitude of metabolic responses and/or identify quick tests (like a cold pressor test) for characterization of individuals.

Finally, the model has only been validated for cold exposure. Next, the model needs validation on an individual level dynamic warm environment.

\section{Concluding remarks and recommendations for future research}

There is considerable inter-individual variation in cold-induced non-shivering thermogenesis, resulting in implications for energy balance. The inter-individual variation is 
shown in response type, by the preference for a metabolic or an insulative response, and response size, where subjects having a relatively large cold induced thermogenesis do so in both summer and winter. Causal factors include body (over) weight with a regulatory role for the sympathetic nervous system.

Future research should focus on a further mechanistical explanation of the variation in cold induced thermogenesis, the relation to diet-induced energy expenditure, the implications for energy balance, and the potential of pharmacological interventions. 


\section{Literature}

1 Alvarez GE, Beske SD, Ballard TP and Davy KP. Sympathetic neural activation in visceral obesity. Circulation 106: 2533-2536, 2002.

2 Astrup A and MacDonald I. Sympathoadrenal system and metabolism. In: Handbook of Obesity, edited by Bray G, Bouchard C and James W. New York: Marcel Dekker, 1988, p. 491-511.

3 Bicudo JE, Bianco AC and Vianna CR. Adaptive thermogenesis in hummingbirds. J Exp Biol 205: 2267-2273, 2002.

4 Cabanac $M$ and Massonnet $B$. Thermoregulatory responses as a function of core temperature in humans. $J$ Physiol 265: 587-596, 1977.

5 Cannon B and Nedergaard J. Brown adipose tissue: function and physiological significance. Physiol Rev 84: 277-359, 2004.

6 Chamberlain PD, Jennings KH, Paul F, Cordell J, Berry A, Holmes SD, Park J, Chambers J, Sennitt MV, Stock MJ, Cawthorne MA, Young PW and Murphy GJ. The tissue distribution of the human beta3adrenoceptor studied using a monoclonal antibody: direct evidence of the beta3-adrenoceptor in human adipose tissue, atrium and skeletal muscle. Int J Obes Relat Metab Disord 23: 1057-1065, 1999.

7 Clement K, Ruiz J, Cassard-Doulcier AM, Bouillaud F, Ricquier D, Basdevant A, Guy-Grand B and Froguel P. Additive effect of A-->G (-3826) variant of the uncoupling protein gene and the Trp64Arg mutation of the beta 3-adrenergic receptor gene on weight gain in morbid obesity. Int J Obes Relat Metab Disord 20: 1062-1066, 1996.

8 Denborough M. Malignant hyperthermia. Lancet 352: 1131-1136, 1998.

9 Dulloo AG, Seydoux $\mathrm{J}$ and Jacquet J. Adaptive thermogenesis and uncoupling proteins: a reappraisal of their roles in fat metabolism and energy balance. Physiol Behav 83: 587-602, 2004.

10 Fanger PO. Assessment of man's thermal comfort in practice. Br J Ind Med 30: 313-324, 1973.

11 Fiala D, Lomas KJ and Stohrer M. A computer model of human thermoregulation for a wide range of environmental conditions: the passive system. J Appl Physiol 87: 1957-1972, 1999.

12 Fiala D, Lomas KJ and Stohrer M. Computer prediction of human thermoregulatory and temperature responses to a wide range of environmental conditions. Int J Biometeorol 45: 143-159., 2001.

13 Gordon RG. The response fo human thermoregulatory system in the cold. PhD Thesis: University of California, 1974.

14 Himms-Hagen J. Does brown adipose tissue (BAT) have a role in the physiology or treatment of human obesity? Rev Endocr Metab Disord 2: 395-401, 2001.

15 Huizinga $\mathrm{C}$, Zang $\mathrm{H}$ and Arens $\mathrm{E}$. A model of human physiolog yand comfort for assessing complex thermal environments. Build Environ 36: 1943-1954, 2001.

16 Jbilo O, Ravinet-Trillou C, Arnone M, Buisson I, Bribes E, Peleroux A, Penarier G, Soubrie P, Le Fur G, Galiegue $S$ and Casellas $P$. The $C B 1$ receptor antagonist rimonabant reverses the diet-induced obestity phenotype though the regulation of lipolysis and energy balance. The FASEB J 19: 1567-1569, 2005.

17 Karason K, Molgaard H, Wikstrand $\mathrm{J}$ and Sjostrom L. Heart rate variability in obesity and the effect of weight loss. Am J Cardiol 83: 1242-1247, 1999.

18 Keith SW, Redden DT, Katzmarzyk PT, Boggiano MM, Hanlon EC, Benca RM, Ruden D, Pietrobelli A, Barger JL, Fontaine KR, Wang C, Aronne LJ, Wright SM, Baskin M, Dhurandhar NV, Lijoi MC, Grilo CM, DeLuca M, Westfall $A O$ and Allison DB. Putative contributors to the secular increase in obesity: exploring the roads less traveled. Int J Obes (Lond) 30: 1585-1594, 2006.

19 Krief S, Lonnqvist F, Raimbault S, Baude B, Van Spronsen A, Arner P, Strosberg AD, Ricquier D and Emorine LJ. Tissue distribution of beta 3-adrenergic receptor mRNA in man. J Clin Invest 91: 344-349, 1993.

20 Landsberg L, Saville ME and Young JB. Sympathoadrenal system and regulation of thermogenesis. Am J Physiol 247: E181-189, 1984.

21 Levine M, Duffy L, Moore DC and Matej LA. Acclimation of a non-indigenous sub-Arctic population: seasonal variation in thyroid function in interior Alaska. Comp Biochem Physiol A Physiol 111: 209-214, 1995.

22 Lotens WA. Heat transfer from humans wearing clothing. PhD Thesis: Delft University of Technology, 1993.

23 Lowell BB and Spiegelman BM. Towards a molecular understanding of adaptive thermogenesis. Nature 404: 652-660, 2000.

24 Macdonald IA. Advances in our understanding of the role of the sympathetic nervous system in obesity. Int $J$ Obes Relat Metab Disord 19 Suppl 7: S2-S7, 1995.

25 Matsumoto T, Miyawaki T, Ue H, Kanda T, Zenji C and Moritani T. Autonomic responsiveness to acute cold exposure in obese and non-obese young women. Int J Obes Relat Metab Disord 23: 793-800, 1999.

26. Mekjavic IB and Bligh J. Core threshold temperatures for sweating. Can J Physiol Pharmacol 67: 1038-1044, 1989. 
27 Mekjavic IB and Eiken O. Contribution of thermal and nonthermal factors to the regulation of body temperature in humans. J Appl Physiol 100: 2065-2072, 2006.

28 Nedergaard J, Bengtsson T and Cannon B. Unexpected evidence for active brown adipose tissue in adult humans. Am J Physiol Endocrinol Metab 293: E444-452, 2007.

29 Oberkofler H, Dallinger G, Liu YM, Hell E, Krempler F and Patsch W. Uncoupling protein gene: quantification of expression levels in adipose tissues of obese and non-obese humans. J Lipid Res 38: 2125-2133, 1997.

30 Oppert JM, Vohl MC, Chagnon M, Dionne FT, Cassard-Doulcier AM, Ricquier D, Perusse L and Bouchard C. DNA polymorphism in the uncoupling protein (UCP) gene and human body fat. Int $J$ Obes Relat Metab Disord 18: 526-531, 1994.

31 O'Sullivan GH, McIntosh JM and Heffron JJ. Abnormal uptake and release of Ca2+ ions from human malignant hyperthermia-susceptible sarcoplasmic reticulum. Biochem Pharmacol 61: 1479-1485, 2001.

32 Pennes $\mathrm{HH}$. Analysis of tissue and arterial blood temperatures in the resting human forearm. 1948. J Appl Physiol 85: 5-34, 1998.

33 Poehlman ET, Gardner AW, Goran MI, Arciero PJ, Toth MJ, Ades PA and Calles-Escandon J. Sympathetic nervous system activity, body fatness, and body fat distribution in younger and older males. J Appl Physiol 78 802-806, 1995.

34 Ravussin E, Lillioja S, Knowler WC, Christin L, Freymond D, Abbott WG, Boyce V, Howard BV and Bogardus C. Reduced rate of energy expenditure as a risk factor for body-weight gain. N Engl J Med 318: 467-472, 1988.

35 Romanovsky AA. Do fever and anapyrexia exist? Analysis of set point-based definitions. Am J Physiol Regul Integr Comp Physiol 287: R992-995, 2004.

36 Severens NM, van Marken Lichtenbelt WD, Frijns AJ, Van Steenhoven AA, de Mol BA and Sessler DI. A model to predict patient temperature during cardiac surgery. Phys Med Biol 52: 5131-5145, 2007.

37 Silva JE. Thermogenic mechanisms and their hormonal regulation. Physiol Rev 86: 435-464, 2006.

38 Simonsen L, Bulow J, Madsen $\mathrm{J}$ and Christensen NJ. Thermogenic response to epinephrine in the forearm and abdominal subcutaneous adipose tissue. Am J Physiol 263: E850-855, 1992.

39 Stolwijk JA and Wexler I. Peripheral nerve activity in response to heating the cat's skin. J Physiol 214: 377392, 1971.

40 Tikuisis $\mathrm{P}$. Heat balance precedes stabilization of body temperatures during cold water immersion. $J$ App/ Physiol 95: 89-96, 2003.

41 Tikuisis P, Ducharme MB, Moroz D and Jacobs I. Physiological responses of exercised-fatigued individuals exposed to wet-cold conditions. J Appl Physiol 86: 1319-1328, 1999.

42 van Marken Lichtenbelt WD, Schrauwen P, van De Kerckhove S and Westerterp-Plantenga MS. Individual variation in body temperature and energy expenditure in response to mild cold. Am J Physiol Endocrinol Metab 282: E1077-1083, 2002.

43 Van Ooijen AM, Van Marken Lichtenbelt WD, Van Steenhoven AA and Westerterp KR. Seasonal changes in metabolic and temperature responses to cold air in humans. Physiol Behav 82: 545-553, 2004.

44 Webb P. The physiology of heat regulation. Am J Physiol 268: R838-850, 1995.

45 Weyer C, Pratley RE, Snitker S, Spraul M, Ravussin E and Tataranni PA. Ethnic differences in insulinemia and sympathetic tone as links between obesity and blood pressure. Hypertension 36: 531-537, 2000.

46 Wijers SL, Saris WH and van Marken Lichtenbelt WD. Individual thermogenic responses to mild cold and overfeeding are closely related. J Clin Endocrinol Metab 92: 4299-4305, 2007.

47 Wijers SL, Schrauwen P, Saris WH and van Marken Lichtenbelt WD. Human skeletal muscle mitochondrial uncoupling is associated with cold induced adaptive thermogenesis. PLoS ONE 3: e1777, 2008.

48 Wissler EH. Mathematical simulation of human thermal behavior using whole body models. In: Heat transfer in medicine and biology : analysis and applications, edited by Shitzer A and Eberhart RC. New York: Plenum press, 1985. 
Summary 
This thesis reports on the variation in human metabolic and insulative responses to mild cold.

Whether a significant amount of cold-induced non-shivering thermogenesis exists in adult humans, is still under debate. The existence and variation of cold-induced nonshivering thermogenesis was shown by exposing healthy volunteers to mild cold (Chapter 2). Measurements were performed in summer and repeated in winter (Chapter 3 ) to investigate seasonal changes in cold response. The magnitude of the cold response was a function of cold acclimatization. On average, non-shivering thermogenesis was higher in winter compared to summer. Interestingly, the relative contribution of metabolic and temperature response was subject specific and consistent throughout the seasons. This means that a person with a relatively large response in summer does so again in winter although the size of the response is not necessarily the same. In addition, subjects that show a metabolic response, i.e. a high metabolism during cold, show a small insulative response, i.e. a decreased skin temperature during cold, and vice versa. Once this was established, the magnitude of the metabolic increase prior to the initiation of shivering was studied (Chapter 4). Subjects with a comparatively large heat production during cold exposure maintained a relatively high skin temperature but started shivering earlier, independent of differences in body composition. This combination of responses is in line with a metabolic defense mechanism of the body to a mild cold stimulus.

In the previous experiments, the relation between thermogenesis during cold and body composition was studied in lean subjects. Subsequently, lean and overweight subjects were compared with respect to thermogenesis and insulation in response to mild cold and rewarming (Chapter 5). The increase in heat production corrected for body surface area was relatively low in overweight subjects during cold exposure and rewarming. It is argued that not body temperature triggers heat production, but that differences in heat balance may explain the differences between lean and overweight subjects. The energy efficient response of the overweight subjects can have consequences for energy balance in the long term. If heat balance leans towards an insulative response, the body conserves energy instead of expending it, possibly resulting in a positive energy balance that causes weigh gain.

In search of factors related to cold-induced non-shivering thermogenesis, sympathetic nervous system activity was studied (Chapter 6). Both whole body and local cooling showed that both groups respond very different to the same environmental temperature change. During both conditions the overweight subjects seemed to conserve more heat and showed lower cold-induced thermogenesis compared to their lean controls. The observed larger increase in cold-induced norepinephrine levels in overweight subjects indicates a blunted response of the sympathetic nervous system that can contribute to body weight gain and resistance to weight loss. Thus, the sympathetic nervous system plays a role in cold-induced thermogenesis differences between lean and overweight subjects.

Differences in thermoregulation between individuals may lead to inaccuracies in body temperature predictions from thermal models. The data that was collected during the research for this thesis was used to validate a model for the predictions of body temperature (Chapter 7). The successful incorporation of individual data in this model showed 
that research is needed to define subject-specific characteristics that predict the metabolic response or to identify tests for characterization of individuals.

In conclusion, the considerable variation in cold-induced non-shivering thermogenesis has potential implications for energy balance. Weight status and the sympathetic nervous system are determinants. Future research should focus on further explanation of variation in cold-induced thermogenesis, relation to diet-induced energy expenditure and skin perfusion, implications for energy balance and the potential of pharmacological interventions. 
Samenvatting 
Dit proefschrift beschrijft variatie in de reactie van de warmte productie en de lichaams temperatuur op milde koude bij mensen.

Bij de mens was koudegeïnduceerde warmte productie zonder rillen nog niet eerder eenduidig vastgesteld. Het bestaan en de variatie hierin is in nu aangetoond door het blootstellen van gezonde personen aan milde koude. (Hoofdstuk 2). Om seizoensinvloeden in reactie op de koude te onderzoeken werden metingen, verricht in de zomer, herhaald in de winter (Hoofdstuk 3). De grootte van de reactie op kou was een functie van acclimatisatie. Interessant was dat de relatieve bijdrage van de reactie van het metabolisme en de lichaams temperatuur persoonsafhankelijk was en consistent gedurende de verschillende seizoenen. Dit betekent dat een persoon met een relatief sterke metabole reactie in de zomer, ook een relatief sterke reactie heeft in de winter hoewel de absolute waarde van de reactie in zomer en winter niet gelijk hoeft te zijn. Verder, vertoonden personen met een meer metabole reactie, een sterkere verhoging van de warmte productie in de kou, een minder sterke reactie in isolatie, een lagere huid temperatuur in de kou en omgekeerd. Nadat dit was vastgesteld, werd de grootte van de stijging in warmte productie voordat men begint te rillen onderzocht (Hoofdstuk 4). Proefpersonen met een relatief hoge warmte productie gedurende de koude handhaafden een relatief hoge huid temperatuur en begonnen relatief vroeg met rillen, onafhankelijk van verschillen in lichaamssamenstelling. Deze combinatie van reacties illustreert een metabool verdedigingsmechanisme van het lichaam tegen een milde koude prikkel.

De hierboven genoemde experimenten, werden gedaan met slanke proefpersonen. Hierna werden slanke personen en personen met overgewicht met elkaar vergeleken wat betreft verandering van warmte productie en isolatie bij blootstelling aan milde koude en opwarming daarna (Hoofdstuk 5). De stijging in warmte productie, gecorrigeerd voor verschillen in lichaamsoppervlak, was relatief laag bij personen met overgewicht, zowel gedurende blootstelling aan de koude als tijdens het opwarmen daarna. Deze verschillen konden worden verklaard door verschillen in warmtebalans tussen slanke personen en personen met overgewicht. De efficiëntere reactie van proefpersonen met overgewicht kan gevolgen hebben voor de energie balans op langere termijn. Als de warmte balans meer de kant van een verhoogde isolatie uitgaat, wordt energie bespaard, met als gevolg een groter risico op het ontstaan van een positieve ergiebalans in een omgeving met een ruim voedselaanbod.

Het regulatiemechanisme van koudegeïnduceerde warmte productie zonder te rillen werd onderzocht door metingen te doen aan de activiteit van het sympathisch zenuwstelsel (Hoofdstuk 6). Zowel bij lokale afkoeling als bij afkoeling van het gehele lichaam reageerden de twee groepen verschillend op dezelfde verandering in omgevingstemperatuur. Proefpersonen met overgewicht hadden een lagere warmte productie in de kou, die gepaard ging met een grotere stijging van koudegeïnduceerde plasma noradrenaline waarden. Dit wijst op een minder gevoelige respons van het sympathisch zenuw stelsel. Het sympathisch zenuwstelsel speelt dus een rol bij verschillen in koudegeïnduceerde warmte productie tussen slanke proefpersonen en die met overgewicht.

Individuele verschillen in de regulatie van de lichaamstemperatuur leiden tot onnauwkeurigheid in voorspellingen van lichaamstemperatuur op basis van simulatie modellen. De verzamelde gegevens wat betreft de effecten van relevante persoonskenmerken werden daarom gebruikt voor de validatie van een model voor voorspellingen van lichaamstem- 
peratuur (Hoofdstuk 7). De toevoeging van persoonsspecifieke gegevens aan dit model liet de noodzaak zien van onderzoek naar persoonskarakteristieken die individuen kunnen karakteriseren wat betreft hun reactie op een verandering van omgevingstemperatuur.

Concluderend heeft de aanzienlijke variatie in koudegeïnduceerde warmte productie tussen personen mogelijk gevolgen voor de energie balans. Lichaamsgewicht en het sympathisch zenuwstelsel zijn bepalende factoren. Toekomstig onderzoek zou zich moeten richten op verdere verklaring van de variatie in koudegeïnduceerde warmte productie, de relatie met dieetgeïnduceerde warmte productie en huiddoorbloeding, de gevolgen voor energiebalans en de mogelijkheid van farmacologische interventies. 
Dankwoord 
De totstandkoming van dit proefschrift heeft dan wel lang geduurd, toch zijn de jaren voorbij gevlogen en moet ik enorm wennen aan het idee dat het af is! Of eigenlijk bijna af want ik moet nog "even" het dankwoord schrijven, slechts enkele dagen voordat alles gedrukt gaat worden.

Wouter, jij als eerste bedankt, voor al je hulp en aanmoediging gedurende het hele traject. Ik denk nog vaak aan het brainstormen en je enorme input aan ideeën voor werkelijk alles! Ik had altijd het idee dat ik een uurtje gezellig had gekletst en dan had ik ideen voor een maand werk. Zo heb ik eindeloos kunnen profiteren van je creatieve geest en van je eeuwig geduldige antwoorden op de typische levensvragen van de AIO zoals: Waarom doe ik dit ook alweer? Belangrijker vind ik dat ik ook altijd welkom was voor een hapje of drankje "op 't Rooth" of hoe zeg je dat ook weer? Waar je een verassend Bourgondisch stekje hebt, voor een "Hollander".

Klaas, bedankt voor je support en inzet, ook toen Wouter er even niet was, kon ik meteen bij je terecht. Altijd razendsnel en nooit heb ik meegemaakt dat je van een afspraak afweek. Door jou vastberadenheid en overtuiging geloofde ik dat dit laatste stukje snel genoeg afgerond kon worden.

Anton, bedankt voor je altijd enthousiaste ideeen en goede inzicht. Voor mij ben jij het bewijs dat intelligentie en vriendelijkheid in een en dezelfde persoon kunnen bestaan.

De beoordelingscommissie, Prof. dr. Kingma, Prof. dr. Teulle, Dr. van Someren, Prof. dr. v.d. Vusse en Prof. dr. Daanen, bedankt voor het lezen en beoordelen van mijn proefschrift en dat jullie daar allemaal op korte termijn, tijd voor wisten te maken. Ik waardeer het enorm dat de meesten van jullie ook nog aanwezig kunnen zijn in de corona. Hein, op meerdere momenten tijdens het onderzoek heb ik van je expertise gebruik mogen maken. Ik vind het dan ook erg leuk dat je bij de laatste loodjes betrokken wilt zijn.

Boy Houben, Marleen van Baak, bedankt voor jullie hulp en snelle reviews.

Loek en Paul, ik heb niet zoveel in jullie labs gezeten als jullie zelf, maar toch wel veel. Jullie hebben me allebei dan ook regelmatig geholpen met zo ongeveer alles wat mis kan gaan met mijn in alle opzichten experimentele opstellingen. Bedankt voor alle reddingen en gezellige tijd die daarbij hoorde

Marleen, Anne, ik ben hartstikke trots dat jullie mijn paranimfen willen zijn. Ik heb al jaren heel veel met jullie gedeeld en ik vind en hoop dat dat nog lang zo mag blijven.

Stagiaires Martine en Francis, ik heb verbazingwekkend veel van jullie geleerd.

En dan mijn meest favoriete collega HB AiO's, oeps, ik zeg al bijna "uit mijn tijd" bedankt. Marleen, van jou weet ik nog precies hoe onze eerste ontmoeting was, toen wist je altijd al precies wat je wilde. In tegenstelling to mij overigens, ik was nog met mijn stage bezig en had zoals gebruikelijk nog geen flauw benul van wat de toekomsts mij moest brengen. Annemarie, je was mijn eerste echte "collegaatje" ooit. Wat hebben we een plezier gehad, samen op de kamer, veel over het werk maar ook kletsen, sporten, eten. Om nooit meer te vergeten! Liebe Tanja, es gibt keine wörter... en zeker niet in het Duits (want daar hebben je ouders nog van meegenoten), voor onze gezellige tijden. Mirjam, 
wat hebben wij het veel over voedsel en baby's gehad! Annemiek, wat was het toch altijd weer een troost als ik jou om een uurtje of 7 's ochtends tegenkwam, met een nóg groter ochtend humeur dan ik! Manuela en Guy in mijn herinnering waren jullie er altijd en dan vooral bij de "Jura" die mij altijd trouw in een van mijn grootste levensbehoeftes voorzag. Joost, gelukkig (voor jou) heb je er een stuk korter over gedaan dan ik! Ik kan nog altijd bij Maaike verhaal halen over hoe het met je gaat, want dat kan ik nog altijd niet missen. Na zóveel jaren bij elkaar in de klas en "in het jaar" te zitten, en niet te vergeten op ons handen te staan naar aanleiding van een stelling van Annemarie.

Niet te vergeten, degenen met wie ik iets minder tijd heb gedeeld, maar daarom niet minder plezier, gesprekken en kopjes koffie en thee: Eva, Freddie, Chris, Marije, Lydia, Neeltje en Kristel. Claudia het is net of ik nooit ben weggeweest als ik je weer tegenkom. Jos, ik bevond me wel eens op de afdeling op dagen of tijden dat ik me afvroeg, "Wat doe ik hier eigenlijk?" en "Wie waagt zich nu nog in dit gebouw?", maar gelukkig nooit zonder jou tegen te komen.

Dankjewel, alle medewerkers van HB, waar ik me altijd thuis heb gevoeld, en nog steeds erg welkom ben. En niet te vergeten al mijn proefpersonen, die speciaal voor mij, wat meer of wat minder kou leden, in een kamer werden opgesloten, moesten fietsen tot ze erbij neervielen en ongeveer een minuut onderwater moesten blijven.

Heel CRDM-CE ook bedankt voor jullie welhaast verdacht enthousiaste aanmoedigingen om mijn proefschrift tot een goed einde te brengen. Jongens (of eigenlijk vooral meisjes), allemaal bedankt! Ik heb serieus het vermoeden dat jullie het nog jaren vol hadden kunnen houden! Of waren jullie het beu en was dit de enige methode die over was in de hoop dat ik het af zou maken? Toch zijn er enkelen die me zo mogelijk nog harder hebben aangemoedigd, en hen zou ik graag bij naam willen noemen, namelijk: Daphne, Kitty, Myriam, Margriet, Rinie, Pascal (tijdens de aller aller aller laatste loodjes), Judith, Saskia, Suzanne en Marleen (ja alweer!). Maar het allermeest wil ik jullie (mijn "nieuwe collegaatjes") bedanken voor het feit dat ik alweer zulke leuke collega's heb getroffen

Tot slot de belangrijkste mensen in mijn leven:

Mam en Pap, bedankt dat jullie er altijd voor me zijn. Jullie hebben me altijd geleerd om mijn eigen keuzes te maken, me vooral niks van anderen aan te trekken en iedereen met evenveel respect te behandelen. Dat is het belangrijkste wat ik ooit heb geleerd en dat zal ik altijd onthouden. Dit proefschrift heeft dan wat lang op zich laten wachten, het was wel helmaal mijn keuze.

Lieve Jac, samen zijn we op zijn best en dat gaan we nog heel lang volhouden. Linde, je begrijpt er nu nog geen snars van maar door jou heb ik eindelijk leren relativeren en heb ik nu toch de moed bijeengeraapt om te promoveren (“Grouphug!"). Baby 2, jij bent de enige die ooit invloed heeft gehad op de tijdsplanning van dit proefschrift. Gezien je er nog niet bent, kan ik alleen maar vermoeden wat dit betekend voor je toekomst, en je eigen willetje (alvast een kusje van mama).

ledereen bedankt! 
Curriculum Vitae 
Anne Marie Japke van Ooijen was born on January 8, 1976 in Breda, the Netherlands. In 1994 she received her VWO diploma at the Onze Lieve Vrouwe Lyceum in Breda. In the same year, she started her study Health Sciences at Maastricht University specializing in Movement Sciences. She did her Master thesis entitled "Activity associated energy expenditure: predicted values versus measured values and accelerometry" at the department of Human Biology. Part of the research for her Master thesis was completed at the Institute of Physiology from the University of Lausanne, Switzerland. She graduated and started her PhD research in 1999 at the department of Human Biology at Maastricht University. The research for this thesis was performed in close cooperation with the department of Biomedical Engineering from the University of Technology in Eindhoven. The work performed during her $\mathrm{PhD}$ period is described in this thesis.

Since 2004, she is working for the Medtronic Bakken Research Center in Maastricht, at the department of Cardiac Rhythm and Disease Management. She works as a study manager on clinical trials designed to evaluate implantable cardiac rhythm devices (e.g. pacemakers) for market release. 
Publications 


\section{Full papers}

van Ooijen AMJ, van Marken Lichtenbelt WD, Westerterp KR. Individual differences in body temperature and the relation to energy expenditure: the influence of mild cold. J Therm Biol (2001) 26: 455 - 459

van Ooijen AMJ, van Marken Lichtenbelt WD, van Steenhoven AA, Westerterp KR. Seasonal changes in metabolic and temperature responses to cold air in humans. Physiol behav (2004) 2-3: 545 - 553

van Marken Lichtenbelt WD, Frijns AJH, Fiala D, Janssen FEM, Van Ooijen AMJ, Van Steenhoven AA. Effect of individual characteristics on a mathematical model of human thermoregulation. J Therm Biol (2004) 29: 577 - 581

Westerterp-Plantenga MS, Lejeune MP, Nijs I, van Ooijen M, Kovacs EM. High protein intake sustains weight maintenance after body weight loss in humans. Int $\mathrm{J}$ Obes Relat Metab Disord (2004) 28: 57 - 64

van Ooijen AMJ, van Marken Lichtenbelt WD, van Steenhoven AA, Westerterp KR. Cold induced heat production preceding shivering. Br J Nutr (2005) 93: 387 - 391

Claessens - van Ooijen AMJ, Westerterp KR, Wouters L, Schoffelen PFM, van Steenhoven AA, van Marken Lichtenbelt WD. Heat production and body temperature during cooling and rewarming in overweight and lean men. Obesity (2006) 14: 1914 1920

Claessens - van Ooijen AMJ, Westerterp KR, Houben AJHM, van Baak M, van Marken Lichtenbelt WD. Sympathetic activity, skin blood flow and thermogenesis in lean and overweight men: effects of cold exposure. Submitted for publication

van Marken Lichtenbelt WD, Frijns AJH, van Ooijen MJ, Fiala D, Kester AM, van Steenhoven AA. Validation of an individualized model of human thermoregulation for predicting responses in cold air. Int J Biometeorol (2007) 51: 169 - 179 